Florida International University FIU Digital Commons

$11-3-2010$

\title{
Arctic Ecosystem Responses to Changes in Water Availability and Warming: Short and Long-Term Responses
}

Paulo C. Olivas

Florida International University, poliv001@fiu.edu

DOI: $10.25148 /$ etd.FI10112007

Follow this and additional works at: https://digitalcommons.fiu.edu/etd

Part of the Biology Commons, and the Plant Biology Commons

\section{Recommended Citation}

Olivas, Paulo C., "Arctic Ecosystem Responses to Changes in Water Availability and Warming: Short and Long-Term Responses" (2010). FIU Electronic Theses and Dissertations. 333.

https://digitalcommons.fiu.edu/etd/333 


\title{
FLORIDA INTERNATIONAL UNIVERSITY
}

Miami, Florida

\section{ARCTIC ECOSYSTEM RESPONSES TO CHANGES IN WATER AVAILABILITY AND WARMING: SHORT AND LONG-TERM RESPONSES}

\author{
A dissertation submitted in partial fulfillment of the \\ requirements for the degree of \\ DOCTOR OF PHILOSOPHY \\ in \\ BIOLOGY \\ by \\ Paulo C. Olivas
}


To: Dean Kenneth G. Furton

College of Arts and Sciences

This dissertation, written by Paulo C. Olivas, and entitled Arctic Ecosystem Responses to Changes in Water Availability and Warming: Short and Long-Term Responses, having been approved in respect to style and intellectual content, is referred to you for judgment.

We have read this dissertation and recommend that it be approved.

David Lee

Jennifer H. Richards

William Anderson Jr.

Krishnaswamy Jayachandran

Steve F. Oberbauer, Major Professor

Date of Defense: November 3, 2010

The dissertation of Paulo C. Olivas is approved.

\begin{tabular}{r}
$\begin{array}{r}\text { Dean Kenneth G. Furton } \\
\text { College of Arts and Sciences }\end{array}$ \\
\hline Interim Dean Kevin O'Shea \\
University Graduate School
\end{tabular}

Florida International University, 2010 


\section{DEDICATION}

I want to dedicate this work to la famila: my mom Isabel, my sister Raquel and grandmother Alicia for their invaluable support at all times, and to my wife Elizabeth for her unconditional love and unselfish support. I have made it this far because of all of you. 


\section{ACKNOWLEDGMENTS}

I want to thank my family for their invaluable support. Also I want to thank my friend and major professor Dr. Steve F. Oberbauer.

My fieldwork required extended hours in the cold Arctic. Thus without the help and collaboration of field assistants and friends, my work would not have been possible. I thank Jose Luciani, Robert Wilder, Elizabeth Eubanks, Dr. Craig Tweedie, Mark Lara, Lewis Brower, David Lin, Adrian Aguirre, and the rest of the crew including Jason Shone and several high school students from the local school. Thanks to the help of everyone, all field campaigns were a success.

Also I want to thank the Barrow Environmental Observatory, Barrow Arctic Consortium, Florida International University, San Diego State University, the Ukpeagivik Iñupiat Corporation (UIC), and the National Science Foundation Biocomplexity in the Environment coupled Biogeochemical Cycles program (Award\# 0421588).

I also want to thank Florida International University and the Dissertation Year Fellowship for the significant contribution to the accomplishment] of this work. 


\title{
ABSTRACT OF THE DISSERTATION \\ ARCTIC ECOSYSTEM RESPONSES TO CHANGES IN WATER AVAILABILITY \\ AND WARMING: SHORT AND LONG-TERM RESPONSES
}

\author{
by \\ Paulo C. Olivas \\ Florida International University, 2010 \\ Professor Steve F. Oberbauer, Major Professor
}

Arctic soils store close to $14 \%$ of the global soil carbon. Most of arctic carbon is stored below ground in the permafrost. With climate warming the decomposition of the soil carbon could represent a significant positive feedback to global greenhouse warming. Recent evidence has shown that the temperature of the Arctic is already increasing, and this change is associated mostly with anthropogenic activities. Warmer soils will contribute to permafrost degradation and accelerate organic matter decay and thus increase the flux of carbon dioxide and methane into the atmosphere. Temperature and water availability are also important drivers of ecosystem performance, but effects can be complex and in opposition. Temperature and moisture changes can affect ecosystem respiration (ER) and gross primary productivity (GPP) independently; an increase in the net ecosystem exchange can be a result of either a decrease in ER or an increase in GPP. Therefore, understanding the effects of changes in ecosystem water and temperature on the carbon flux components becomes key to predicting the responses of the Arctic to climate change. The overall goal of this work was to determine the response of arctic systems to simulated climate change scenarios with simultaneous changes in temperature and moisture. A temperature and hydrological manipulation in a naturally-drained 
lakebed was used to assess the short-term effect of changes in water and temperature on the carbon cycle. Also, as part of International Tundra Experiment Network (ITEX), I determined the long-term effect of warming on the carbon cycle in a natural hydrological gradient established in the mid 90's. I found that the carbon balance is highly sensitive to short-term changes in water table and warming. However, over longer time periods, hydrological and temperature changed soil biophysical properties, nutrient cycles, and other ecosystem structural and functional components that down regulated GPP and ER, especially in wet areas. 


\section{TABLE OF CONTENTS}

CHAPTER

PAGE

1. Introduction

Figures 8

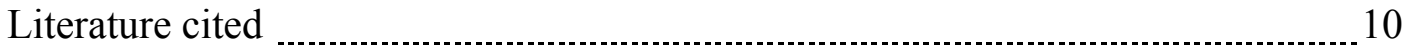

2. Chapter 1: Responses of $\mathrm{CO}_{2}$ Flux Components of Alaskan Coastal Plain

Tundra to Shifts in Water Table

Abstract

Introduction

Methods

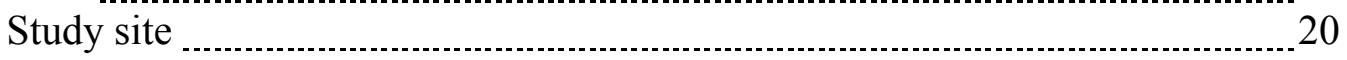

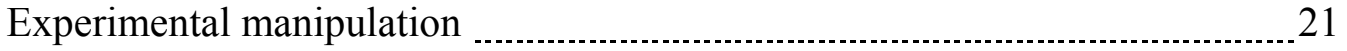

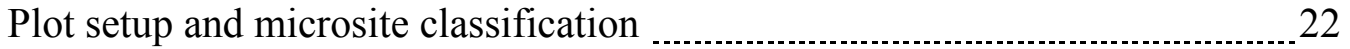

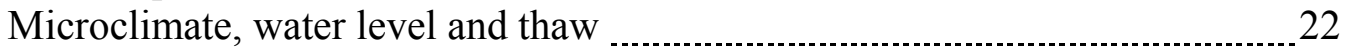

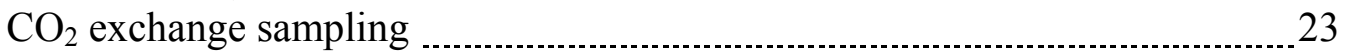

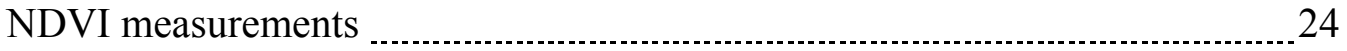

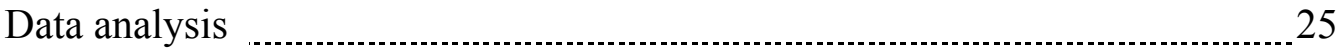

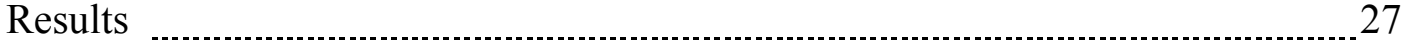

Microenvironment

Seasonal patterns of carbon flux components and NDVI _._._.

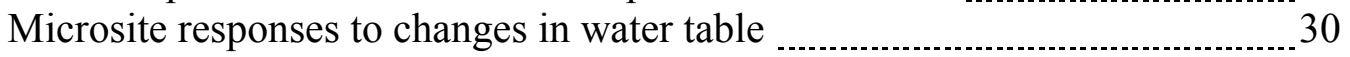

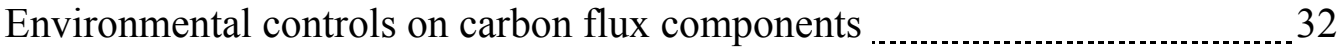

Discussion

Water table controls of temporal and spatial $\mathrm{CO}_{2}$ fluxes $\ldots \ldots \ldots \ldots$

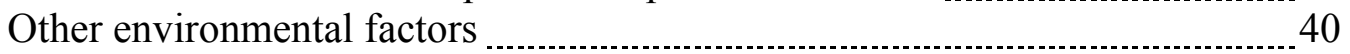

Conclusions $\ldots \ldots$

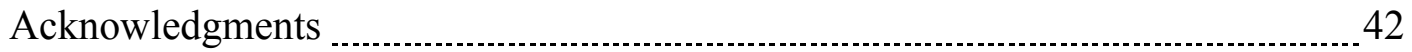

Tables

Figures

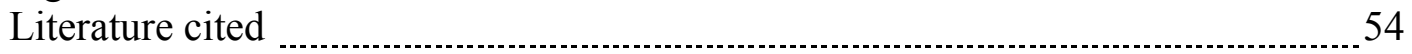

3. Chapter 2: Response of Carbon Fluxes of Alaskan Coastal Plain Tundra to the Synergistic Effect of Water and Temperature Changes ................................. 58



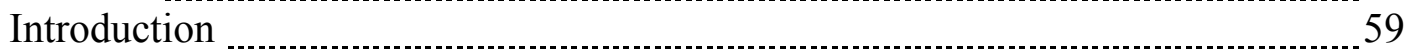

Methods

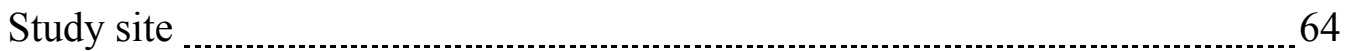

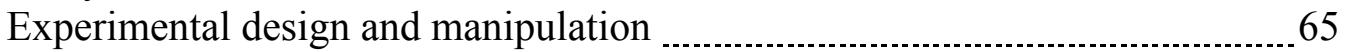

Meteorological data $\ldots \ldots \ldots$

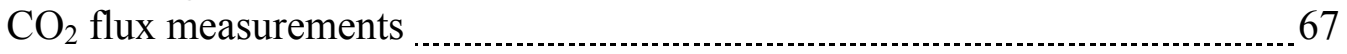

Peak season $\mathrm{CH}_{4}$ flux measurements _...................................................... 67

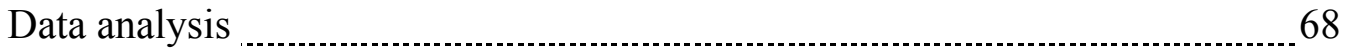


Results

Weather and hydrological manipulation

$\mathrm{CO}_{2}$ flux components

Methane

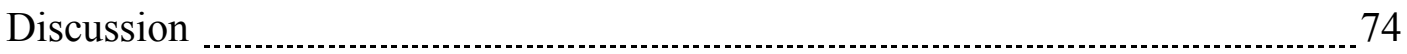

Ecosystem biophysical responses to water table change and warming ……......... 74

$\mathrm{CO}_{2}$ flux responses to water table change and warming ................................. 75

Peak season $\mathrm{CH}_{4}$ responses to water table and warming ……_...................... 79

Conclusions _..._.

Acknowledgments

Tables

Figures $\ldots \ldots+\cdots$

Literature cited

4. Chapter 3: Effects of Long-Term Warming on the Peak Season $\mathrm{CO}_{2}$ Flux

Components of Arctic Tundra at a Continental and Coastal Location in

Northern Alaska

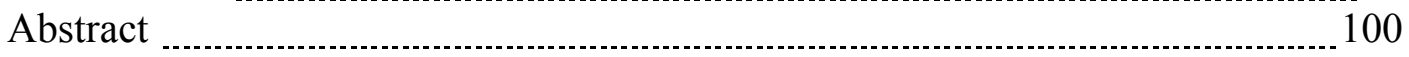

Introduction

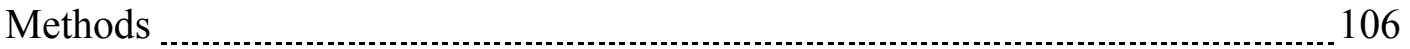

Study site $\ldots \ldots \ldots$

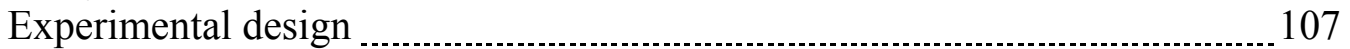

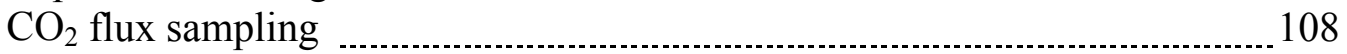

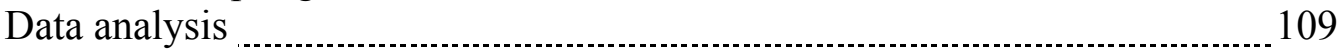

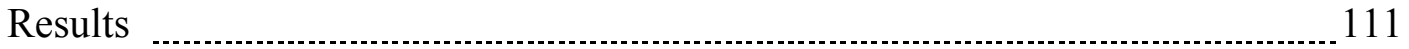

Interannual variability in the $\mathrm{CO}_{2}$ flux components and warming effects 111



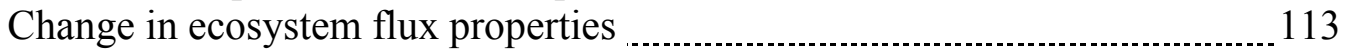

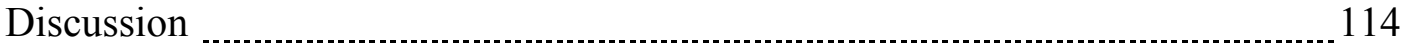

Location and site effects on changes of ecosystem flux characteristics ......... 118

Previous findings

Long-term ecosystem response to warming _..._._._._.

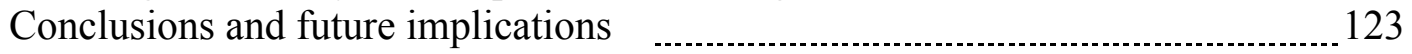

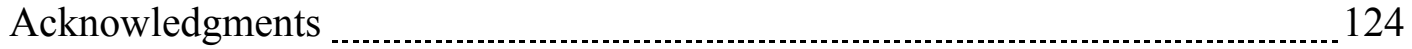

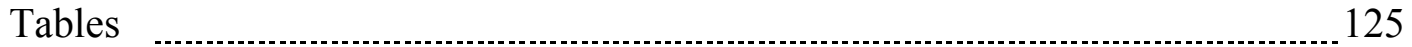

Figures 127

Literature cited

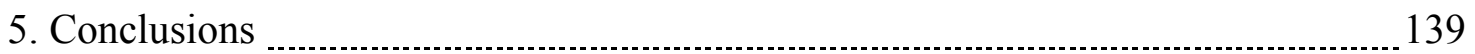

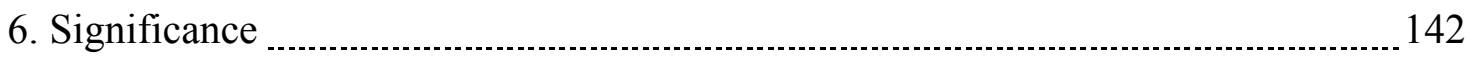

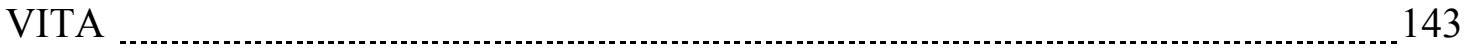




\section{LIST OF TABLES}

TABLE

PAGE

Chapter 1: Responses of $\mathrm{CO}_{2}$ Flux Components of Alaskan Coastal Plain

Tundra to Shifts in Water Table

1. Seasonal means of gross primary productivity (GPP), net ecosystem exchange (NEE), ecosystem respiration (ER), normalized difference vegetation index (NDVI), seasonal water table $(\mathrm{cm})$, and thaw $(\mathrm{cm})$. Flux values follow ecosystem flux notation, positive values indicate $\mathrm{CO}_{2}$ uptake and negative mean $\mathrm{CO}_{2}$ losses. Water table and thaw were referenced to the top of the surface or at moss layer if present. N represents the overall sample size, with the same $\mathrm{N}$ for each lake section within years, and 6 plots in each lake section. Means were compared using a two-way ANOVA

2. Results of the two-way analysis of variance (ANOVA) analyzing the seasonal measurements of gross primary productivity (GPP), net ecosystem exchange (NEE), ecosystem respiration (ER), normalized difference vegetation index (NDVI), water table $(\mathrm{cm})$, and thaw

3. Linear correlations (Adj. $\mathrm{R}^{2}$ ) between $\mathrm{CO}_{2}$ flux components and water table.

Correlations are significant to $\mathrm{p}<0.001$, unless specified within parentheses. $\mathrm{N}$ represents the overall sample sizes, with 8 plots for wet sedge, 6 for intermediate and 4 for the polygon $\operatorname{rim}(\mathrm{PR})$. GPP $=$ gross primary productivity, $\mathrm{NEE}=$ net ecosystem exchange, and $\mathrm{ER}=$ ecosystem respiration

Chapter 2: Response Of Carbon Fluxes Of Alaskan Coastal Plain Tundra To The Synergistic Effect Of Water And Temperature Changes

1. Summary of a 3-way analysis of variance (ANOVA) with water table category nested within years for the seasonal means of the $\mathrm{CO}_{2}$ flux components across water and temperature manipulations. Significant $\mathrm{P}$ values are indicated in bold

2. Nonlinear regression parameters for gross primary productivity (GPP), and ecosystem respiration (ER) during 2007 and 2008 using Eq. 1 and 2 respectively with $80 \%$ of the data. Temperature control plots, T-CTL, and warmed plots, OTC

3. Independent testing of the models. Linear correlations between measured and expected GPP and ER using $20 \%$ of the flux values randomly selected from the original data set. These data were not used in model construction. Temperature control plots, T-CTL, and warmed plots, OTC 
Chapter 3: Effects of Long-Term Warming on the Peak Season $\mathrm{CO}_{2}$ Flux Components of Arctic Tundra at a Continental and Coastal Location in Northern

Alaska

1. Summary table of the mixed model effect analysis. Location, site, and treatment where fixed effects, year was the repeated measures effect. Gross primary productivity (GPP), net ecosystem exchange (NEE), ecosystem respiration (ER). We used type III tests of fixed effects and first-order autoregressive structure with heterogeneous variances for the residuals

2. Linear relationship between year and ecosystem respiration (ER) for Atqasuk and Barrow for the Dry and Wet sites. Treatments: temperature control plots (T-CTL), and warmed plots (open top chambers, OTC)

3. Linear relationship between peak season air temperature and ecosystem respiration (ER) for Atqasuk and Barrow for the Dry and Wet sites. Treatments: temperature control plots (T-CTL), and warmed plots (open top chambers, OTC) 


\section{LIST OF FIGURES}

FIGURE

PAGE

Introduction

1. Hypothetical response of the Coastal Plain ecosystem to changes in water availability and temperature. Scenario A: warming and lowering of water table could enhance $\mathrm{CO}_{2}$ emission and reduce $\mathrm{CH}_{4}$, B: intermediate or control condition, warming is expected to affect emissions according to topographic position, $\mathrm{C}$ : flooding is expected to decrease $\mathrm{CO}_{2}$ emissions but to increase $\mathrm{CH}_{4}$. Trapezoids represent OTCs (open top chambers) used for warming

Chapter 1: Responses Of $\mathrm{CO}_{2}$ Flux Components Of Alaskan Coastal Plain Tundra To Shifts In Water Table

1. Photosynthetically active radiation (PAR, $\mu \mathrm{mol} \mathrm{m} \mathrm{m}^{-2}$ ) and air temperature $\left({ }^{\circ} \mathrm{C}\right)$ for the three growing seasons. Values represent daily averages \pm one standard error

2. Water table $(\mathrm{cm})$, thaw $(\mathrm{cm})$ and soil temperature (at $1 \mathrm{~cm}$ depth) for the three growing seasons. Values for water table and thaw represent the average of all plots along each lake section, and negative values represent points below the surface. Error bars represent \pm one standard error. Soil temperature was measured at one location during the three seasons

3. Seasonal $\mathrm{CO}_{2}$ flux components and NDVI from 2006 to 2008 within the three lake sections. Sample sizes are 6 plots for north, central and south lake sections. $\mathrm{CO}_{2}$ flux components are presented using the ecosystem perspective, where positive values represent $\mathrm{CO}_{2}$ uptake and negative values loss of $\mathrm{CO}_{2}$ to the atmosphere. $\mathrm{GPP}=$ gross primary productivity, $\mathrm{NEE}=$ net ecosystem exchange, $\mathrm{ER}=$ ecosystem respiration, $\mathrm{NDVI}=$ normalized difference vegetation index

4. Seasonal means for GPP, NEE, ER, water table, and thaw for all microsites during 2006, 2007 and 2008. For $\mathrm{CO}_{2}$ flux components, positive values indicate uptake and negative values indicate loss. The zero value represents the soil surface for thaw and water table. Error bars represent \pm 1 standard error. $\mathrm{N}$ was the same for all years, with 18 plots: 8 wet sedge, 6 intermediate, and 4 polygon rims. Panels A, B, and C: two-way ANOVA for GPP, NEE, ER. Panels D and E: two-way ANOVA for water table and thaw. Multiple comparison was done using Least Significant Difference, columns under different horizontal lines represent significant difference $\mathrm{p}<0.05$ within years, different letters represent significant difference $p<0.05$ between years 
5. Seasonal pattern of $\mathrm{CO}_{2}$ flux components for growing seasons of 2006, 2007, and 2008 (18 plots). Fluxes use the ecosystem notation where positive values represent $\mathrm{CO}_{2}$ uptake and negative values represent $\mathrm{CO}_{2}$ loss from the system. Values of GPP, NEE and ER on the same date represent diurnal patterns in response to PAR and temperature

6. PATH diagrams illustrate the standardized correlations (R) between predictors and $\mathrm{CO}_{2}$ flux components (unidirectional arrows) and the correlations between predictors (bidirectional arrows). Data used for the analysis include measurements for all growing seasons and sites, $\mathrm{N}=399$ (north, central, south)

Chapter 2: Response Of Carbon Fluxes Of Alaskan Coastal Plain Tundra To The Synergistic Effect Of Water And Temperature Changes

1. Study site, lake sections and plot layout (insert) 85

2. Photosynthetically active radiation (PAR), air temperature, and surface temperature $(-2 \mathrm{~cm})$ for the study site for 2007 and 2008. Errors bars represent \pm one standard error of the mean 86

3. Mean surface temperatures $(-2 \mathrm{~cm})$, water table category and thaw by temperature and water categories and year. Shaded bars represent temperature control plots (T-CTL), unshaded bars represent warmed plots (open top chambers, OTC). Errors bars represent \pm one standard error of the mean. Between water categories, different letters represent significant differences at $\mathrm{p}<0.05$. Within water categories, bar under different line present a significant difference at $\mathrm{p}<0.05$ between temperature treatments

4. Main effect of temperature on $\mathrm{CO}_{2}$ flux components. Seasonal mean $\mathrm{CO}_{2}$ flux for both season separated by temperature and water table categories. GPP, gross primary productivity. NEE, net ecosystem exchange. ER, ecosystem respiration. Temperature control plots, T-CTL. Open top chambers, OTC. Positive numbers represent $\mathrm{CO}_{2}$ uptake. Errors bars represent \pm one standard error of the mean, temperature treatment effect: GPP, $\mathrm{F}=8.214, \mathrm{p}=0.006$, NEE, $\mathrm{F}=3.164, \mathrm{p}=0.081$ and $\mathrm{ER}, \mathrm{F}=7.735, \mathrm{p}=0.007$ 88

5. Seasonal mean $\mathrm{CO}_{2}$ flux separated by temperature and water category and year. GPP, gross primary productivity standardized by PAR (photosynthetically active radiation). NEE, net ecosystem exchange. ER, ecosystem respiration. Positive numbers represent $\mathrm{CO}_{2}$ uptake. Shaded bars represent temperature control plots (T-CTL), unshaded bars represent warmed plots (open top chambers, OTC). Errors bars represent \pm one standard error of the mean. Between water table categories, different letters represent 
significant differences at $p<0.05$. Within water categories, bars under different line present a significant difference at $\mathrm{p}<0.05$ between temperature treatments

6. Gross primary productivity (GPP, upper panel) response to water table change and PPFD; and ecosystem respiration (ER) response to water table and temperature (lower panel). Models based on equations 1 and 2, where PPFD $\left(600 \mu \mathrm{mol} / \mathrm{m}^{2} \mathrm{~s}\right)$, NDVI $(0.6)$, and temperature $\left(10^{\circ} \mathrm{C}\right)$ were kept constant. Temperature control plots, T-CTL, and open top chamber, OTC

7. Peak season $\mathrm{CH}_{4}$ efflux, water table, and soil temperature at $10 \mathrm{~cm}$ separated by warming treatment, water table category and year. Positive numbers represent $\mathrm{CH}_{4}$ release. Water table is referenced to top of the moss layer. Shaded bars represent temperature control plots (T-CTL), unshaded bars represent warmed plots (open top chambers, OTC). Errors bars represent \pm one standard error of the mean. Within years, water table categories with different letters and symbols represent significant differences at $\mathrm{p}<0.05$. Temperature treatments under a different horizontal line present a significant difference at $\mathrm{p}<0.05$

Chapter 3: Effects Of Long-Term Warming On The Peak Season $\mathrm{CO}_{2}$ Flux Components Of Arctic Tundra At A Continental And Coastal Location In Northern Alaska

1. Peak season gross primary productivity (GPP), net ecosystem exchange (NEE), and ecosystem respiration (ER) for temperature control plots (T-CTL), and warmed plots (open top chambers, OTC) in Dry and Wet sites at Atqasuk and Barrow. Bars represent peak season daily means, and error bars one standard error of the mean

2. Linear relationship between ecosystem respiration (ER) and year at peak season for temperature control plots (T-CTL), and warmed plots (open top chambers, OTC) in Dry and Wet sites at Atqasuk and Barrow

3. Ratios of gross primary productivity (GPP) to ecosystem respiration (ER) for temperature control plots (T-CTL), and warmed plots (open top chambers, OTC) in Dry and Wet sites at Atqasuk and Barrow. Dashed line (1:1) represents the $\mathrm{CO}_{2}$ balance line at which net ecosystem exchange is zero. $\mathrm{GPP} / \mathrm{ER}$ ratios less than one represent $\mathrm{CO}_{2}$ sources

4. Light compensation point (LCP) for the warmed plots (open top chambers, OTC) and temperature control plots (T-CTL) in the Dry and Wet site at Atqasuk and Barrow. LCP was calculated using Eq. 2. Bars represent air temperature and error bars the standard error of the mean 
5. Apparent quantum yield $(\phi)$ for the warmed (open top chambers, OTC) and temperature control plots (T-CTL) in the Dry and Wet site at Atqasuk and Barrow. $\phi$ was calculated using Eq. 2. $\phi$ describes the moles of $\mathrm{CO}_{2}$ fixed by moles of light absorbed 


\section{Introduction}

Northern Peatlands present short growing seasons, low temperature, precipitation, and productivity (Chapin et al. 1995, Brooker and van der Wal 2003); however, despite the low productivity, slow organic matter decay has favored soil carbon accumulation (Billings and Peterson 1980, Bockheim et al. 1999, Pastor et al. 2003). The Arctic holds close to $1672 \mathrm{Gt}$ of carbon near the surface and in deep permafrost deposits (Tarnocai et al. 2009). The negative combined effect of low soil temperatures, permafrost, high water tables, low nutrients, and anoxic soil conditions on the microbial activity has enhanced accumulation of soil organic carbon. Historically, arctic ecosystems have been a sink for carbon dioxide $\left(\mathrm{CO}_{2}\right.$, Oechel et al. 1993, Bockheim et al. 1999, Tarnocai et al. 2009), but net sources of methane $\left(\mathrm{CH}_{4}\right.$, Christensen and Cox 1995). Methane has a heat trapping capacity 20 times greater than that of $\mathrm{CO}_{2}$, and methane emission from the Arctic represent $20-25 \%$ of the natural global emissions (Christensen and Cox 1995). Some factors that can reduce $\mathrm{CO}_{2}$ losses can favor methane emissions, for instance, the interaction of water-saturated soils, anoxic conditions, temperature, and vegetation among others (Johnson et al. 1996, King et al. 1998, Christensen et al. 2003, Elberling et al. 2008), therefore, determining the effects that changes in temperature and water table would have on the $\mathrm{CO}_{2}$ and $\mathrm{CH}_{4}$ losses and the implication for a positive feedback to green house effect is not straightforward.

The Intergovernmental Panel of Climate Change (IPCC) has determined that an increase of the global temperature would be magnified in the Polar Regions, and estimated that the climate sensitivity (the change in climate that would trigger significant biological and chemical changes) lies between 2 and $4.5^{\circ} \mathrm{C}$ (IPCC 2007). The mean 
warming predictions for the Arctic Region estimate an increase of $5^{\circ} \mathrm{C}$ (IPCC 2007). However, there is still great uncertainty about hidden temperature thresholds, suggesting that: 1) the climate sensitivity could be higher, and 2) not the same across the arctic landscape. An increase in temperature should have a direct effect on the soil carbon storage by increasing microbial activity, nutrient availability (Hobbie and Chapin 1998, Shaver et al. 2006), and indirectly by increasing depth of thaw and reducing soil moisture (Oberbauer et al. 1991, Oberbauer et al. 1992, Bubier et al. 1998, Merbold et al. 2009). As a result, more oxygen would penetrate into the soil favoring microbial decomposition (Boddy et al. 2008, Schuur et al. 2008). Therefore, drying and warming could increase $\mathrm{CO}_{2}$ emissions, while flooding and warming would increase $\mathrm{CH}_{4}$ emissions (Moosavi and Crill 1997, Christensen et al. 2000, Merbold et al. 2009). Given that drying and flooding could occur under warming scenarios as result of permafrost degradation, erosion, lake drainage, and microtopographic heterogeneity, it is key to understand the magnitude of the physiological response of the ecosystem, taking into account the combined effect of warming drying and flooding.

The Arctic Coastal Plain of Alaska is a complex system of lakes, thawed lake basins, and polygons (Hinkel et al. 2003), where within short distances (in the scale of meters) soil moisture content can change significantly, and thus the ecosystem function and structure (Hinkel et al. 1996, Hinkel et al. 2003, Sjogersten et al. 2006). Therefore, accounting for spatial heterogeneity becomes key for simulations of ecosystem responses at the landscape level, because different topographic features and plant groups could respond differently to warming, flooding or drying (Oberbauer et al. 1998, Hollister et al. 2005, Walker et al. 2006, Oberbauer et al. 2007, Olivas et al. 2010). 
In addition to storing most of the carbon in the arctic terrestrial ecosystems, continuous permafrost plays a key role in the complex hydrology of the Arctic (Tarnocai et al. 2009). Continuous permafrost restricts vertical and horizontal movement of water, reducing the effect of parental material on the biochemical cycles. In ombrotropic systems, such as arctic ecosystems, restricted nutrient inflow is likely to favor low $\mathrm{pH}$, low nutrient availability hindering organic matter turnover, and low primary productivity (Hobbie and Gough 2004, Shaver et al. 2006). On the other hand, shallow permafrost can favor plants by keeping the water near the surface; however, it also contributes to water losses from the system at the beginning of the growing season by restricting infiltration and enhancing runoff during the snowmelt. Under warming conditions, permafrost degradation would not only affect the carbon stored, but also the water availability of arctic ecosystems (Schuur et al. 2008, Frey and McClelland 2009). Increase of the depth of thaw could increase ground water movement, increasing losses of dissolved organic carbon and nitrogen (Pastor et al. 2003, Blodau et al. 2004). Additionally, the ecosystems can present a short and long-term responses that make difficult prediction of the effects of changes in water availability and warming not only for the carbon cycle but also for permafrost degradation and species compositions (Oechel et al. 2000, Hollister et al. 2005, Shaver et al. 2006, Schuur et al. 2008).

Warming, flooding and drying are likely to affect the carbon flux components differently. Thus, looking only at the net ecosystem balance (NEE) might not be sufficient for forecasting how the ecosystem function would be affected by changes in temperature and water availability. For instance, an increase in water availability (flooding, Figure 1C) has the potential of reducing both ecosystem respiration (ER) and 
gross primary productivity (GPP). Flooding can increase soil anoxia, decreasing $\mathrm{CO}_{2}$ production as result of a reduction in microbial and root activity and increasing resistance of $\mathrm{CO}_{2}$ diffusion from soil to atmosphere. On the other hand, wetter conditions are likely to favor the production and emissions of $\mathrm{CH}_{4}$. However, the increase in methane emissions and the decrease in GPP would be tightly related to the vegetation cover and intensity of the flooding (Christensen et al. 2003). Flooding is likely to submerge part or all the leaf area, and as a result, the effective surface area for photosynthesis and gas exchange with the atmosphere would decrease reducing GPP. The long-term response of the ecosystem function and structure would be affected by the ability of the primary producers to adapt to the new conditions. A decrease in water availability (Figure 1A) is likely to decrease $\mathrm{CH}_{4}$ emissions and bryophyte GPP and increase $\mathrm{CO}_{2}$ production and emissions as result of an increase in oxygen availability in the soil for microbial activity. The GPP of the vascular plants will vary depending on their ability to access the water deeper into the soil and the species composition. Drying can also limit heat transfer reducing soil temperature, reducing the performance of vascular plants and microbial community (Starr et al. 2004, Allison and Treseder 2008). Warming alone (Figure 1B) has the potential of increasing soil microbial activity, but the production of $\mathrm{CO}_{2}$ or $\mathrm{CH}_{4}$ will be favored depending on the microtopography, plant cover, anoxic soil conditions, and nutrient availability. Nevertheless, if water is not limited, an increase in soil temperature is likely to have a positive effect on the photosynthetic capacity of the vascular plants, increasing the $\mathrm{CO}_{2}$-sink capacity. Under flooding conditions (Figure 1C), warming could stimulate microbial activity of anoxic microbes, methane production, and depth of thaw (as result of increase thermal conductivity of the soil because of the 
water). In the short-term, warming and drying can reduce water availability and the thermal conductivity of the soil promoting shallower permafrost, but in the long-term warming and drying could significantly reduce productivity and increase decomposition, negatively affecting the integrity of the permafrost.

Given that $\mathrm{CO}_{2}$ flux components such as GPP and ER can respond independently to changes in moisture and temperature, it is key to determine their individual responses to changes in water availability and temperature to better understand and predict the potential ecosystem feedbacks to anthropogenic climate change. Additionally, assessing the short and long-term responses of the ecosystem can give us a better understanding of the dynamics of the ecosystem and its potential for change and acclimatization.

\section{Objectives}

To increase our understanding of the potential responses of the tundra ecosystems to changes in moisture availability and temperature I asked the overall question:

- What are the separate and combined effects of changes in temperature and water availability on the carbon cycle of arctic tundra?

To answer the overall question, I have developed four specific objectives and approaches to meet them:

- Evaluate the individual short-term effects of changing water availability on the ecosystem carbon flux. To test for the effects of changing water availability on carbon flux components, I used a hydrological manipulation with three treatments: flooded, drained and intermediate. 
- Evaluate the combined effect of increasing temperature and changing water availability on the ecosystem carbon flux components. The synergetic effect of water and temperature was tested using three hydrological treatments: flooded, drained and intermediate, with control and warmed plots within each treatment.

- Evaluate the long-term effect of increased temperature on dry and wet tundra ecosystems. I evaluated the response of carbon flux components to long-term warming at the two ends of a natural hydrological gradient on the ecosystem in a coastal and inland location in northern Alaska. The long-term effect of temperature on the ecosystem carbon flux was tested in two ways. First, by comparing the $\mathrm{CO}_{2}$ flux components between the control and warmed plots located in wet and dry sites. Second, by looking at the effect that location (geographical position with respect to the ocean) had on the magnitude of the temperature effect in both wet and dry sites. I used two locations: Barrow and Atqasuk ( 100 km south of Barrow).

I tested the following hypotheses: 1) an increase in temperature will decrease NEE of the ecosystem in the dry areas and increase NEE in the moist areas, 2) an increase in water availability will increase NEE, whereas a decrease in water availability will decrease NEE, 3) increase of water availability and temperature will increase NEE, whereas decrease in water availability and increase in temperature will decrease NEE, 4) geographic location will magnify the effect of increased temperatures on the ecosystem carbon cycle. Dry areas will lose carbon with increased temperature, while wet areas will increase productivity. 
The first chapter of this dissertation has been accepted for publication in Journal of Geophysical Research: Biosciences. Copyright (2010) American Geophysical Union. Further reproduction or electronic distribution is not permitted. Chapters two and three will be submitted to peer review journals to be considered for publication. 


\section{Figures}

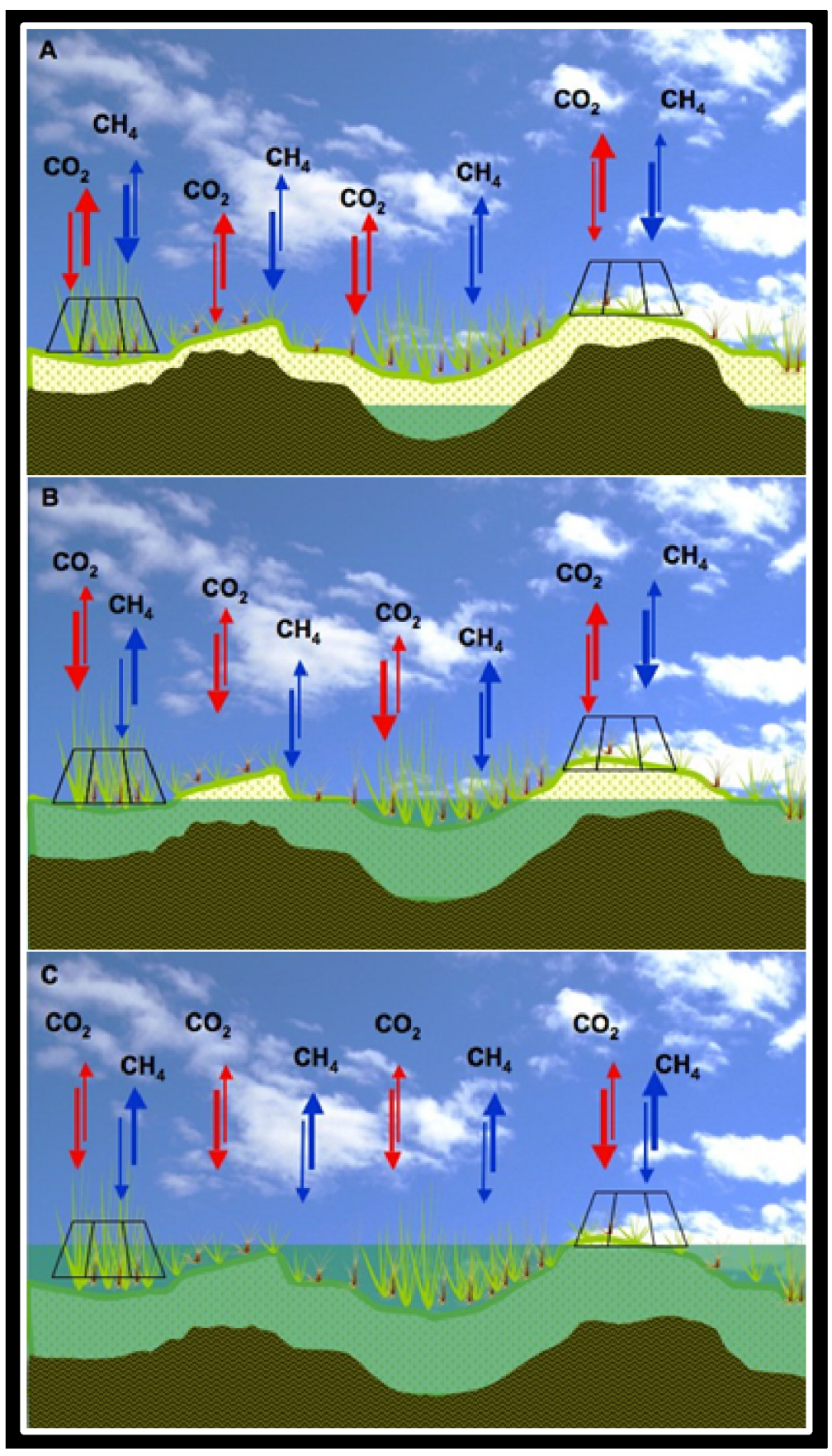

Figure 1. Hypothetical response of the Coastal Plain ecosystem to changes in water availability and temperature. Scenario A: warming and lowering of water table could enhance $\mathrm{CO}_{2}$ emission and reduce $\mathrm{CH}_{4}$, $\mathrm{B}$ : intermediate or control condition, warming is 
expected to affect emissions according to topographic position, C: flooding is expected to decrease $\mathrm{CO}_{2}$ emissions but to increase $\mathrm{CH}_{4}$. Trapezoids represent OTCs (open top chambers) used for warming. 


\section{LITERATURE CITED}

Allison, S. D. and K. K. Treseder. 2008. Warming and drying suppress microbial activity and carbon cycling in boreal forest soils. Global Change Biology 14:2898-2909.

Billings, W. D. and K. M. Peterson. 1980. Vegetational Change And Ice-Wedge Polygons Through The Thaw-Lake Cycle In Arctic Alaska. Arctic and Alpine Research 12:413-432.

Blodau, C., N. Basiliko, and T. R. Moore. 2004. Carbon turnover in peatland mesocosms exposed to different water table levels. Biogeochemistry 67:331-351.

Bockheim, J. G., L. R. Everett, K. M. Hinkel, F. E. Nelson, and J. Brown. 1999. Soil organic carbon storage and distribution in Arctic Tundra, Barrow, Alaska. Soil Science Society of America Journal 63:934-940.

Boddy, E., P. Roberts, P. W. Hill, J. Farrar, and D. L. Jones. 2008. Turnover of low molecular weight dissolved organic $\mathrm{C}$ (DOC) and microbial $\mathrm{C}$ exhibit different temperature sensitivities in Arctic tundra soils. Soil Biology \& Biochemistry 40:1557-1566.

Brooker, R. and R. van der Wal. 2003. Can soil temperature direct the composition of high arctic plant communities? Journal of Vegetation Science 14:535-542.

Bubier, J. L., P. M. Crill, T. R. Moore, K. Savage, and R. K. Varner. 1998. Seasonal patterns and controls on net ecosystem $\mathrm{CO}_{2}$ exchange in a boreal peatland complex. Global Biogeochemical Cycles 12:703-714.

Chapin, F. S., G. R. Shaver, A. E. Giblin, K. J. Nadelhoffer, and J. A. Laundre. 1995. Responses of Arctic Tundra to Experimental and Observed Changes in Climate. Ecology 76:694-711.

Christensen, T. R. and P. Cox. 1995. Response of Methane Emission from Arctic Tundra to Climatic-Change - Results from a Model Simulation. Tellus Series B-Chemical and Physical Meteorology 47:301-309.

Christensen, T. R., T. Friborg, M. Sommerkorn, J. Kaplan, L. Illeris, H. Soegaard, C. Nordstroem, and S. Jonasson. 2000. Trace gas exchange in a high-arctic valley 1. Variations in $\mathrm{CO}_{2}$ and $\mathrm{CH}_{4}$ flux between tundra vegetation types. Global Biogeochemical Cycles 14:701-713.

Christensen, T. R., N. Panikov, M. Mastepanov, A. Joabsson, A. Stewart, M. Oquist, M. Sommerkorn, S. Reynaud, and B. Svensson. 2003. Biotic controls on $\mathrm{CO}_{2}$ and $\mathrm{CH}_{4}$ exchange in wetlands - a closed environment study. Biogeochemistry 64:337-354. 
Elberling, B., C. Nordstrom, L. Grondahl, H. Sogaard, T. Friborg, T. R. Christensen, L. Strom, F. Marchand, and I. Nijs. 2008. High-arctic soil $\mathrm{CO}_{2}$ and $\mathrm{CH}_{4}$ production controlled by temperature, water, freezing and snow. Advances in Ecological Research 40:441-472.

Frey, K. E. and J. W. McClelland. 2009. Impacts of permafrost degradation on arctic river biogeochemistry. Hydrological Processes 23:169-182.

Hinkel, K. M., W. R. Eisner, J. G. Bockheim, F. E. Nelson, K. M. Peterson, and X. Y. Dai. 2003. Spatial extent, age, and carbon stocks in drained thaw lake basins on the Barrow Peninsula, Alaska. Arctic Antarctic and Alpine Research 35:291-300.

Hinkel, K. M., F. E. Nelson, Y. Shur, J. Brown, and K. R. Everett. 1996. Temporal changes in moisture content of the active layer and near-surface permafrost at Barrow, Alaska, USA: 1962-1994. Arctic and Alpine Research 28:300-310.

Hobbie, S. E. and F. S. Chapin. 1998. Response of tundra plant biomass, aboveground production, nitrogen, and $\mathrm{CO}_{2}$ flux to experimental warming. Ecology 79:15261544.

Hobbie, S. E. and L. Gough. 2004. Litter decomposition in moist acidic and non-acidic tundra with different glacial histories. Oecologia 140:113-124.

Hollister, R. D., P. J. Webber, and C. Bay. 2005. Plant response to temperature in Northern Alaska: Implications for predicting vegetation change. Ecology 86:1562-1570.

Intergovernmental Panel on Climate Change (IPCC). 2007. Climate Change 2007: The Physical Science Basis. Contribution of Working Group I to the Fourth Assessment Report (AR4) of the Intergovernmental Panel on Climate Change, edited by S. Solomon et al., 996 pp., Cambridge Univ. Press, Cambridge, U. K.

Johnson, L. C., G. R. Shaver, A. E. Giblin, K. J. Nadelhoffer, E. R. Rastetter, J. A. Laundre, and G. L. Murray. 1996. Effects of drainage and temperature on carbon balance of tussock tundra microcosms. Oecologia 108:737-748.

King, J. Y., W. S. Reeburgh, and S. K. Regli. 1998. Methane emission and transport by arctic sedges in Alaska: Results of a vegetation removal experiment. Journal of Geophysical Research-Atmospheres 103:29083-29092.

Merbold, L., W. L. Kutsch, C. Corradi, O. Kolle, C. Rebmann, P. C. Stoy, S. A. Zimov, and E. D. Schulze. 2009. Artificial drainage and associated carbon fluxes $\left(\mathrm{CO}_{2} / \mathrm{CH}_{4}\right)$ in a tundra ecosystem. Global Change Biology 15:2599-2614. 
Moosavi, S. C. and P. M. Crill. 1997. Controls on $\mathrm{CH}_{4}$ and $\mathrm{CO}_{2}$ emissions along two moisture gradients in the Canadian boreal zone. Journal of Geophysical ResearchAtmospheres 102:29261-29277.

Oberbauer, S. F., C. T. Gillespie, W. Cheng, R. Gebauer, A. S. Serra, and J. D. Tenhunen. 1992. Environmental-effects on $\mathrm{CO}_{2}$ efflux from riparian tundra in the northern foothills of the Brooks Range, Alaska, USA. Oecologia 92:568-577.

Oberbauer, S. F., G. Starr, and E. W. Pop. 1998. Effects of extended growing season and soil warming on carbon dioxide and methane exchange of tussock tundra in Alaska. Journal of Geophysical Research-Atmospheres 103:29075-29082.

Oberbauer, S. F., J. D. Tenhunen, and J. F. Reynolds. 1991. Environmental-effects on $\mathrm{CO}_{2}$ efflux from water track and tussock tundra in arctic Alaska, USA. Arctic and Alpine Research 23:162-169.

Oberbauer, S. F., C. E. Tweedie, J. M. Welker, J. T. Fahnestock, G. H. R. Henry, P. J. Webber, R. D. Hollister, M. D. Walker, A. Kuchy, E. Elmore, and G. Starr. 2007. Tundra $\mathrm{CO}_{2}$ fluxes in response to experimental warming across latitudinal and moisture gradients. Ecological Monographs 77:221-238.

Oechel, W. C., S. J. Hastings, G. Vourlitis, M. Jenkins, G. Riechers, and N. Grulke. 1993. Recent Change of Arctic Tundra Ecosystems from a Net Carbon-Dioxide Sink to a Source. Nature 361:520-523.

Oechel, W. C., G. L. Vourlitis, S. J. Hastings, R. C. Zulueta, L. Hinzman, and D. Kane. 2000. Acclimation of ecosystem $\mathrm{CO}_{2}$ exchange in the Alaskan Arctic in response to decadal climate warming. Nature 406:978-981.

Olivas, P. C., S. F. Oberbauer, C. E. Tweedie, W. C. Oechel, and A. Kuchy. 2010. Responses of $\mathrm{CO}_{2}$ Flux Components of Alaskan Coastal Plain Tundra To Shifts In Water Table. JGR Biosciences: in press.

Pastor, J., J. Solin, S. D. Bridgham, K. Updegraff, C. Harth, P. Weishampel, and B. Dewey. 2003. Global warming and the export of dissolved organic carbon from boreal peatlands. Oikos 100:380-386.

Schuur, E. A. G., J. Bockheim, J. G. Canadell, E. Euskirchen, C. B. Field, S. V. Goryachkin, S. Hagemann, P. Kuhry, P. M. Lafleur, H. Lee, G. Mazhitova, F. E. Nelson, A. Rinke, V. E. Romanovsky, N. Shiklomanov, C. Tarnocai, S. Venevsky, J. G. Vogel, and S. A. Zimov. 2008. Vulnerability of permafrost carbon to climate change: Implications for the global carbon cycle. Bioscience 58:701-714. 
Shaver, G. R., A. E. Giblin, K. J. Nadelhoffer, K. K. Thieler, M. R. Downs, J. A. Laundre, and E. B. Rastetter. 2006. Carbon turnover in Alaskan tundra soils: effects of organic matter quality, temperature, moisture and fertilizer. Journal of Ecology 94:740-753.

Sjogersten, S., R. van der Wal, and S. J. Woodin. 2006. Small-scale hydrological variation determines landscape $\mathrm{CO}_{2}$ fluxes in the high Arctic. Biogeochemistry 80:205-216.

Solomon, S., G.-K. Plattner, R. Knutti, and P. Friedlingstein. 2009. Irreversible climate change due to carbon dioxide emissions. Proceedings of the National Academy of Sciences 106:1704-1709.

Starr, G., D. S. Neuman, and S. F. Oberbauer. 2004. Ecophysiological analysis of two arctic sedges under reduced root temperatures. Physiologia Plantarum 120:458464.

Tarnocai, C., J. G. Canadell, E. A. G. Schuur, P. Kuhry, G. Mazhitova, and S. Zimov. 2009. Soil organic carbon pools in the northern circumpolar permafrost region. Global Biogeochemical Cycles 23: GB2023.

Walker, M. D., C. H. Wahren, R. D. Hollister, G. H. R. Henry, L. E. Ahlquist, J. M. Alatalo, M. S. Bret-Harte, M. P. Calef, T. V. Callaghan, A. B. Carroll, H. E. Epstein, I. S. Jonsdottir, J. A. Klein, B. Magnusson, U. Molau, S. F. Oberbauer, S. P. Rewa, C. H. Robinson, G. R. Shaver, K. N. Suding, C. C. Thompson, A. Tolvanen, O. Totland, P. L. Turner, C. E. Tweedie, P. J. Webber, and P. A. Wookey. 2006. Plant community responses to experimental warming across the tundra biome. Proceedings of the National Academy of Sciences of the United States of America 103:1342-1346. 


\title{
2. Chapter 1: Responses of $\mathrm{CO}_{2}$ Flux Components of Alaskan Coastal Plain Tundra to Shifts in Water Table
}

Paulo C. Olivas ${ }^{1}$, Steven F. Oberbauer ${ }^{1}$, Craig E. Tweedie ${ }^{2}$, Walter C. Oechel ${ }^{3}$, and Andrea Kuchy ${ }^{1}$

${ }^{1}$ Dept. of Biological Sciences, Florida International University, 11200 S.W. $8^{\text {th }}$ St, Miami, FL 33199, USA

${ }^{2}$ Dept. of Biological Sciences, University of Texas at El Paso, 500 West University Avenue, El Paso, TX 79968, USA

${ }^{3}$ Global Research Group, Dept. of Biology, San Diego State University, 5500 Campanile Drive, San Diego, CA 92182, USA

\begin{abstract}
The Arctic stores close to $14 \%$ of the global soil carbon, most of which is in a poorly decomposed state as a result of water-saturated soils and low temperatures. Climate change is expected to increase soil temperature, affecting soil moisture and the carbon storage and sink potential of many Arctic ecosystems. Additionally, increased temperatures can increase thermokarst erosion and flooding in some areas. Our goal was to determine the effects that water table shifts would have on the $\mathrm{CO}_{2}$ sink potential of the Alaskan Coastal Plain tundra. To evaluate the effects of different water regimes, we used a large hydrological manipulation at Barrow, Alaska where we maintained flooded,
\end{abstract}


drained, and intermediate water levels in a naturally-drained thaw lake basin over a period of three seasons: one pretreatment (2006) and two treatment (2007-2008) seasons. To assess $\mathrm{CO}_{2}$ flux components, we used 24-hour chamber-based measurements done on a weekly basis. Increased water table strongly lowered ecosystem respiration (ER) by reducing soil oxygen availability. Flooding decreased gross primary productivity (GPP), most likely by submerging mosses and graminoid photosynthetic leaf area. A decrease in water table increased GPP and ER; however, the increase in root and microbial activity was greater than the increase in photosynthesis, negatively affecting net ecosystem exchange (NEE). In the short-term, ER is the $\mathrm{CO}_{2}$ flux component that responds most strongly to changes in water availability. Our results suggest that drying of the Alaskan Coastal Plain tundra in the short-term could double ER rates, shifting the historic role of some Arctic ecosystems from a sink to a source of $\mathrm{CO}_{2}$.

Key words: $\mathrm{CO}_{2}$, water table, Alaska, Arctic, GPP, NEE, ER, microtopography.

\section{Introduction}

The Arctic is characterized by the presence of large amounts of soil organic carbon (SOC) and unique hydrologic conditions. The highly anoxic soils, low soil temperatures and microbial activity, and slow turnover of the organic matter have resulted in the slow accumulation of nearly $14 \%$ of the global soil carbon in the Arctic, most of which is in a labile state (Post et al., 1982). Recent estimates of SOC in the North American Arctic region suggest a carbon pool of $98.2 \mathrm{Gt}$, with $19.2 \mathrm{Gt}$ in the surface layer, $42.1 \mathrm{Gt}$ in the subsurface active layer and $36.9 \mathrm{Gt}$ in the permafrost (Ping et 
al., 2008). In some Arctic areas, shallow permafrost, low evapotranspiration, and minimal ground water movement contribute to the formation of a unique system of wetlands comprised of ice wedge polygons, lakes, and rivers, where water is a dominant driver of ecosystem structure and function (Hinzman and Kane, 1992; Oberbauer et al., 1992; Ostendorf et al., 1996; Hinkel and Nelson, 2003). For instance, on the Barrow Peninsula of the Coastal Plain of Alaska, nearly $50 \%$ of the surface consists of lakes and ponds (Hinkel et al., 2003).

Changes in temperature and hydrological regimes in the Arctic are likely to negatively impact the processes that have favored carbon accumulation. In fact, they may accelerate the turnover of the labile carbon, particularly accumulated SOC in anoxic and frozen areas, as a result of an increase in the microbial component of the ER. Recent climate reconstruction models suggest that a long-term cooling trend in the Arctic has been reversed as result of contemporary warming associated with anthropogenic activities (Intergovernmental Panel on Climate Change (IPCC), 2007; Kaufman et al., 2009). As a result of climate change, drying of some tundra ecosystems is likely to increase because of the combined effect of an increase in temperature, particularly in the summer, and low annual precipitation ( $\sim 200 \mathrm{~mm}$ a year). Most of the precipitation is in the form of snow that is lost as runoff during the snowmelt.

The ecosystem response to drying and flooding is likely to be complex, as plants (vascular and non-vascular) and $\mathrm{CO}_{2}$ flux components may respond independently to changes in temperature and water availability (Oberbauer et al., 1991; Oberbauer et al. 1992; Sommerkorn, 2008; Sullivan et al., 2008). For instance, an increase in water table is likely to decrease ecosystem respiration (ER) by reducing oxygen availability in the 
soil (Oberbauer et al., 1991; Bubier et al., 1998; Oechel et al., 1998). However, an increase in water table could also decrease gross primary productivity (GPP), if vascular plants are flood-sensitive or if water levels were sufficient to submerge the moss layer or vascular leaf area. On the other hand, drying is likely to increase ER, although severe drying could also decrease ER (Oberbauer et al., 1992; Oechel et al., 1998). With drying, GPP of the moss layer could decrease as result of desiccation, while GPP of the vascular plants could increase as result of increased soil aeration and their ability to access suprapermafrost water.

Relatively smooth landscape features characterize the northern areas of the Alaska Arctic Coastal Plain. However, the presence of continuous permafrost affects the development of several microtopographic features that, in turn, interact with the permafrost and water table to influence ecosystem function and structure (Tieszen, 1978, Engstrom et al., 2005; Sommerkorn, 2008; Sullivan et al., 2008; P. C. Olivas et al., Effects of fine-scale topography on $\mathrm{CO}_{2}$ flux components of Alaskan Coastal Plain Tundra: Response to contrasting growing seasons, submitted to Arctic, Antarctic, and Alpine Research, 2010). Microtopography describes landscape features with small differences in elevation that are a result of the freezing and cracking of the soil and water promoting the formation of a polygonized patterned ground (Tieszen, 1978). Some common microtopographic features are the ice wedges, low-centered, high-centered polygons, and the polygon rims, which are the areas between the ice wedges and lowcentered polygons. For instance, the low-centered polygons are features with a depressed center where drainage is poor. The low-centered polygons form as result of the expansion of a system of ice wedges surrounding the polygon (overlaid by troughs) that, 
as they expand, they up thrust the ground, producing elevated areas (the rims) relative to the center of the polygon (Billings and Peterson, 1980). The size of the low-centered polygons is variable, ranging from 5-12 $\mathrm{m}$ in diameter (Tieszen, 1978).

The Alaskan Arctic Coastal Plain is dominated by several graminoid species and bryophytes (Walker et al., 2005), and in recent decades, increasing cover of deciduous shrubs (Sturm et al., 2001). Graminoids and bryophytes are likely to respond differently to short and long-term changes in water availability, thereby affecting ecosystem carbon uptake and loss (Riutta et al., 2007). As a result of the lack of a vascular system, the productivity of mosses could be negatively affected by a decrease in the water table (Riutta et al., 2007). In contrast, some graminoid species have the ability to grow in both wet and dry microsites; therefore, graminoids are likely to play an important role in the capacity of some Arctic ecosystems to maintain their carbon sink potential in the future. For instance, Carex spp. is a particularly important component of some Arctic Coastal Plain ecosystems because of its ability to grow in polygon rims, low-centered polygons and wet troughs.

In the short-term, lowering of the water table is likely to have a larger impact on the productivity of the Arctic than severe flooding, potentially changing the historic role of Arctic ecosystems as carbon sinks by increasing microbial activity (Oechel et al., 1993). However, increased nutrient availability as a result of organic matter turnover could increase the productivity of vascular plants and offset carbon losses, but shifts in ecosystem structure and function are also expected to accompany lowering of the water table (Shaver et al., 2000, Riutta et al., 2007). 
Our main goal was to determine the complex interactions of drying and flooding on the individual $\mathrm{CO}_{2}$ flux components using a large-scale hydrological manipulation of a naturally-drained thaw lake. Our hypotheses were that: 1) lowering the water table should increase ER and decrease GPP, 2) raising the water table should decrease ER and increase GPP, 3) microtopography should affect the magnitude of the response of ER and GPP to the decrease and increase of the water table. For instance, ER in polygon rims should be less affected by an increase in water table than in low areas. Previously, experimental manipulation of the water table of tundra ecosystems has been attempted at the microcosm (Billings et al., 1984; Johnson et al., 1996) or plot scale (Oechel et al., 1998). However, at those scales, thermal interactions between water level, vegetation properties and microtopography are likely obscured.

We focused our $\mathrm{CO}_{2}$ assessments on plot-scale chamber-based measurements that allow evaluation of the role of microtopography in the response of the ecosystem to water level changes. In addition to water table, we examined the direct and indirect effects of other environmental parameters, such as thaw, soil and air temperature on the $\mathrm{CO}_{2}$ exchange.

The $\mathrm{CO}_{2}$ response was evaluated using gross primary productivity (GPP, or total photosynthesis), ecosystem respiration (ER, plant and soil $\mathrm{CO}_{2}$ losses), and net ecosystem $\mathrm{CO}_{2}$ exchange (NEE, balance between ER and GPP). The data collected included one control growing season prior to the manipulation (2006, 62 days) and two seasons of experimental manipulation (2007, 64 days, and 2008, 61 days). 


\section{Methods}

Study site

The hydrological manipulation and carbon exchange measurements were conducted at the Barrow Environmental Observatory in Barrow, Alaska $\left(71.32{ }^{\circ} \mathrm{N}\right.$, $\left.156.62^{\circ} \mathrm{W}\right)$. The site is a 62 ha naturally-drained lakebed located near the northernmost point of the Alaskan Arctic Coastal Plain. The lakebed was $1.4 \mathrm{~km}$ by $0.3 \mathrm{~km}$, longitudinally oriented in a north-south direction. Prevailing northwest winds and the proximity to the Arctic Ocean influence the climate in Barrow and the orientation of lakes. Annual precipitation is low ( $200 \mathrm{~mm})$, with most precipitation as snow during winter and spring. August has the highest pluvial precipitation. The snow-free season varies, but usually begins during the first week of June and ends in September. The study area exhibits shallow summer thaw, with active layers less than $50 \mathrm{~cm}$ deep on average. The landscape is characterized by small thaw ponds and low and high-centered polygons. These landscape features represent different stages of the thaw lake cycle where the constant freezing and thawing of soil creates small changes in relief that are sufficient to affect water regimes and vegetation cover (Billings and Peterson, 1980).

Wet sedge communities dominate the lake basin, but some aquatic and dry vegetation types are also present. The wet sedge communities dominate the waterlogged areas of the low-centered polygons and low areas with poor drainage. Dominant species in these areas include Carex aquatilis Whalenb., Eriophorum scheuchzeri Hoppe, and Dupontia fisheri R. Br., interspersed with some Sphagnum spp. A thick layer of Sphagnum spp. dominates the areas with better drainage, such as the polygon rims, along with some individuals of $C$. aquatilis that usually present fewer and shorter leaves than 
those individuals in the moist and wet sites. The aquatic sites are dominated by Arctophylla fulva (Trin.) Rupr., C. aquatils and Dupontia fisheri R. Br.

\section{Experimental manipulation}

In March 2007, the lakebed was divided into three isolated sections (north, central and south) by installation of two cross-lake dikes constructed of plastic panels inserted below maximum depth of thaw (Zona et al., 2009). During experimental treatment, water was added to the northernmost lake section, the central was drained, and the southern section left as reference (intermediate water level). The objective of the manipulation was to maintain the water table $15 \mathrm{~cm}$ below and above that of the intermediate treatment in the drained and flooded sections, respectively. Although we maintained flooding and drying treatments, interannual differences in water availability during the growing seasons of the study affected the water table of the intermediate (reference) section between years. As a result, the water level objectives and realized values for the treatment sections differed among the years depending on overall water availability as a function of spring snow cover, rainfall, and evaporative demand. Lake sections will be referred to as north, central and south. The water manipulation was carried out by moving water from the central section (drained treatment) into the north (flooded treatment) immediately following snowmelt, using large pumps distributed among the low centered polygons. The differences in water table were achieved by allowing the combined effects of evapotranspiration and seasonal thaw to further lower the water tables of the drained section. In 2008, additional water was pumped from a nearby lake to help maintain the water tables in the north section. 


\section{Plot setup and microsite classification}

A 200-m boardwalk was built within each treatment (north, central, and south), perpendicular to the long axis of the lakebed to allow site access while minimizing trampling effects on the tundra. Each boardwalk was divided into six blocks of $30 \mathrm{~m}$ (10 $m$ at each end were used as a buffer). One plot was randomly selected within each block, for a total of 18 plots, six in each treatment.

To further understand the effects of water table shifts on the $\mathrm{CO}_{2}$ flux components across the landscape, we classified the 18 plots into three vegetation groups following

Olivas et al. (submitted). Plant cover, soil moisture conditions, and polygon position (if present), combined with a high-resolution digital elevation model (DEM, Tweedie et al. unpublished data), were used to separate the plots into: 1) wet sedge: high vascular cover and waterlogged soils, 2) intermediate areas: transition areas with better drainage, higher moss cover and lower vascular canopy than wet sedge areas, 3) polygon rims: high moss cover, low vascular canopy and well drained. The resulting plot classification included eight wet sedge plots, six intermediate areas, and four polygon rims.

\section{Microclimate, water level and thaw}

Atmospheric conditions, such as air and soil temperature, photosynthetically active radiation (PAR), and relative humidity, were recorded and stored every $30 \mathrm{~min}$ on a Campbell Scientific CR10X data logger located at the center of the lakebed. Temperature and relative humidity were measured with a CS500 sensor (Campbell Scientific, Logan UT, USA) and PAR with a quantum sensor (LI-COR Li-190). Soil temperature was measured at $2 \mathrm{~cm}$ deep using a thermocouple. Thaw depth and water 
table were measured twice a week over the course of the season at each plot. Thaw depth was measured using a metal probe to nearest centimeter. Water table was measured to the nearest tenth of a centimeter inside of perforated PVC wells $(2.5 \mathrm{~cm}$ diameter $)$ inserted into the permafrost. The top of the green moss layer was used as the surface reference.

$\mathrm{CO}_{2}$ exchange sampling

Net ecosystem exchange and ER were measured using an infrared gas analyzer (LI-6200, LI-COR Inc., Lincoln, NE) with enclosed chamber techniques following Oberbauer et al. (2007). The photosynthesis system was calibrated prior to each sampling date using a NIST-relatable gas standard $\left(\mathrm{CO}_{2}\right.$ in air). The cylindrical chamber was constructed from clear acrylic plastic (95\% light transmission) with two internal fans for mixing. The chamber had a volume of approximately $80 \mathrm{~L}$ depending on the location of the water table (basal area $1574 \mathrm{~cm}^{2}, 50.8 \mathrm{~cm}$ height). Pressure gradients were minimized by: 1) detaching the head sensor of the infrared gas analyzer from the chamber before placement on the plot to allow air to flow freely between inside to outside of the chamber, 2) and by using a small diameter tube connecting the inside and outside of the chamber. The base of the chamber was attached to a short section of PVC pipe coupling. During measurements, the chamber was coupled to a PVC pipe chamber base $(46 \mathrm{~cm}$ diameter) permanently installed in each plot (Olivas et al., submitted). These bases facilitated rapid sealing of the chamber during $\mathrm{CO}_{2}$ flux measurements while minimizing plot damage and soil disturbance during the repeated samplings. 
Net ecosystem exchange (NEE) was estimated by the $\mathrm{CO}_{2}$ exchange rate of the enclosed ecosystem under ambient light. Ecosystem respiration (ER) was assessed by determining the $\mathrm{CO}_{2}$ exchange rate with the chamber covered by a heavy black cloth. Gross primary production (GPP) was calculated as the absolute difference between ER and NEE. Seasonal means of NEE, GPP, and ER assessments were used to determine the effect of the water treatments on the $\mathrm{CO}_{2}$ fluxes. Measurements of NEE and ER on all plots were made weekly during the growing season (June-August) over $24 \mathrm{~h}$ periods divided into six samplings of $4 \mathrm{~h}$. Because of the long distance between lake sections, plots were divided into two sets of nine (three plots in each treatment) to complete measurements on all plots within the sample period.

\section{NDVI measurements}

Normalized difference vegetation index (NDVI) has been a valuable tool for use in scaling up ground-based measurements, such as carbon fluxes, to larger scales with airplane or satellite imagery (Hope et al.,1993; Vourlitis et al., 2000; Steltzer and Welker, 2006). The NDVI is a ratio defined by the reflectance of the red light (RED) and near infrared light (NIR) (NDVI=(NIR-RED)/(NIR+RED)). The NDVI correlates well with green biomass and has the potential to distinguish between different vegetation types, but caution must be used when applying relationships derived from temporal variation to data based on spatial variability (La Puma et al., 2007).

We used NDVI to evaluate changes in green biomass over the growing season and in response to water table manipulation. In 2006, we used digital images taken with an Agricultural Digital Camera (ADC Model 4, Dycam Inc., Woodland Hills, CA) to 
determine NDVI. For the analysis of the images we used software provided with the camera, BRIV-32. During 2007 and 2008 we measured NDVI with a single-channel reflectometer (UniSpec-SC, PP SYSTEMS, Amesbury, MA, USA). Reflectances from the 680 (RED) and 800 (NIR) bands were used to calculate NDVI. We used a Teflon panel as a reflectance standard. Under cloudy sky conditions, measurements of the Teflon panel were taken before each plot to reduce the effects of changing light conditions. Under clear sky conditions, measurements of the panel were done every twelve plots (approximate every 20 minutes). All measurements were taken horizontally above the vegetation surface in a two-hour window, bracketing solar noon to minimize shadow effects, and within a day of $\mathrm{CO}_{2}$ measurements.

Data analysis

To assess the effect of drying and flooding of the tundra, we first evaluated the effects of differences in water availability on $\mathrm{CO}_{2}$ fluxes within the three sections of the thaw lake (north, central and south). Seasonal means of the NDVI, $\mathrm{CO}_{2}$ flux components, water table, and thaw were compared in a two-way ANOVA (factors: site, 3 levels, and year, 3 levels). Subsequently, we evaluated the effect of microtopography on the relationship between water table and $\mathrm{CO}_{2}$ flux components. The $\mathrm{CO}_{2}$ flux components were regressed against water table changes using Standard Least Squares (JMP ${ }^{\circledR}$ 7.0.2, SAS Institute). Seasonal means of the NDVI, $\mathrm{CO}_{2}$ flux components, water table, and thaw were compared in a two-way ANOVA (factors: microtopography, 3 levels, and year, 3 levels). For the pairwise comparisons, we used Least Significant 
Difference. Means are accompanied by plus or minus one standard error of the mean. The analysis was done using PASW Statistics GradPack 18 (SPSS Inc., 2009). Additionally, we used PATH analysis to assess the relative importance of other environmental factors on ecosystem $\mathrm{CO}_{2}$ flux. Although similar to a multiple regression, PATH analysis is a useful tool for data analysis when causal or correlational information is known a priori about the relationships among variables. Different from a multiple regression that assumes independence of the predicting variables, PATH analysis is a more appropriate tool for data evaluation when the independence of the predictors is not certain or they are expected to be dependent. On the basis of our ability to assess water tables at each plot, for the PATH analyses we combined the data from all plots, years and treatments (lake sections) and treated the water table as a continuous variable rather than treatment categories. The approach of treating water table as a continuous variable allowed us to assess the carbon flux responses to periods with high, low and intermediate soil moisture and different weather conditions in addition to the flooding and drying treatments.

We designed our $\mathrm{CO}_{2}$ emissions model assuming water table, thaw depth, soil and air temperature, PAR (photosynthetically active radiation), and vapor pressure deficit (VPD) as potential predictors of carbon fluxes. The interrelated paths of the variables and predictors were used to evaluate the direct and indirect effects of the predictors on the carbon flux components. Final models included only those parameters that were significant predictors. 


\section{Results}

\section{Microenvironment}

The study site presented considerable variation in weather conditions among seasons. Air temperature was lowest in 2006 followed by 2008 and 2007, even though we recorded similar PAR conditions throughout the three growing seasons (Figure 1). On average, water tables in all lake sections were higher in 2006 than in 2008, and 2007 presented the lowest water tables. The south section (intermediate or reference) presented higher water tables in 2006 than in 2007, with intermediate water tables in 2008 (Table 1 and Figure 2). Water tables in 2006 (the pretreatment season) were above the soil surface for all plots for most of the growing season (Figure 2). In 2007, (treatment year 1) the average water table of the plots along the intermediate lake section (reference) was above the surface only immediately after snowmelt. Water tables in the north and central sections in 2007 showed similar patterns to those of the south section, but were shifted higher. In 2008, water tables of the central section were slightly below those of the south section. For the same year, water tables in the north section were about $5 \mathrm{~cm}$ higher than those in the south section until mid season.

The depth of thaw presented similar seasonal patterns in all three years; however the ranking of the lake sections changed among years in response to the hydrological treatments (Figure 2). On average, the thaw in the north section changed from being the shallowest in 2006 to the deepest in 2008. Conversely the central section went from being one of the deepest in 2006 to be the shallowest in 2008. The south section was generally intermediate (Figure 2). Differences within years among lake sections were not 
significant, except in 2008 when the central section was significantly shallower than both north $(\mathrm{p}<0.004)$ and south $(\mathrm{p}<0.021$, Table 1$)$.

Soil temperatures were similar among all lake sections in 2006 (Figure 2). In 2007 , temperatures were slightly warmer than those of 2006, but again were similar among the sections, especially later in the season. In contrast, soil temperatures in 2008 differed among the sections in response to hydrological treatments, with highest temperatures in the north section and lowest in the central section (Figure 2).

\section{Seasonal patterns of carbon flux components and NDVI}

Values of GPP, NEE, and ER reflected differences in weather and soil water levels. The ANOVA revealed that Year (main factor) had a significant effect on all $\mathrm{CO}_{2}$ flux components. Site and the interaction Year*Lake section effects were not significant for any of the $\mathrm{CO}_{2}$ flux components (Table 1).

On average, GPP rates were higher in 2007 than in 2006 ( $\mathrm{p}=0.004$, Table 1), with intermediate rates in 2008. Within seasons, the GPP rates in 2006 and 2007 between lake sections did not differ. In 2008, the north section had lower GPP rates than the south $(\mathrm{p}=0.017)$. The central section did not differ from either section. Across years, the seasonal mean GPP rates tended to be higher in 2007 for the north and central sections (only in 2007, north lake section was significantly higher), followed by 2008. The south section presented the highest rates in 2008 , but the difference was not significant across years (Table 1, Figure 3).

In general, the seasonal NEE indicated a positive net uptake associated with high water tables. On average, NEE rates were highest in 2006 followed by 2008 and 2007, 
and the south section presented the highest uptake followed by the north and central (Table 1). Lake sections did not differ significantly within years except during 2008, when the $\mathrm{CO}_{2}$ uptake of the central section responded negatively to low water table having significantly lower NEE rates than the south section $(\mathrm{p}<0.004)$. The north section did not differ from the other sections. Across years, the north section did not differ. The central section presented higher rates in 2006 than in $2007(p=0.013)$ and 2008 $(\mathrm{p}=0.012)$. The south section presented significantly lower rates in 2007 than in 2006 $(p=0.003)$ and $2008(p=0.001$, Table 1, Figure 3$)$

Interannual differences in NEE largely reflected the differences in ER. The ER rates were higher in 2007 (more negative) than in $2006(\mathrm{p}<0.0001)$ and $2008(\mathrm{p}=0.001)$. Respiratory losses were also higher in 2008 than in $2006(\mathrm{p}<0.0001)$. On average, the north section presented lower ER rates than central and south sections (differences nonsignificant, NS). Within years, ER did not differ among lake sections, except in 2008 when the north section presented lower respiratory losses than the central section $(p=0.004)$. Across years, the north section had higher ER rates during periods of low water tables (2007) than during wet conditions (2006). Respiratory losses in the central section were lower in 2006 than in $2007(\mathrm{p}<0.0001)$ and $2008(\mathrm{p}<0.0001)$. North and south sections presented the highest respiratory losses in 2007 , with no difference between 2006 and 2008 (Table 1, Figure 3).

For NDVI, the ANOVA revealed that values were higher in $2006(0.453 \pm 0.009)$ than in $2007(0.355 \pm 0.009, \mathrm{p}<0.0001)$ and $2008(0.316 \pm 0.009, \mathrm{p}<0.0001)$. The NDVI was also significantly higher in 2007 than in $2008(\mathrm{p}=0.005)$. The main effects (Year and Site) had significant effects on NDVI, but the interaction was not significant (Table 
1). Within years, lake sections did not differ in 2006. In 2007, the north section had higher NDVI than the central section $(p<0.001)$, and the south section did not differ from the other two sections. In 2008, the central section had lower NDVI than the north $(p<0.02)$ and south $(p<0.0001)$ sections, and the north and south sections did not differ significantly (Table 1, Figure 3).

Microsite responses to changes in water table

We divided the study plots into the most prevalent topographic features and vegetation cover types present at the site: wet sedge and low-centered polygon centers, intermediate or transition areas, and polygon rims. The ANOVA revealed that Microtopography (main factor) had a significant effect on ER, but not on NEE, nor GPP. Year (main factor) had a significant effect on NEE, and ER, but not on GPP. The interaction Microtopography*Year was not significant for any of the $\mathrm{CO}_{2}$ flux components (Table 2).

On average, GPP rates in all categories tended to be lower in 2006 than in 2007, with intermediate GPP rates in 2008 (Figure 4). Within years, the polygon rims presented higher GPP rates than the intermediate and the wet sedge plots in 2006, but differences were not significant. In 2007 and 2008, all microsites presented similar rates (Figure 4). Across years, the GPP rates of wet sedge tended to be higher in 2007 than in 2006 and 2008, but did not differ from either year. The polygon rim plots presented similar GPP rates across years. The rates of intermediate plots tended to be lower in 2006 than in 2007 and 2008, but differences were not significant (Figure 4). 
On average, all cover types showed higher growing season NEE during the wet conditions in 2006 (Figure 4). Generally, NEE rates of wet sedge and intermediate plots were similar and slightly higher than those of the polygon rims plots. Within years, NEE rates between cover types did not differ for any year. However, dry conditions in 2007 led to lower $\mathrm{CO}_{2}$ accumulation in all cover types especially in the polygon rim plots, but differences were not significant. Across years, the wet sedge plots presented higher uptake (NEE) in 2006 than in 2007 ( $p=0.039$ ), with NEE rates in 2008 not differing from either year. The intermediate and polygon rim plots presented the same pattern, where NEE rates were higher in 2006 than in 2007.

On average, ER rates were higher in 2007 than in $2006(\mathrm{p}<0.0001)$ and 2008 $(p=0.001)$, ER rates were also higher in 2008 than in $2006(p<0.0001)$. Generally, polygon rims presented higher respiratory losses than the wet sedge $(p=0.001)$ and intermediate plots $(\mathrm{p}=0.001)$. Within years, lower water tables at the polygon rim plots in 2006 resulted in higher ER rates compared to those of the wet sedge $(p=0.003)$ and intermediate plots ( $\mathrm{p}=0.001$, Figure 4$)$, with no differences between wet sedge and intermediate plots. In 2007, vegetation cover types did not differ, regardless of much lower water tables in the polygon rim plots. Similarly, in 2008, vegetation cover types did not differ. Across years, wet sedge and intermediate plots presented similar linear responses to water table shifts (Table 3). Wet sedge presented higher ER rates in 2007 than in $2006(\mathrm{p}<0.0001)$, and $2008(\mathrm{p}=0.009)$. Intermediate plots presented lower ER rates in 2006 than in $2007(\mathrm{p}<0.0001)$ and $2008(\mathrm{p}=0.001)$, with no difference between 2007 and 2008. The polygon rim plots presented lower rates in 2006 than in 2007 $(p=0.022)$, with rates in 2008 not differing from either year (Figure 4). 


\section{Environmental controls on carbon flux components}

We evaluated the relationship between $\mathrm{CO}_{2}$ flux components and water table by performing correlation analysis. We found that as a result of the low variation in water table during 2006, correlations between weekly water table and $\mathrm{CO}_{2}$ flux components were not significant for the individual microsites except for ER in the wet sedge (Table 3). During the strong dry down in 2007, water table was a strong predictor of GPP and ER in the wet sedge (vascular-dominated microsites, Table 3). Correlations between water table and GPP, NEE and ER were intermediate in strength in 2008.

The polygon rims (moss-dominated microsites) showed non-significant or low correlations with water table for all carbon flux components during all seasons (Table 3). Polygon rims also generally had the lowest water tables (Figure 4). Similar to the wet sedge microsites, the water table in the intermediate microsites best predicted GPP and ER during periods with very low water availability (e.g., 2007, Table 3). In general, water table was not a good predictor of weekly NEE rates for any of the microsites except for polygon rims in 2008 (Table 3).

Correlations between weekly water table and $\mathrm{CO}_{2}$ flux components across all years combined revealed that: 1) water table is not a good predictor of NEE; 2) ER is the flux component most affected by changes in water availability followed by GPP; and 3) among all microsites wet sedge is the most responsive to changes in water table (Table 3).

Although weekly assessments showed a weak relationship between water table and NEE, the seasonal NEE revealed a strong correspondence between mean seasonal water table and carbon accumulation; wet conditions presented the highest $\mathrm{CO}_{2}$ uptake. 
Wet sedge microsites were generally higher carbon sinks, except in 2006 when intermediate microsites were a slightly stronger sink. The $\mathrm{CO}_{2}$ balance of the polygon rim microsites was the lowest during all seasons; polygon rims had the lowest water levels in all three years. The 2007 dry conditions increased the carbon respiratory losses in all microsites, shifting the polygon rim to a source of $\mathrm{CO}_{2}$ for the growing season (Figure 4).

For NDVI, Year and Microtopography had significant effects, while the effect of the interaction Year*Microtopography was not significant (Table 2). On average, the NDVI was higher in $2006(0.453 \pm 0.010)$ than in $2007(0.362 \pm 0.010, \mathrm{p}<0.0001)$, and $2008(0.324 \pm 0.010, \mathrm{p}<0.0001)$. The NDVI in 2007 was higher than in $2008(\mathrm{p}=0.014)$. Polygon rims $(0.412 \pm 0.012)$ presented on average, higher NDVI than the wet sedge $(0.365 \pm 0.009, p=0.004)$ and intermediate plots $(0.363 \pm 0.010, p=0.003)$. In 2006, microsites did not significantly differ. In 2007 and 2008, the polygon rims presented higher values than the wet sedge ( $\mathrm{p}=0.013, \mathrm{p}=0.009$, respectively), and the intermediate plots $(\mathrm{p}=0.007, \mathrm{p}=0.004)$. The difference between wet sedge and intermediate plots was not significant for either year. Across years, the wet sedge plots presented higher values in $2006(0.448 \pm 0.015)$ than in $2007(0.343 \pm 0.015, \mathrm{p}<0.0001)$ and $2008(0.305 \pm 0.015$, $\mathrm{p}<0.0001$ ), with no difference between the last two seasons. Similarly, intermediate plots presented higher values in $2006(0.449 \pm 0.021)$ than in $2007(0.410 \pm 0.021, \mathrm{p}<0.0001)$ and $2008(0.376 \pm 0.021, \mathrm{p}<0.0001)$, with no difference between 2007 and 2008. Polygon rim plots were higher in $2006(0.463 \pm 0.017)$ than in $2008(0.292 \pm 0.017, \mathrm{p}=0.019)$, with measurements in $2007(0.332 \pm 0.017)$ not differing from either season. 
To visualize the spatial and temporal relationships between water table and carbon flux components, we combined data from all years and sections (Figure 5). We found that the response to changes in water table for GPP and ER were different. Although the highest GPP rates were associated with water tables lower than $-5 \mathrm{~cm}$, low rates of GPP were also observed under similar water table conditions. On average, the GPP rates were the highest when water table was at or just below the surface (e.g., south section in 2008); however, the response was not as strong as in ER rates. The ER rates were strongly affected by the presence of water above the surface. The highest ER rates were observed when the water table was lower than $-5 \mathrm{~cm}$ (e.g., south and north sections in 2007, Table 1, Figure 5). The combined response of GPP and ER to water table shifts resulted in NEE values that represent a strong sink when water is near the surface and a strong source when water is near or lower than $-10 \mathrm{~cm}$ (e.g., south section in 2007, Table 1 and Figure 5).

Seasonal responses of the GPP and ER to water table were consistent throughout the growing seasons, and were particularly strong for ER. Very low GPP rates observed at the beginning of the growing season occurred when leaf areas were low and were not likely to respond to water table. Low ER rates were generally associated with high water tables (Figure 5).

Water table correlations with the $\mathrm{CO}_{2}$ flux components across all seasons revealed that $E R$ is the component most strongly controlled by water $\left(R^{2}=0.42, p<0.001\right)$, followed by GPP $\left(\mathrm{R}^{2}=0.24, \mathrm{p}<0.001\right)$. The correlation between NEE and water table was not significant. 
PATH analysis revealed that the predictors that significantly affect flux rates differed for each $\mathrm{CO}_{2}$ flux component. The ER rates have water table and air temperature as the strongest predictors followed by PAR, VPD and thaw (an indicator of seasonality). NEE rates were most affected by thaw followed by air temperature, PAR and water table. The GPP rates were most strongly affected by thaw followed by PAR and water table (Figure 6).

\section{Discussion}

Significant shifts in thaw depth between 2006 and 2008 and among lake sections in response to the hydrological treatments suggest that draining or flooding, combined with warmer temperatures, have the potential to increase and decrease, respectively, the active layer depth in the long-term (Jorgenson et al.,2006; Zhou et al.,2009). However, as a result of the effects of water addition and removal on depth of thaw, manipulation of the depth of water table with respect to the soil surface is not straightforward.

The top of the permafrost sets the base of the water table, and because of the strong effects of water level on soil thermal conductivity and albedo, the addition and removal of water to raise and lower water tables, respectively, could act counter to the objective of raising and lowering water table relative to the soil surface. Water addition increases transfer of heat into deeper soil layers and water above the surface increases solar absorption, resulting in greater depth to the frozen layer, lowering the base of the water table with respect to the surface. Water removal increases albedo and lowers soil thermal conductivity, decreasing the thaw depth and increasing the base of the water the table with respect to the surface. For instance, in 2008, the water addition and water 
removal resulted in the depth of thaw of the water addition treatment close to $\sim 4 \mathrm{~cm}$ below that of the water removal treatment $(\mathrm{p}=0.004$, Table 1$)$.

Water table controls of temporal and spatial $\mathrm{CO}_{2}$ fluxes

The study site experienced seasons with very distinct weather conditions during the three years of the study (Figure 1). To our advantage we were able to assess the response of the carbon flux components to water table during a wet year (2006), a dry and warm year (2007), and a year with intermediate soil moisture and temperature (2008). These large differences resulted in very different background water levels against which the water manipulation treatments were applied.

Across all years, water table was an important controller of the $\mathrm{CO}_{2}$ respiratory losses. These results follow previous findings in field and laboratory experiments on the effects of water table on $\mathrm{CO}_{2}$ flux components, especially on ER (Billings et al., 1982; Oberbauer et al., 1991; Oberbauer et al., 1992; Ostendorf, 1996). A change in NEE can be a result of multiple conditions, such as an increase in GPP, decrease in ER, or differential in the magnitude of the response of GPP and ER to altered water table. In general, weekly assessments of net ecosystem exchange did not show a significant response to water table fluctuations (Table 3) because changes in water table had effects of similar magnitude on GPP and ER resulting in little or no significant variation in net exchange rates (Sulman et al., 2009).

Overall, although the highest ER rates were associated with low water tables (more than $20 \mathrm{~cm}$ below the surface), similar rates were also observed with water tables above $-10 \mathrm{~cm}$ (Figure 5), suggesting that even though soil moisture conditions were 
sufficient to support microbial activity at very low water tables, an important portion of the total ER comes from the top soil layers (Sommerkorn, 2008).

Among all microsites, ER was the carbon flux component that had the strongest response to changes in water table. Polygon rim plots presented the highest seasonal ER rates during all years; however, the correlation with water table in this microsite was also the poorest because of a small variation in water table with respect to ER. Nevertheless, the significant correlation $\left(\mathrm{R}^{2}=0.22, \mathrm{p}<0.001\right)$ between water table and $E R$ from polygon rims in 2007 suggests that under very dry conditions, water table exerts more control on ER in these microsites than during wet or intermediate soil moisture conditions (Table 3 and Figure 4). Conversely, the strongest response to changes in water table was observed in the wet microsites (wet sedge and intermediate, Figure 4). The ER in the wet sedge (wettest microsites) presented the strongest correlations during all years, and although small, the ER in this microsite presented a significant correlation with water table even during periods of very high water tables (Table 3). Our results suggest that in these microsites, small fluctuations in water table can translate into important changes in ER, and water at or near the surface represents a strong control on ER (Sommerkorn, 2008).

The magnitude of the effect of water table was not the same for all $\mathrm{CO}_{2}$ flux components during all seasons. We found that during wet years, water table was not a strong predictor of any of the $\mathrm{CO}_{2}$ flux components, while in dry years water table was a strong predictor (Table 3); however, on average, low GPP and ER rates were associated with high water table conditions. The control of water table on ER and GPP can be attributed to the combined effects of increasing resistance to diffusion of $\mathrm{O}_{2}$ through the water column (above and below the surface) and soil pores, the rapid depletion of 
available $\mathrm{O}_{2}$ in the soil as a result of microbial activity (Gebauer et al., 1996), and increased resistance to diffusion of $\mathrm{CO}_{2}$ out of the soil (D. Zona et al., Microtopographic controls on ecosystem respiration in the Arctic tundra, submitted to Journal of Geophysical Research, 2010). The GPP was affected by water tables above the surface, but the response was not as strong as in ER. For GPP, severe flooding and oxygen deprivation reduces the ability of roots to take up water and in extreme cases submerges the leaf area, decreasing photosynthesis, especially that of mosses, as a result of the inability of the leaves to exchange $\mathrm{CO}_{2}$ with the atmosphere (Oberbauer et al., 1991, Elberling et al., 2008). However, the presence of anoxia-tolerant species, such as Carex spp., can dampen the effects of loss of root function on GPP (Peterson et al., 1984).

Oxidation-reduction potential measurements at the study site determined that soil just below the water table is anoxic (Zona et al., submitted), thus suggesting that oxygen available in the soil might leak from roots. Although we did not assess oxidation around roots, roots can be an important oxygen supply for the microbial community in anaerobic soils (Conrad,1996). The ER represents a combination of the microbial activity from oxygenated zones plus root and foliage respiration (Billings et al., 1984; Sommerkorn, 2008). Our results suggest that the fraction of ER most affected by the fluctuation in water table is the microbial component because of the anoxic conditions found in the study site under high water tables. The ability of the water table to control root respiration in flooding tolerant vascular plants might be indirect and a function of the available leaf area above the water surface capable of exchanging $\mathrm{O}_{2}$ with the atmosphere and transporting it to the roots via aerenchyma. For instance, Carex aquatilis, the dominant vascular species in the study site, has shown no significant growth responses to 
changes in water table (Peterson et al., 1984) suggesting that their ability to maintain physiological processes such as root respiration are not affected by flooding conditions.

Differences in the vegetation cover among the microtopographic features should affect the response of the GPP to water table fluctuation. However, GPP did not differ between microtopographic features, except when water table was above the surface (e.g. wet sedge and intermediate microsites in 2006, Figure 4). The similarity of GPP rates among microtopographic features was an unexpected result, especially the small change of GPP rates in the polygon rims (NS) regardless of a significant decrease in water table (e.g. 2007, Figure 4). Since these areas are moss-dominated we expected that the lack of a vascular system would negatively affect water uptake and eventually photosynthesis; however, this was not observed. In general the polygon rims presented higher NVDI values than the other microsites, suggesting that the moss layer in the polygon rims was photosynthetically active (La Puma et al., 2007). The high NDVI values of the polygon rims suggest that sufficient moisture was still present in these microsites to support moss photosynthesis, or the few vascular plants present in these areas experienced an increase in the photosynthetic rates that offset a decrease in moss photosynthesis.

The NDVI was able to detect differences in microtopography, especially between polygon rims and wet sedge plots. However, NDVI also changed in response to water table differences between years and sites (Table 1), suggesting that both microtopography (Table 2), and water table had a significant effect on the NDVI measurements. As a result, the interpretation of NDVI values is not straightforward. Since NDVI measurements are taken perpendicular to the ground, and in our study site the leaves of the vascular plants (mostly graminoids) have very steep angles, NDVI measurement 
might have captured primarily the greenness of the mosses rather than that of the vascular plants, failing to detect a change in the productivity of the graminoids. The highest NDVI values were observed in 2006, when the GPP values were the lowest and water tables the highest. Perhaps, these high NDVI measurements can be explained by an increase of the greenness of the mosses regardless of low GPP rates, suggesting that an increase of the graminoid productivity might not be detected by the NDVI measurements. Therefore, in tundra areas with poor drainage, combined with high moss and graminoid cover, the NDVI might not be a strong predictor of GPP.

\section{Other environmental factors}

Water table alone explained $42 \%$ of the variation in ER ( $<<0.001), 24 \%$ of seasonal variation of GPP the ( $\mathrm{p}<0.001)$, and had no relationship with NEE (Figure 4). The PATH analysis revealed that in addition to water table, air temperature and PAR are important predictors of the $\mathrm{CO}_{2}$ flux components. Although on a daily basis, PAR is expected to drive the variation of GPP rates, air and soil temperature, water table, and thaw also play an important role in the seasonal variation of GPP (Figure 6).

\section{Conclusions}

We determined that water table interacts differently with GPP, NEE and ER. We conclude that: 1) low water tables increased GPP but also ER, negatively affecting NEE because the response of ER was larger than that of GPP; 2) high water tables reduced GPP and ER, but the effect on the ER was larger increasing therefore the seasonal uptake; and 3) microtopography had a significant effect on ER, but not on GPP. However, the 
difference in strength of the correlations between water table and GPP among the different microsites suggests that microtopography position affects the response of GPP to water table, especially in the wet sedge microsites.

Water addition and removal had complex effects on depth of water table with respect to the surface and therefore effects on ER. Although the polygon rims had the highest ER rates during all years, they also showed the lowest correlations with water table. Nevertheless, the increase in ER as a result of warm and dry conditions was sufficient to turn the polygon rim microsites from sinks to sources of $\mathrm{CO}_{2}$ during the growing season. On the other hand, wet sedge and intermediate areas were strongly affected by small changes in water table, significantly increasing the ER rates as result of water table decrease. Taking into account that wet sedge and intermediate microsites cover a large area in the lakebed compared to polygon rims, and that anthropogenic warming will likely accelerate drying of the tundra (Kaufman et al., 2009), the seasonal emission rates from these microsites have the potential to double in magnitude as it was observed between 2006 and 2007.

The prohibitive cost of such a large hydrological manipulation limited our study to a single lake, restricting our ability to scale up our results to the whole Coastal Plain. However, wet sedge and polygon rim microsites represent similar plant communities across the area, suggesting that the response of the microsites in other areas is likely to be similar.

Even though the focus of our research was to assess the controls of water table on $\mathrm{CO}_{2}$ flux components, we acknowledge the important effects that other environmental factors have on the $\mathrm{CO}_{2}$ fluxes, especially temperature. Additionally, the intertwined 
effects that changes in water table and/or temperature have on each other and the influence on other environmental factors, such as depth of thaw, adds a level of the complexity to the system that should be explored in further detail.

\section{Acknowledgments}

This research was conducted on the Barrow Environmental Observatory, a private reserve owned by the Ukpeagvik Inupiat Corporation (UIC). This work is based in part on funding from the National Science Foundation Biocomplexity in the EnvironmentCoupled Biogeochemical Cycles program (award \# 0421588) with logistics funded by the Office of Polar Programs. We are especially grateful to the Barrow Scientific Consortium (BASC), Chico Perales and CPS, UIC, the North Slope Borough, Florida International University, and the ARCUS PolarTREC program for logistical support. We also thank the two anonymous reviewers for their contribution to improve this manuscript. 


\section{Tables}

Table 1. Seasonal means of gross primary productivity (GPP), net ecosystem exchange (NEE), ecosystem respiration (ER), normalized difference vegetation index (NDVI), seasonal water table $(\mathrm{cm})$, and thaw $(\mathrm{cm})$. Flux values follow ecosystem flux notation, positive values indicate $\mathrm{CO}_{2}$ uptake and negative mean $\mathrm{CO}_{2}$ losses. Water table and thaw were referenced to the top of the surface or at moss layer if present. $\mathrm{N}$ represents the overall sample size, with the same $\mathrm{N}$ for each lake section within years, and 6 plots in each lake section. Means were compared using a two-way ANOVA.

\begin{tabular}{|c|c|c|c|c|}
\hline \multirow[t]{2}{*}{ Variable } & \multirow[t]{2}{*}{ Location } & \multicolumn{3}{|c|}{ Seasonal mean \pm Std. Error } \\
\hline & & 2006 & 2007 & 2008 \\
\hline GPP & North & $0.597 \pm 0.077^{a_{\dagger}}$ & $0.826 \pm 0.077^{\mathrm{a}}+$ & $0.608 \pm 0.077^{a_{\dagger}}$ \\
\hline \multirow[t]{2}{*}{$\left(\mu m o l m^{-2} s^{-1}\right)$} & Central & $0.621 \pm 0.077^{a_{\dagger}}$ & $0.810 \pm 0.077^{a_{\dagger}}$ & $0.766 \pm 0.077^{a b_{\dagger}}$ \\
\hline & South & $0.667 \pm 0.077^{\mathrm{a}_{\dagger}}$ & $0.823 \pm 0.077^{\mathrm{a}_{\dagger}}$ & $0.877 \pm 0.077^{b_{\dagger}}$ \\
\hline$N E E$ & North & $0.193 \pm 0.052^{\mathrm{a}_{\dagger}}$ & $0.068 \pm 0.052^{a_{\dagger}}$ & $0.130 \pm 0.052^{a b} \uparrow$ \\
\hline \multirow[t]{2}{*}{$\left(\mu m o l m^{-2} s^{-1}\right)$} & Central & $0.224 \pm 0.052^{\mathrm{a}_{\dagger}}$ & $0.033 \pm 0.052^{a}+$ & $0.032 \pm 0.052^{a_{t}}$ \\
\hline & South & $0.207 \pm 0.052^{a_{\dagger}}$ & $-0.021 \pm 0.052^{a_{\dagger}}$ & $0.255 \pm 0.052^{b_{\dagger}}$ \\
\hline$E R$ & North & $-0.395 \pm 0.060^{\mathrm{a}}+$ & $-0.753 \pm 0.060^{\mathrm{a}_{\dagger}}$ & $-0.476 \pm 0.060^{a_{+}}$ \\
\hline \multirow[t]{2}{*}{$\left(\mu \mathrm{mol} \mathrm{m}^{-2} \mathrm{~s}^{-1}\right)$} & Central & $-0.393 \pm 0.060^{a}+$ & $-0.772 \pm 0.060^{a_{\dagger}}$ & $-0.734 \pm 0.060^{b_{\dagger}}$ \\
\hline & South & $-0.454 \pm 0.060^{a}+$ & $-0.842 \pm 0.060^{a_{\dagger}}$ & $-0.622 \pm 0.060^{a b}+$ \\
\hline \multirow[t]{3}{*}{ NDVI } & North & $0.451 \pm 0.016^{\mathrm{a}_{\dagger}}$ & $0.395 \pm 0.016^{\mathrm{a}}+$ & $0.323 \pm 0.016^{\mathrm{a} *}$ \\
\hline & Central & $0.432 \pm 0.016^{\mathrm{a}_{\dagger}}$ & $0.313 \pm 0.016^{\mathrm{b}}+$ & $0.269 \pm 0.016^{\mathrm{b}}+$ \\
\hline & South & $0.477 \pm 0.016^{\mathrm{a}}{ }_{\dagger}$ & $0.355 \pm 0.016^{\mathrm{ab}}+$ & $0.357 \pm 0.016^{\mathrm{a}}$ \\
\hline \multirow{3}{*}{$\begin{array}{l}\text { Water table } \\
(\mathrm{cm})\end{array}$} & North & $2.4 \pm 1.5^{\mathrm{a}} \uparrow$ & $-5.6 \pm 1.5+$ & $0.2 \pm 1.5^{\mathrm{a}} \uparrow$ \\
\hline & Central & $6.0 \pm 1.5^{\mathrm{a}} \uparrow$ & $-3.4 \pm 1.5 \stackrel{a}{t}$ & $-4.9 \pm 1.5^{b}+$ \\
\hline & South & $4.1 \pm 1.5^{\mathrm{a}} \uparrow$ & $-7.6 \pm 1.5^{a}+$ & $-1.9 \pm 1.5^{a b_{*}}$ \\
\hline \multirow{3}{*}{$\begin{array}{l}\text { Thaw } \\
\text { (cm) }\end{array}$} & North & $-14.9 \pm 0.9^{a_{\dagger}}$ & $-18.2 \pm 0.9^{a}+$ & $-22.0 \pm 0.9^{\mathrm{a}} *$ \\
\hline & Central & $-15.8 \pm 0.9^{\mathrm{a}_{\dagger}}$ & $-18.7 \pm 0.9^{a}+$ & $-18.2 \pm 0.9^{b}+t$ \\
\hline & South & $-15.8 \pm 0.9^{\mathrm{a}_{\dagger}}$ & $-17.8 \pm 0.9^{a_{\dagger}}$ & $-21.2 \pm 0.9$ \\
\hline Sample size & $\mathrm{N}$ & 18 & 18 & 18 \\
\hline \multicolumn{5}{|c|}{ Note. ANOVA summary: Site had a significant effect on NDVI $(F=12.274, p<0.0001), b$} \\
\hline
\end{tabular}


The interaction Site*Year was not significant for any of the $\mathrm{CO}_{2}$ flux components or for NDVI. For water table and thaw, Year was significant for water table $(F=32.459$, $p<0.0001)$, and thaw $(F=23.816, p<0.0001)$. Site was not significant for either. Interaction Year*Site was significant for water table $(F=3.014, p=0.028)$, but not for thaw. Multiple comparison tests were done using Least Significant Difference. Different letters represent significant difference $p<0.05$ within years, different symbols represent significant difference $p<0.05$ across years. 
Table 2: Results of the two-way analysis of variance (ANOVA) analyzing the seasonal measurements of gross primary productivity (GPP), net ecosystem exchange (NEE), ecosystem respiration (ER), normalized difference vegetation index (NDVI), water table $(\mathrm{cm})$, and thaw.

\begin{tabular}{|c|c|c|c|}
\hline Variable & $\mathrm{df}$ & $\mathrm{F}$ & $\mathrm{P}$ \\
\hline \multicolumn{4}{|l|}{$G P P$} \\
\hline Year & 2 & 3.090 & 0.055 \\
\hline Microtopography & 2 & 1.402 & 0.257 \\
\hline Year*Microtopography & 4 & 0.940 & 0.449 \\
\hline Error & 45 & & \\
\hline \multicolumn{4}{|l|}{$N E E$} \\
\hline Year & 2 & 8.610 & 0.001 \\
\hline Microtopography & 2 & 1.501 & 0.234 \\
\hline Year*Microtopography & 4 & 0.305 & 0.873 \\
\hline Error & 45 & & \\
\hline \multicolumn{4}{|l|}{$E R$} \\
\hline Year & 2 & 28.054 & 0.001 \\
\hline Microtopography & 2 & 7.866 & $<0.0001$ \\
\hline Year*Microtopography & 4 & 1.062 & 0.387 \\
\hline Error & 45 & & \\
\hline \multicolumn{4}{|l|}{ NDVI } \\
\hline Year & 2 & 40.537 & $<0.0001$ \\
\hline Microtopography & 2 & 5.802 & 0.006 \\
\hline Year*Microtopography & 4 & 2.066 & 0.101 \\
\hline Error & 45 & & \\
\hline \multicolumn{4}{|l|}{ Water table } \\
\hline Year & 2 & 58.866 & $<0.0001$ \\
\hline Microtopography & 2 & 22.639 & $<0.0001$ \\
\hline Year*Microtopography & 4 & 2.467 & 0.058 \\
\hline Error & 45 & & \\
\hline \multicolumn{4}{|l|}{ Thaw } \\
\hline Year & 2 & 27.447 & $<0.0001$ \\
\hline Microtopography & 2 & 10.034 & $<0.0001$ \\
\hline Year*Microtopography & 4 & 0.524 & 0.719 \\
\hline Error & 45 & & \\
\hline
\end{tabular}


Table 3: Linear correlations (Adj. $\mathrm{R}^{2}$ ) between $\mathrm{CO}_{2}$ flux components and water table.

Correlations are significant to $\mathrm{p}<0.001$, unless specified within parentheses. $\mathrm{N}$ represents the overall sample sizes, with 8 plots for wet sedge, 6 for intermediate and 4 for the polygon rim $(\mathrm{PR}) . \mathrm{GPP}=$ gross primary productivity, $\mathrm{NEE}=$ net ecosystem exchange, and $\mathrm{ER}=$ ecosystem respiration.

\begin{tabular}{llllll}
\hline $\begin{array}{c}\mathbf{C O}_{2} \text { flux } \\
\text { component }\end{array}$ & Cover type & $\mathbf{2 0 0 6}$ & $\mathbf{2 0 0 7}$ & $\mathbf{2 0 0 8}$ & All years \\
\hline $\boldsymbol{G P P}$ & Wet sedge & NS & 0.61 & 0.37 & 0.41 \\
& $\begin{array}{l}\text { Intermediate } \\
\text { Polygon rim }\end{array}$ & NS & 0.40 & 0.22 & 0.28 \\
& NS & NS & 0.32 & NS \\
\hline $\boldsymbol{N E E}$ & Intermediate & NS & 0.12 & NS & NS \\
& Polygon rim & NS & NS & NS & NS \\
& Wet sedge & $0.15(0.024)$ & 0.64 & 0.32 & $0.04(0.04)$ \\
\hline $\boldsymbol{E R}$ & Intermediate & NS & 0.48 & 0.21 & 0.53 \\
& Polygon rim & NS & 0.22 & NS & 0.48 \\
& Wet sedge & 45 & 59 & 73 & 0.13 \\
\hline $\boldsymbol{N}$ & Intermediate & 32 & 46 & 56 & 177 \\
& Polygon rim & 22 & 30 & 36 & 80 \\
\hline
\end{tabular}




\section{Figures}

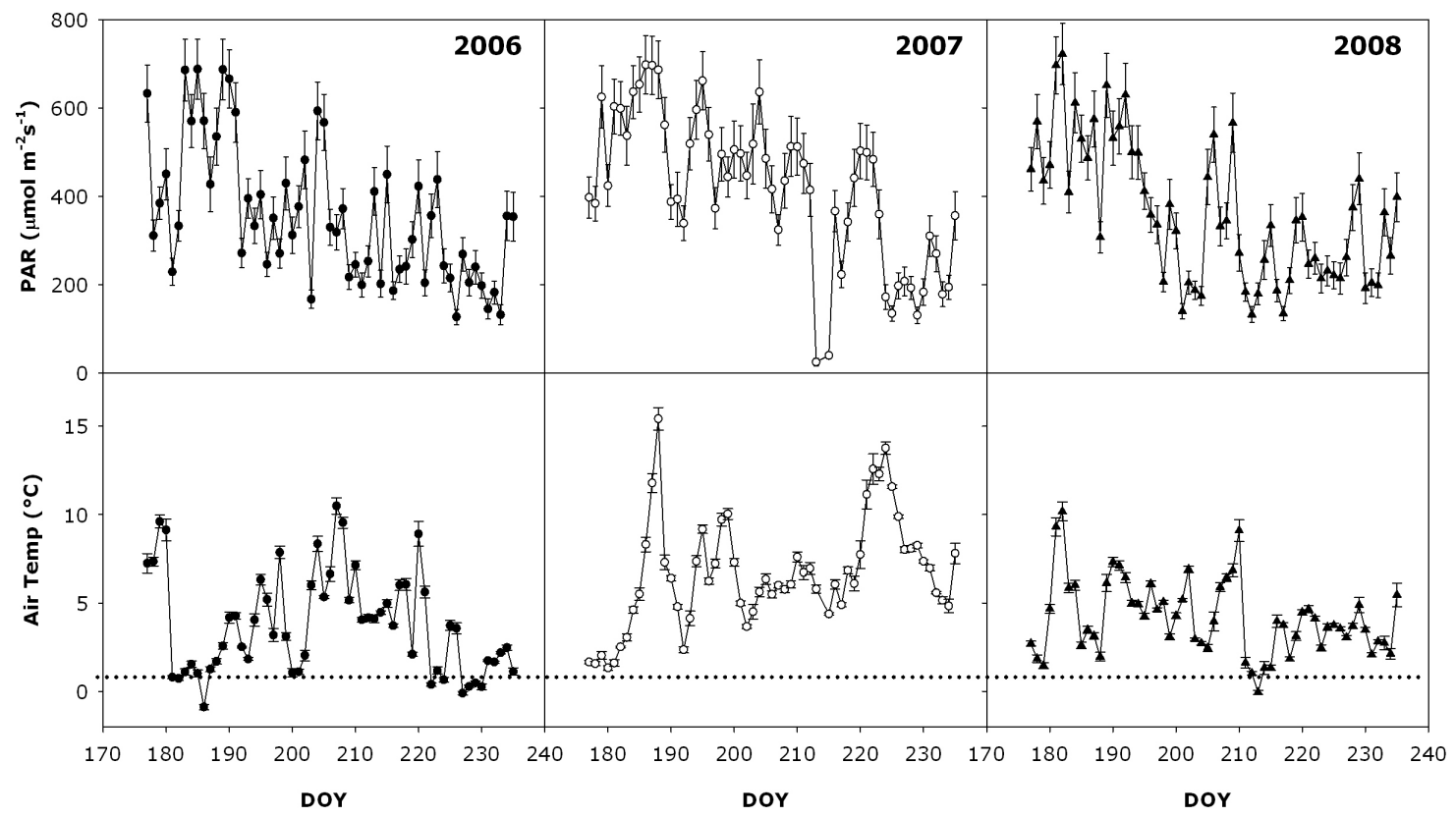

Figure 1. Photosynthetically active radiation (PAR, $\left.\mu \mathrm{mol} \mathrm{m} \mathrm{m}^{-2}\right)$ and air temperature $\left({ }^{\circ} \mathrm{C}\right)$ for the three growing seasons. Values represent daily averages \pm one standard error. 


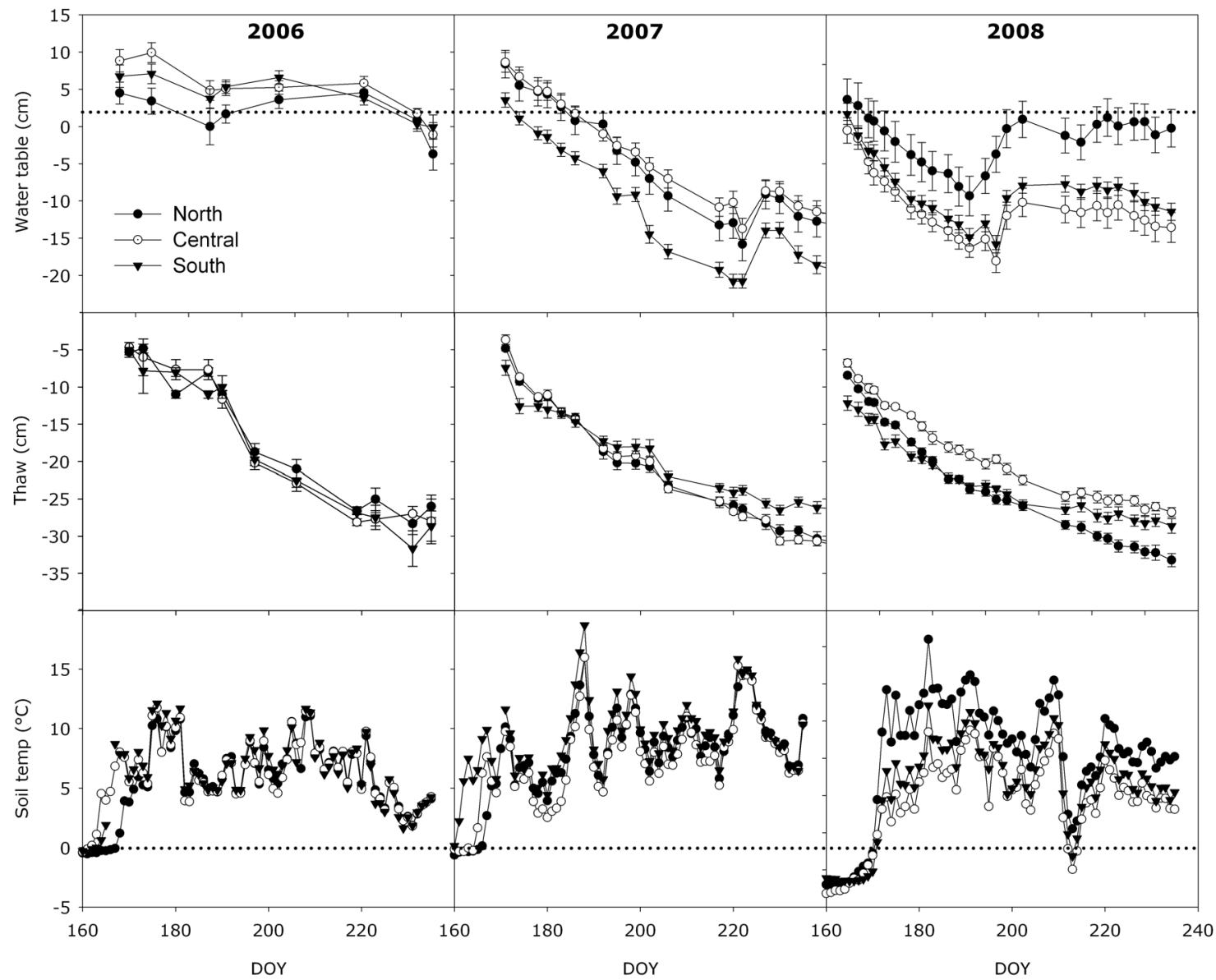

Figure 2. Water table $(\mathrm{cm})$, thaw $(\mathrm{cm})$ and soil temperature (at $1 \mathrm{~cm}$ depth) for the three growing seasons. Values for water table and thaw represent the average of all plots along each lake section, and negative values represent points below the surface. Error bars represent \pm one standard error. Soil temperature was measured at one location during the three seasons. 


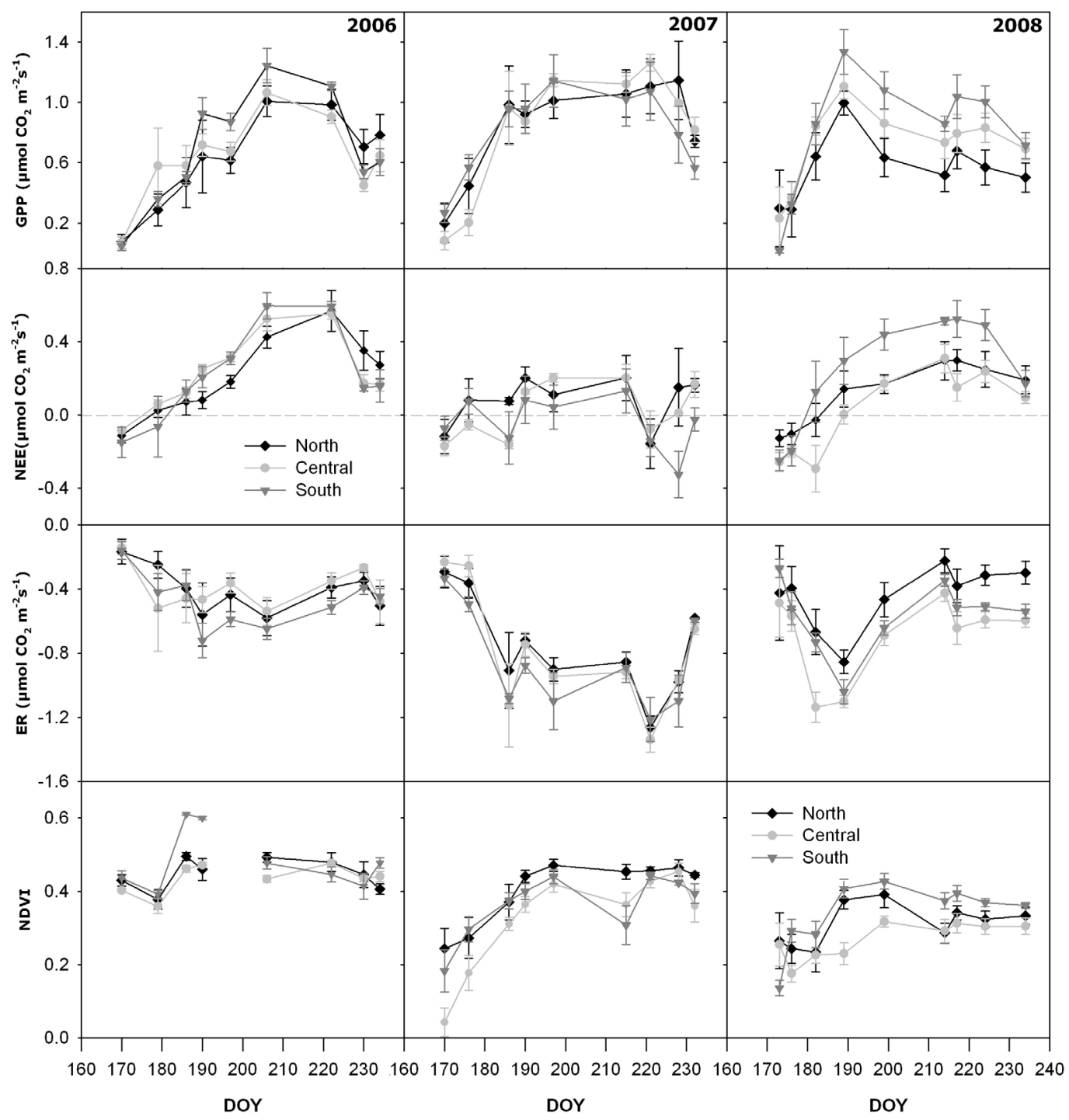

Figure 3. Seasonal $\mathrm{CO}_{2}$ flux components and NDVI from 2006 to 2008 within the three lake sections. Sample sizes are 6 plots for north, central and south lake sections. $\mathrm{CO}_{2}$ flux components are presented using the ecosystem perspective, where positive values represent $\mathrm{CO}_{2}$ uptake and negative values loss of $\mathrm{CO}_{2}$ to the atmosphere. Day of the year $=$ DOY $. \mathrm{GPP}=$ gross primary productivity, $\mathrm{NEE}=$ net ecosystem exchange, $\mathrm{ER}=$ ecosystem respiration, $\mathrm{NDVI}=$ normalized difference vegetation index. 


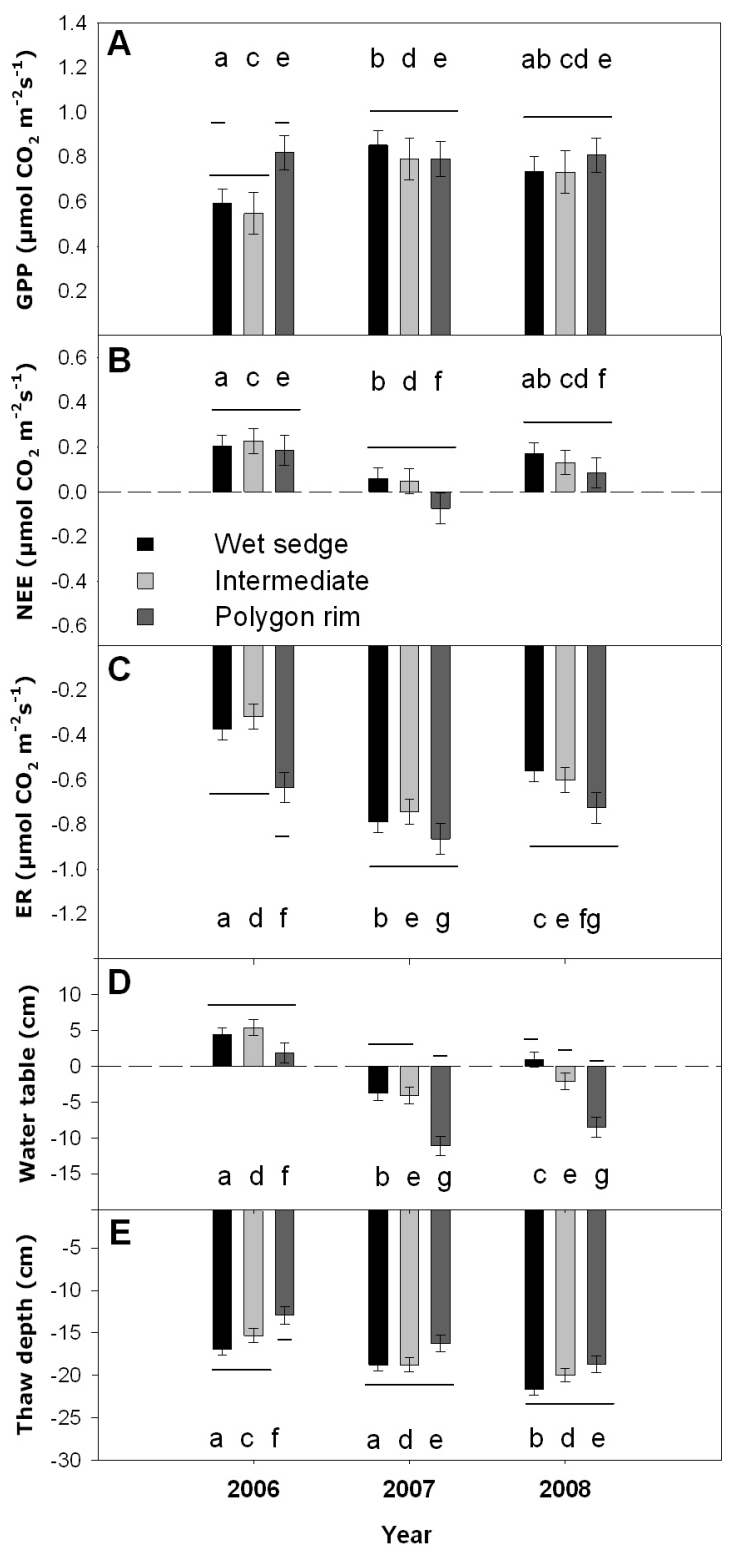

Figure 4. Seasonal means for GPP, NEE, ER, water table, and thaw for all microsites during 2006, 2007 and 2008. For $\mathrm{CO}_{2}$ flux components, positive values indicate uptake and negative values indicate loss. The zero value represents the soil surface for thaw and water table. Error bars represent \pm 1 standard error. $\mathrm{N}$ was the same for all years, with 18 plots: 8 wet sedge, 6 intermediate, and 4 polygon rims. Panels A, B, and C: two-way ANOVA for GPP, NEE, ER. Panels D and E: two-way ANOVA for water table and 
thaw. Multiple comparison was done using Least Significant Difference, columns under different horizontal lines represent significant difference $\mathrm{p}<0.05$ within years, different letters represent significant difference $\mathrm{p}<0.05$ between years. 


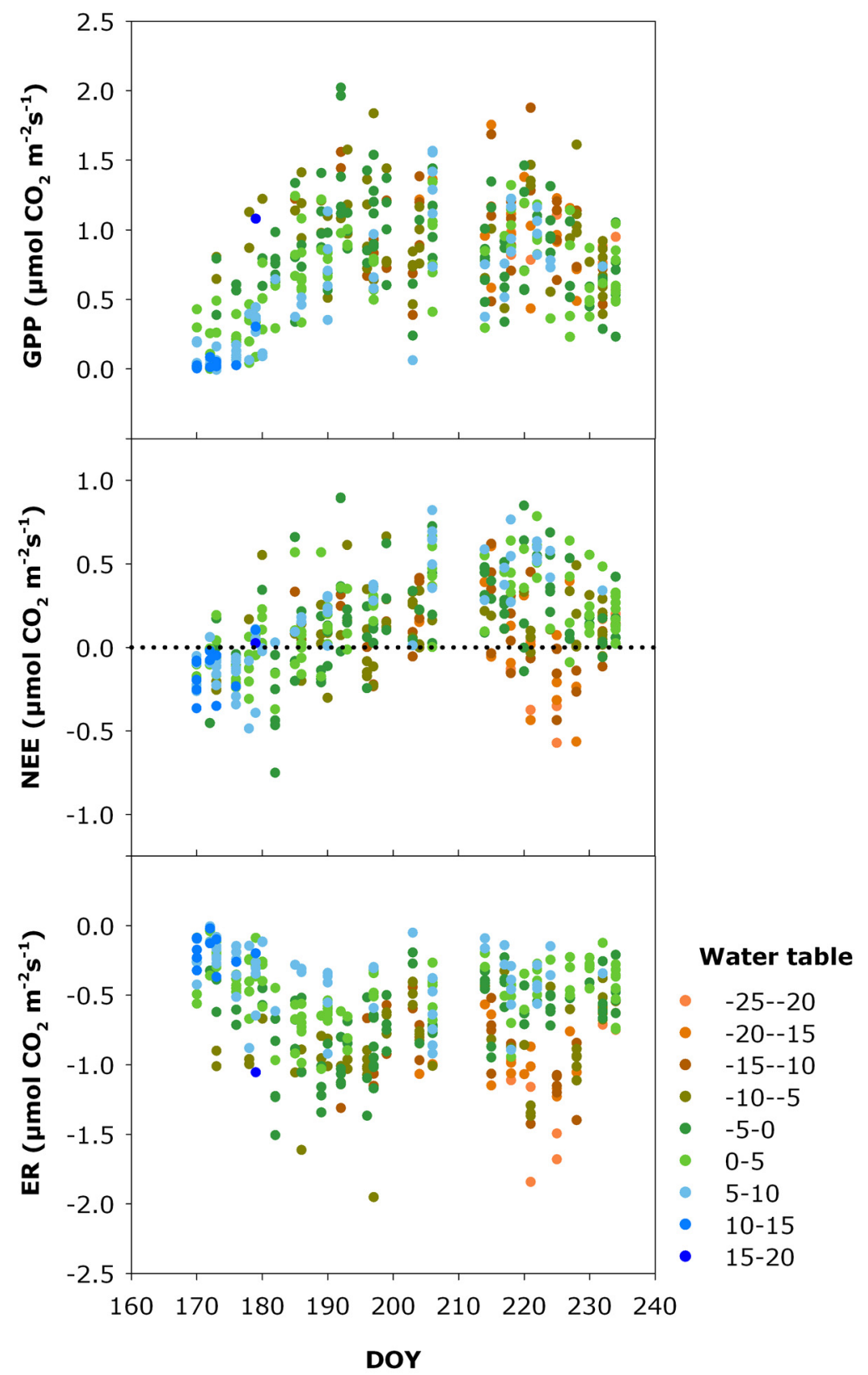

Figure 5. Seasonal pattern of $\mathrm{CO}_{2}$ flux components for growing seasons of 2006, 2007, and 2008 (18 plots). Fluxes use the ecosystem notation where positive values represent $\mathrm{CO}_{2}$ uptake and negative values represent $\mathrm{CO}_{2}$ loss from the system. Values of GPP, NEE and ER on the same date represent diurnal patterns in response to PAR and temperature. 

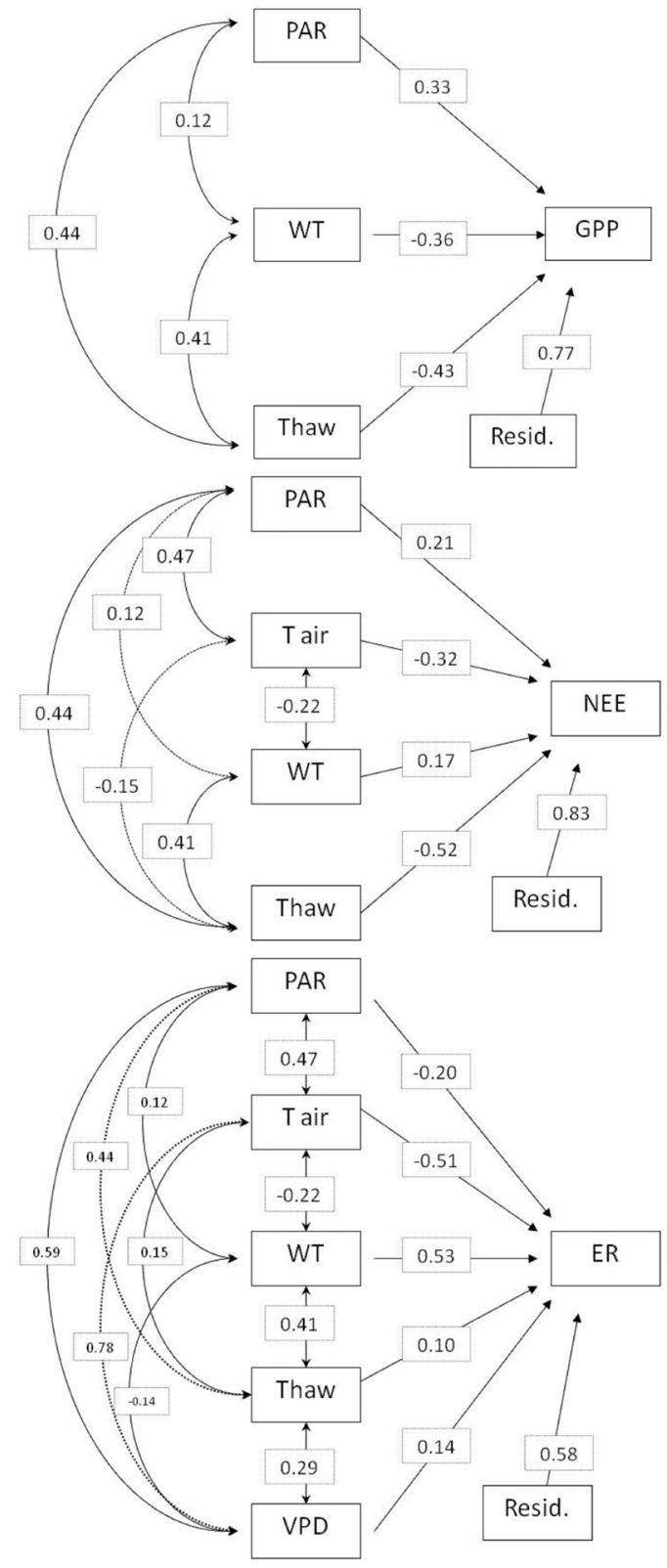

Figure 6. PATH diagrams illustrate the standardized correlations (R) between predictors and $\mathrm{CO}_{2}$ flux components (unidirectional arrows) and the correlations between predictors (bidirectional arrows). Data used for the analysis include measurements for all growing seasons and sites, $\mathrm{N}=399$ (north, central, south). 


\section{LITERATURE CITED}

Billings, W. D., J. O. Luken, D. A. Mortensen, and K. M. Peterson. 1982. Arctic tundra a source or sink for atmospheric carbon-dioxide in a changing environment, Oecologia 53:7-11.

Billings, W. D., J. O. Luken, D. A. Mortensen, and K. M. Peterson. 1983. Increasing atmospheric carbon-dioxide - possible effects on arctic tundra. Oecologia 58:286289.

Billings, W. D. and K. M. Peterson. 1980. Vegetational Change and Ice-Wedge Polygons through the Thaw-Lake Cycle in Arctic Alaska. Arctic and Alpine Research 12:413-432.

Billings, W. D., K. M. Peterson, J. O. Luken, and D. A. Mortensen. 1984. Interaction of increasing atmospheric carbon-dioxide and soil-nitrogen on the carbon balance of tundra microcosms, Oecologia 65:26-29.

Bubier, J. L., P. M. Crill, T. R. Moore, K. Savage, and R. K. Varner. 1998. Seasonal patterns and controls on net ecosystem $\mathrm{CO}_{2}$ exchange in a boreal peatland complex, Global Biogeochemical Cycles 12:703-714.

Conrad, R. 1996. Soil microorganisms as controllers of atmospheric trace gases $\left(\mathrm{H}_{2}, \mathrm{CO}\right.$, $\mathrm{CH}_{4}, \mathrm{OCS}, \mathrm{N}_{2} \mathrm{O}$, and NO). Microbiological Reviews 60:609.

Elberling, B., C. Nordstrom, L. Grondahl, H. Sogaard, T. Friborg, T. R. Christensen, L. Strom, F. Marchand, and I. Nijs (2008), High-arctic soil $\mathrm{CO}_{2}$ and $\mathrm{CH}_{4}$ production controlled by temperature, water, freezing and snow, Advances in Ecological Research 40:441-472.

Engstrom, R., A. Hope, H. Kwon, D. Stow, and D. Zamolodchikov. 2005. Spatial distribution of near surface soil moisture and its relationship to microtopography in the Alaskan Arctic coastal plain, Nordic Hydrology 36:219-234.

Gebauer, R. L. E., J. D. Tenhunen, and J. F. Reynolds. 1996. Soil aeration in relation to soil physical properties, nitrogen availability, and root characteristics within an arctic watershed, Plant and Soil 178:37-48.

Hinkel, K. M., W. R. Eisner, J. G. Bockheim, F. E. Nelson, K. M. Peterson, and X. Y. Dai. 2003. Spatial extent, age, and carbon stocks in drained thaw lake basins on the Barrow Peninsula, Alaska, Arctic Antarctic and Alpine Research 35:291-300.

Hinkel, K. M. and F. E. Nelson. 2003. Spatial and temporal patterns of active layer thickness at Circumpolar Active Layer Monitoring (CALM) sites in northern Alaska, 1995-2000. Journal of Geophysical Research-Atmospheres 108:8168. 
Hinzman, L. D. and D. L. Kane. 1992. Potential response of an arctic watershed during a period of global warming, Journal of Geophysical Research-Atmospheres 97:2811-2820.

Hope, A. S., J. S. Kimball, and D. A. Stow. 1993. The Relationship between Tussock Tundra Spectral Reflectance Properties and Biomass and Vegetation Composition, International Journal of Remote Sensing 14:1861-1874.

Intergovernmental Panel on Climate Change (IPCC). 2007. Climate Change 2007: The Physical Science Basis. Contribution of Working Group I to the Fourth Assessment Report (AR4) of the Intergovernmental Panel on Climate Change, edited by S. Solomon et al., 996 pp., Cambridge Univ. Press, Cambridge, U. K.

Johnson, L. C., G. R. Shaver, A. E. Giblin, K. J. Nadelhoffer, E. R. Rastetter, J. A. Laundre, and G. L. Murray. 1996. Effects of drainage and temperature on carbon balance of tussock tundra microcosms. Oecologia 108:737-748.

Jorgenson, M. T., Y. L. Shur, and E. R. Pullman. 2006. Abrupt increase in permafrost degradation in Arctic Alaska. Geophysical Research Letters 33:L02503.

Kaufman, D. S., D. P. Schneider, N. P. McKay, C. M. Ammann, R. S. Bradley, K. R. Briffa, G. H. Miller, B. L. Otto-Bliesner, J. T. Overpeck, and B. M. Vinther. 2009. Recent Warming Reverses Long-Term Arctic Cooling, Science 325:1236-1239.

La Puma, I. P., T. E. Philippi, and S. F. Oberbauer. 2007. Relating NDVI to ecosystem $\mathrm{CO}_{2}$ exchange patterns in response to season length and soil warming manipulations in arctic Alaska, Remote Sensing of Environment 109:225-236.

Oberbauer, S. F., C. T. Gillespie, W. Cheng, R. Gebauer, A. S. Serra, and J. D. Tenhunen. 1992. Environmental-effects on $\mathrm{CO}_{2}$ efflux from riparian tundra in the northern foothills of the Brooks Range, Alaska, USA, Oecologia 92:568-577.

Oberbauer, S. F., J. D. Tenhunen, and J. F. Reynolds. 1991. Environmental-effects on $\mathrm{CO}_{2}$ efflux from water track and tussock tundra in arctic Alaska, USA, Arctic and Alpine Research 23:162-169.

Oberbauer, S. F., C. E. Tweedie, J. M. Welker, J. T. Fahnestock, G. H. R. Henry, P. J. Webber, R. D. Hollister, M. D. Walker, A. Kuchy, E. Elmore, and G. Starr. 2007. Tundra $\mathrm{CO}_{2}$ fluxes in response to experimental warming across latitudinal and moisture gradients. Ecological Monographs 77:221-238.

Oechel, W. C., S. J. Hastings, G. Vourlitis, M. Jenkins, G. Riechers, and N. Grulke. 1993. Recent Change of Arctic Tundra Ecosystems from a Net Carbon-Dioxide Sink to a Source. Nature 361:520-523. 
Oechel, W. C., G. L. Vourlitis, S. J. Hastings, R. P. Ault, and P. Bryant. 1998. The effects of water table manipulation and elevated temperature on the net $\mathrm{CO}_{2}$ flux of wet sedge tundra ecosystems, Global Change Biology 4:77-90.

Ostendorf, B. 1996. Modeling the influence of hydrological processes on spatial and temporal patterns of $\mathrm{CO}_{2}$ soil efflux from an arctic tundra catchment, Arctic and Alpine Research 28:318-327.

Peterson, K. M., W. D. Billings, and D. N. Reynolds. 1984. Influence of water-table and atmospheric $\mathrm{CO}_{2}$ concentration on the carbon balance of arctic tundra, Arctic and Alpine Research 16:331-335.

Ping, C. L., G. J. Michaelson, M. T. Jorgenson, J. M. Kimble, H. Epstein, V. E. Romanovsky, and D. A. Walker. 2008. High stocks of soil organic carbon in the North American Arctic region, Nature Geoscience 1:615-619.

Post, W. M., W. R. Emanuel, P. J. Zinke, and A. G. Stangenberger. 1982. Soil carbon pools and world life zones, Nature 298:156-159.

Riutta, T., J. Laine, and E. S. Tuittila. 2007. Sensitivity of $\mathrm{CO}_{2}$ exchange of fen ecosystem components to water level variation. Ecosystems 10:718-733.

Shaver, G. R., J. Canadell, F. S. Chapin, J. Gurevitch, J. Harte, G. Henry, P. Ineson, S. Jonasson, J. Melillo, L. Pitelka, and L. Rustad. 2000. Global warming and terrestrial ecosystems: A conceptual framework for analysis. Bioscience 50:871882.

Sommerkorn, M. 2008. Micro-topographic patterns unravel controls of soil water and temperature on soil respiration in three Siberian tundra systems, Soil Biology \& Biochemistry 40:1792-1802.

Steltzer, H. and J. M. Welker. 2006. Modeling the effect of photosynthetic vegetation properties on the NDVI-LAI relationship, Ecology 87:2765-2772.

Sturm, M., C. Racine, and K. Tape. 2001. Climate change - Increasing shrub abundance in the Arctic. Nature 411:546-547.

Sullivan, P. F., S. J. T. Arens, R. A. Chimner, and J. M. Welker. 2008. Temperature and microtopography interact to control carbon cycling in a high arctic fen, Ecosystems 11:61-76.

Sulman, B. N., A. R. Desai, B. D. Cook, N. Saliendra, and D. S. Mackay. 2009. Contrasting carbon dioxide fluxes between a drying shrub wetland in Northern Wisconsin, USA, and nearby forests, Biogeosciences 6:1115-1126. 
Tieszen, L. L. 1978. Introduction. Pages 3-18 in L. L. Tieszen, editor. Vegetation and production ecology of an Alaskan arctic tundra. Springer-Verlag, New York.

Vourlitis, G. L., W. C. Oechel, A. Hope, D. Stow, B. Boynton, J. Verfaillie, R. Zulueta, and S. J. Hastings. 2000. Physiological models for scaling plot measurements of $\mathrm{CO}_{2}$ flux across an arctic tundra landscape, Ecological Applications 10:60-72.

Walker, D. A., M. K. Raynolds, F. J. A. Daniels, E. Einarsson, A. Elvebakk, W. A. Gould, A. E. Katenin, S. S. Kholod, C. J. Markon, E. S. Melnikov, N. G. Moskalenko, S. S. Talbot, and B. A. Yurtsev. 2005. The Circumpolar Arctic vegetation map, Journal of Vegetation Science 16:267-282.

Whalen, S. C. (2005), Biogeochemistry of methane exchange between natural wetlands and the atmosphere, Environmental Engineering Science 2:73-94.

Zhou, F. Q., A. N. Zhang, R. Li, and E. Hoeve. 2009. Spatio-temporal simulation of permafrost geothermal response to climate change scenarios in a building environment, Cold Regions Science and Technology 56:141-151.

Zona, D., W. C. Oechel, J. Kochendorfer, K. T. P. U, A. N. Salyuk, P. C. Olivas, S. F. Oberbauer, and D. A. Lipson. 2009. Methane fluxes during the initiation of a large-scale water table manipulation experiment in the Alaskan Arctic tundra, Global Biogeochemical Cycles 23: GB2013. 


\title{
3. Chapter 2: Response of Carbon Fluxes of Alaskan Coastal Plain Tundra to the Synergistic Effect of Water and Temperature Changes
}

Paulo C. Olivas ${ }^{1}$, Steven F. Oberbauer ${ }^{1}$, Joseph Von Fisher ${ }^{2}$, Craig E. Tweedie ${ }^{3}$.

${ }^{1}$ Dept. of Biological Sciences, Florida International University, 11200 S.W. $8^{\text {th }}$ St, Miami, FL 33199, USA

${ }^{2}$ Dept. of Biology, Colorado State University, 100 West Lake St, Fort Collins, CO 80523, USA

${ }^{3}$ Dept. of Biological Sciences and the Environmental Science and Engineering Program, University of Texas at El Paso, 500 West University Avenue, El Paso, TX 79968, USA

\begin{abstract}
Arctic soil carbon reserves total nearly $1672 \mathrm{Pg}, 191-495 \mathrm{Pg}$ of which are in a labile state. High soil moisture and low temperatures have played a crucial role in soil carbon accumulation by limiting microbial activity. Climate change is likely to dramatically increase temperatures in the Arctic, disturbing surface soil moisture patterns, increasing thaw and conditions for microbial activity, ultimately reversing the role of the Arctic as a carbon sink. Responses of tundra ecosystems to simultaneous changes in temperature and soil water are likely to be complex and non-linear, creating uncertainty about the direction and magnitude of those responses. Our goal was to experimentally determine the short-term $\mathrm{CO}_{2}$ and $\mathrm{CH}_{4}$ flux responses to drying and flooding with warming. The
\end{abstract}


experiment was conducted in a 62 ha thawed lake basin near Barrow, Alaska during 2007 and 2008. The thaw lake was divided into three sections: drained, flooded and undisturbed, with temperature-treatment plots replicated within each section. $\mathrm{The}^{\mathrm{CO}_{2}}$ responses to water and temperature treatments were evaluated using chamber-based measurements of the growing season pattern of gross primary production (GPP), ecosystem respiration (ER), and net ecosystem exchange (NEE). Methane response was assessed at peak season, also using chamber measurements. We found a strong response of $\mathrm{CO}_{2}$ and $\mathrm{CH}_{4}$ to changes in water table and warming. Flooding increased NEE by strongly reducing ER, but high water tables also reduced GPP. Drying alone reduced NEE by increasing ER, but drying plus warming had the opposite effect by increasing GPP. Methane showed a positive response to water table rise and warming. In the shortterm, our data suggest flooding can reduce $\mathrm{CO}_{2}$ losses and increase $\mathrm{CH}_{4}$ efflux. Drying can have the opposite effect. Warming plus drying can change the direction of the response of NEE. In the long-term, vascular plant growth is likely to increase and may offset carbon losses from drying and thawing. However, the response of the moss layer to drying and warming and the resulting effects on the stability of the permafrost and soil carbon remain uncertain.

\section{Introduction}

Recent estimates suggest that Arctic regions account for nearly 50\% (1672 Pg) of global soil organic carbon (Tarnocai et al. 2009). Although most of this carbon is present in permanently frozen soils, close to $191-495 \mathrm{Pg}$ of soil organic carbon $(0-100 \mathrm{~cm}$ deep) is stored in labile conditions (Post et al. 1982, Tarnocai et al. 2009). Model predictions 
suggest that recent warming has reversed long-term Arctic cooling (Kaufman et al. 2009) and that as a result of anthropogenic activities atmospheric $\mathrm{CO}_{2}$ concentration and global temperatures are expected to increase significantly in the coming years (Solomon et al. 2009). In Arctic regions, increased temperatures are likely to negatively affect biophysical processes that have promoted soil carbon accumulation including permafrost, waterlogged soils, low temperatures, reduced microbial activity, and slow turnover of the organic matter (Hinzman and Kane 1992, Oechel et al. 1993). Although warming is expected to thicken the active layer, negatively affecting the labile soil carbon and increasing organic matter turnover and $\mathrm{CO}_{2}$ emissions (Gorham 1991, Oechel et al. 1993, Boike et al. 2008), warming could also increase biomass production and accumulation thereby increasing soil insulation and thinning the active layer (Beringer et al. 2001, Walker et al. 2003). Nevertheless, the potential decomposition of the labile carbon in the Arctic could represent a positive feedback to the greenhouse effect by adding 50-100 ppm of $\mathrm{CO}_{2}$ to the atmosphere (Friedlingstein et al. 2006).

In the Arctic, the effect of warming on ecosystem processes is strongly coupled with soil water availability (Hinzman and Kane 1992, Oberbauer et al. 2007, Elberling et al. 2008, Huemmrich et al. 2010). Warming is expected to increase evapotranspiration resulting in lower water tables that, in turn, will increase soil oxygen availability, microbial activity, and organic matter decomposition, reducing the Arctic's carbon sink potential (Schreader et al. 1998, Oberbauer et al. 2007). However, as a result of high spatial heterogeneity of the arctic landscape, differences in microtopography are likely to interact with temperature to control near the surface moisture changes (Engstrom et al. 2005). Moreover, recent climate models predict an increase in precipitation in the Arctic 
(IPCC 2007), thus warming accompanied by an increase in precipitation will most likely increase thermokarst erosion and soil water availability (Boike et al. 2008, Schuur et al. 2008).

The responses of $\mathrm{CO}_{2}$ balance (net ecosystem exchange, NEE) and net $\mathrm{CH}_{4}$ flux to changes in temperature and water table are likely to be complex (Christensen et al. 2003, Elberling et al. 2008, Zona et al. 2009). The response of $\mathrm{CO}_{2}$ balance to warming and water table shifts is determined by the individual responses of the flux components (Oberbauer et al. 2007, Sullivan et al. 2008): gross primary productivity (GPP) and ecosystem respiration (ER). Gross primary productivity responses to warming and water table changes are directly related to the ecosystem structure (Chapin et al. 1995, Oberbauer et al. 2007). For instance, vascular and non-vascular plants respond differently to warming and drying (Hollister et al. 2005, Strack et al. 2009); the lack of roots and stomata in many non-vascular plants limit their ability to control water loss, negatively affecting their photosynthetic potential under warm and dry conditions.

Alternatively, vascular plants might be able to maintain GPP rates by accessing moisture located below the ground surface. For instance, deep roots of Eriophorum sp. have been shown to follow the depth of thaw through the growing season (Billings et al. 1977). Conversely, under high water tables (i.e., above the ground surface), the leaf area from vascular and particularly non-vascular plants may become submerged, reducing the area for gas exchange. Additionally, submersion of the leaf area might promote the allocation of resources to stem elongation to be able to perform gas exchange. Drying and warming are likely to increase microbial activity, increasing ER, while flooding is likely to have the opposite effect (Oberbauer et al. 1992, Oechel et al. 1998, Chivers et al. 2009). Net 
ecosystem exchange is affected by the differential responses of vascular and non-vascular plants and microbes to warming and water changes (Sjogersten et al. 2006, Strack et al. 2009). The combined effect of warming and drying could reduce NEE as a result of decreased bryophyte productivity and increased microbial activity, but a potential increase in vascular productivity as a result of warmer temperatures could offset the increase in ER, maintaining NEE rates (Hobbie and Chapin 1998). On the other hand, warming and flooding could increase NEE in response to lower ER as a result of oxygen depletion and lower root and microbial activity or increased vascular and non-vascular productivity, however, oxygen deprivation of roots could also reduce GPP (Gebauer et al. 1995).

Ecosystem $\mathrm{CH}_{4}$ flux is likely to respond differently than $\mathrm{CO}_{2}$ fluxes to changes in water availability and warming (Funk et al. 1994, Christensen et al. 2000, Elberling et al. 2008, Zona et al. 2009). The production of $\mathrm{CH}_{4}$ is primarily driven by the presence of anoxic conditions and negatively affected by low soil temperatures and moisture (Vourlitis et al. 1993, Bubier 1995, Berestovskaya et al. 2005, Turetsky et al. 2008). Methane diffusion through water is slow and usually reaches the atmosphere in the form of bubbles with a patchy distribution (Le Mer and Roger 2001, Christensen et al. 2003, Walter et al. 2008) or via plant tissue pathways (King et al. 1998, Verville et al. 1998). Up to $20-40 \%$ of $\mathrm{CH}_{4}$ production may be oxidized within the surface of the soil (Whalen 2005). Therefore, flooding alone should positively affect $\mathrm{CH}_{4}$ production. Flooding and warming are likely to further increase methanogen activity as a result of the combined effect of soil oxygen depletion and increased soil temperatures. Drying alone should have the opposite effect, reducing $\mathrm{CH}_{4}$ emissions by increasing oxidation 
(Elberling et al. 2008, Merbold et al. 2009). Drying and warming should have a magnifying effect and further reduce $\mathrm{CH}_{4}$. However, during warm and dry conditions when $\mathrm{CH}_{4}$ emissions are expected to be low, deep roots of vascular plants could reach anoxic areas just above the frozen layer, where $\mathrm{CH}_{4}$ can diffuse into the roots and be transported from soil to the atmosphere, bypassing the soil oxidation layer (King et al. 1998, Verville et al. 1998, von Fischer and Hedin 2002). The overall effect of changing soil environments in the Arctic on greenhouse gas forcing is complex because even though the rate of $\mathrm{CH}_{4}$ production is much lower than that of $\mathrm{CO}_{2}, \mathrm{CH}_{4}$ has a warming potential 25 times higher than that of $\mathrm{CO}_{2}$.

Changes in soil temperature and water table position are expected to significantly affect the stability of the permafrost (Hinzman et al. 2005, Schuur et al. 2008). Flooding could increase depth of thaw as a result of the high thermal conductivity of the organic layer under wet conditions and the low albedo of surface water. Warming and flooding could further accelerate permafrost degradation. Drying, on the other hand, is likely to reduce heat transfer from atmosphere to the soil promoting shallower permafrost. Warming and drying could increase permafrost formation under the presence of an insulating layer such as moss or thick organic mats (Beringer et al. 2001, Gornall et al. 2007). However, in the long-term drying and warming could accelerate organic matter decomposition and reduce moss cover, negatively affecting the insulating properties of the soil therefore increasing permafrost thawing and exposure of deeper carbon to microbial decomposition (Beringer et al. 2001, Gornall et al. 2007).

As a result of the expected changes in temperature and water availability in the Arctic and the uncertainty and importance of the ecosystem responses to those changes, 
we initiated a hydrological and temperature manipulation that sought to determine tundra ecosystem responses to drying, flooding, and warming. We expected significant interactions between water table depth, soil temperatures, surface warming, and depth of thaw. These changes in the biophysical properties of the soil are expected to directly affect carbon balance $\left(\mathrm{CO}_{2}\right.$ and $\left.\mathrm{CH}_{4}\right)$ as well as the depth of thaw that in turn should affect the water table position. Our objectives were to determine the $\mathrm{CO}_{2}$ and $\mathrm{CH}_{4}$ fluxes from Alaskan Coastal Plain tundra in response to different water table and temperature scenarios: 1) drying of the tundra, 2) drying plus warming, 3) flooding of the tundra, and 4) flooding plus warming. We hypothesized: 1) drying will increase ER and GPP and decrease $\mathrm{CH}_{4}$ net flux, 2) drying and warming will increase ER and GPP and decrease $\mathrm{CH}_{4}$ net flux, 3) flooding will decrease both ER and GPP and increase $\mathrm{CH}_{4}$ net flux, 4) flooding and warming will decrease ER and GPP and further increase $\mathrm{CH}_{4}$ net flux. We determined the effects of these treatments on the seasonal pattern of the components of $\mathrm{CO}_{2}$ flux and on peak season net $\mathrm{CH}_{4}$ flux during two growing seasons, 2007 and 2008, that had strongly differing temperature and moisture regimes.

\section{Methods}

Study site

The study site was a 62 ha naturally-drained thaw lake basin within the Barrow Environmental Observatory, in Barrow, Alaska $\left(71.32^{\circ} \mathrm{N}, 156.62^{\circ} \mathrm{W}\right)$. The basin is elongated north to south in the direction perpendicular to the prevailing wind and drains out to a small stream at the south end. We used the lakebed because it had a relatively homogenous land cover of wet and seasonally flooded vegetation types. The site 
contains high and low centered polygons with some ponds, but the dominant landcover is wet graminoid tundra. The vascular vegetation cover is dominated by Carex aquatilis Whalenb., Eriophorum scheuchzeri Hoppe, Dupontia fisheri R. Br., and Arctophila fulva (Trin.) Rupr. ex Andersson. The non-vascular cover is dominated by Sphagnum spp. moss, with other moss and lichen species present, particularly in the raised areas.

The Barrow area has a mean annual precipitation of $118 \mathrm{~mm}$ (water equivalent, Curtis et al. 1998). The snow-free growing season extends from early June to early September, with peak green season near the end of July and beginning of August. July is the warmest month, $3.7{ }^{\circ} \mathrm{C}$, and August has the largest pluvial precipitation, $26 \mathrm{~mm}$ (National Climatic Data Center, NCDA, National Oceanic and Atmospheric Administration, NOAA). Much of the moisture in the basin results from spring snowmelt and ice breakup in early June, which is the dominant hydrological event of the year.

\section{Experimental design and manipulation}

The lakebed was divided into three sections: north - flooded, central - drained, and south - intermediate (Figure 1). The lake sections were separated using plastic dikes buried into the permafrost (Zona et al. 2009). Water from the central section was moved into the north section using pumps started at the first thaw of snowmelt. Pumping from the central section was continued until the water table fell below the surface. Further reduction in the water table was accomplished with the combined effect of seasonal thawing and evapotranspiration. In 2007, logistical issues limited the amount of water added to the north sections and the primary treatment effect was the restriction of flow across the lake basin by the dikes. In 2008 water tables in the north section were 
maintained above the surface by pumping water from the drained section and additional water from a nearby lake. The goal of the water manipulation was to maintain the water level approximately 10-15 cm lower and higher than the south section (control or reference).

Within each lakebed section, study plots were established that were subjected to either ambient temperature or elevated temperature. The warming was accomplished using open top chambers (OTCs, Marion et al. 1997, Hollister and Webber 2000, Oberbauer et al. 2007). Six temperature control plots (T-CTL) and six OTC plots were located in stratified random design along $200 \mathrm{~m}$ of a cross-basin boardwalk perpendicular to the long axis of the lakebed through each lake section, for a total of 18 T-CTL and 18 OTC plots.

\section{Meteorological data}

A weather station was located at the center boardwalk of the lakebed to measure air and soil temperature, relative humidity, and photosynthetically active radiation (PAR). Data were stored in a CR10X data logger (a Campbell Scientific, Logan UT, USA). Relative humidity and air temperature were measured using a Campbell CS500 sensor, and PAR was measured using a LI-190 quantum sensor (LI-COR, Inc, Lincoln NE USA). Soil temperature was measured with a thermocouple at $2 \mathrm{~cm}$ deep. Soil temperatures were also measured at $-2 \mathrm{~cm}$ and $-10 \mathrm{~cm}$ depth with a digital thermocouple reader at each plot throughout the season in conjunction with the $\mathrm{CO}_{2}$ measurements.

Water table and depth of thaw were measured three times a week over the course of the growing season at each plot. We measured the depth to water table inside of 
perforated $2.5 \mathrm{~cm}$ diameter PVC wells referenced to the top of the moss layer. Also, referenced to the top of the moss layer, thaw depth was measured to the nearest $0.5 \mathrm{~cm}$ using a metal thaw probe.

$\mathrm{CO}_{2}$ flux measurements

The $\mathrm{CO}_{2}$ flux measurements were conducted twice a week during the growing season using an infrared gas analysis system (LI-6200, LI-COR, Lincoln, NE USA) and a vented clear chamber following static chamber techniques used in Oberbauer et al. (2007). Assessments were divided into three components: NEE, GPP, and ER. Each plot was fitted with a PVC base that coupled with the chamber to minimize gas leaks and plot damage. Net ecosystem exchange was measured by placing the chamber on the base and recording the rate of $\mathrm{CO}_{2}$ change for a period of $60 \mathrm{~s}$. Ecosystem respiration was measured by recording the rate of $\mathrm{CO}_{2}$ change while an opaque black cloth covered the chamber, preventing light from reaching the vegetation. Gross primary productivity was calculated as the difference between NEE and ER. We present the data using the ecosystem perspective, where positive values indicate uptake and negative numbers loss to the atmosphere.

\section{Peak season $\mathrm{CH}_{4}$ flux measurements}

Methane fluxes were determined once during peak season from chamber headspace air samples collected at $0,3,6$ and 9 min using the $\mathrm{CO}_{2}$ chamber (covered with the cloth) fitted with a three-way valve for air sampling. Air samples were stored in pre-evacuated vials and analyzed using a gas chromatograph. 


\section{Data analysis}

Water was successfully moved from the central to the north section; however, isolated micro- and meso-catchment areas (e.g., low-centered polygons) within the lakebed sections limited the horizontal water movement in some areas, reducing the water treatment effect in some plots. Therefore, we categorized the plots based on measured water table depth rather than assigned flooding/draining treatment. Using the measured water table at each plot allowed us to create three water categories based on driest, wettest and intermediate plots regardless of their location within the lakebed. For the classification we used the mean seasonal water table for each plot and year. Contrasting weather conditions between years resulted in different water classifications for some plots. In 2007, plots with seasonal water table lower than $-8.0 \mathrm{~cm}$ were classified as dry, between -8.0 and $-2.2 \mathrm{~cm}$ were classified as intermediate, and plots with seasonal water table higher than $-2.2 \mathrm{~cm}$ were classified as flooded. In 2008, plots with water table lower than $-3.7 \mathrm{~cm}$ were classified as dry. The intermediate plots had water tables between -3.7 to $-0.2 \mathrm{~cm}$, and the plots with water tables above -0.2 were classified as flooded. Between 2007 and 2008, 67\% of OTC and 50\% for the T-CTL plots changed water category. These circumstances allowed us to test our hypotheses using different sets of plots. Plots for the temperature treatments were maintained the same for both years. In 2007, we measured carbon fluxes on 18 T-CTL plots but only on 12 OTC plots because of time limitations. In 2008, site logistical improvements allowed decreased travel times between lake sections, and we were able to measure all 18 plots of both TCTL and OTC plots. 
The effects of water table and temperature treatments on the seasonal $\mathrm{CO}_{2}$ flux components were tested using a similar three-way nested ANOVA, with three fixed factors: year (two levels), temperature treatment (two levels), and water categories nested within years (three levels). Statistical analyses were performed using SPSS 11 (SPSS Inc. 2002).

Seasonal PAR and air temperature were compared using a one-way analysis of variance (ANOVA, fixed factor: year, two levels). Water table differences between water (dry, intermediate and flooded) and temperature treatments (T-CTL and OTC) were compared using a three-way nested ANOVA (factors: year, 2 levels, temperature, 2 levels, and water category nested within year, 3 levels).

To further understand the effects of water table and temperature on $\mathrm{CO}_{2}$ flux components, we modeled GPP and ER following Tuittila et al. (2004) and Chivers et al. (2009). We modeled GPP and ER separately for each temperature treatment (T-CTL and OTC), but combined the plots from all water categories to cover a wider range of water tables. We randomly divided the data set, using $80 \%$ for model construction and $20 \%$ for model validation. The GPP model included a light-saturation term defining the maximum photosynthetic capacity at optimal soil moisture (upper limit), and a water table term that defines the optimum water table and limits of minimum and maximum water tables necessary for metabolic activities and gas exchange respectively. We modeled the GPP dependence on light (PPFD) and water as:

$\mathrm{GPP}=\mathrm{GPP}_{\max (\mathrm{PPFD}, \mathrm{WT})} *[\mathrm{PPFD} /(\mathrm{k}+\mathrm{PPFD})]^{*} \exp \left[-0.5 *\left(\mathrm{WT}-\mathrm{uGPP}^{2}\right) / \mathrm{tGPP}^{2}\right] * \mathrm{NDVI}$ (Eq. 1) where $\mathrm{GPP}_{\max (\mathrm{PPFD}, \mathrm{WT})}$ is the maximum GPP under saturated light conditions and optimal water table position for photosynthesis, $\operatorname{PPFD}\left(\mu \mathrm{mol} \mathrm{m}^{-2} \mathrm{~s}^{-1}\right)$ is the photon flux 
density, WT is the water table $(\mathrm{cm}), k\left(\mu \mathrm{mol} \mathrm{m} \mathrm{m}^{-2}\right)$ is the PPFD at which GPP rate is half of the GPP ${ }_{\max }$, NDVI is the normalized difference vegetation index used to relate photosynthesis to time of the season and vegetation cover, $u \mathrm{GPP}$ is the optimum water table position for $\mathrm{GPP}_{\max }, t \mathrm{GPP}$ is the tolerance or water table range for optimal GPP (Tuittila et al. 2004, Chivers et al. 2009).

We modeled the dependence of ER on water table following a sigmoid form because we expected water table to exert control over ER at high water tables as a result of oxygen depletion (upper asymptote) and at low levels as a result of limited soil moisture for microbial activity (lower asymptote). We modeled ER as:

$\mathrm{ER}=\mathrm{ER}_{\max (\mathrm{WT})}{ }^{*} \exp \left[-0.5 *\left(\mathrm{WT}-u \mathrm{ER}^{2}\right) / t \mathrm{ER}^{2}\right]^{*} \mathrm{NDVI} * \exp \left(c^{*} \mathrm{~T}\right)$

where $\mathrm{ER}_{\max (\mathrm{WT})}$ is the maximum ecosystem respiration, WT is the water table, $u \mathrm{ER}$ is the optimum WT position for ecosystem respiration, $t \mathrm{ER}$ is the tolerance or water table range, NDVI is the normalized difference vegetation index used to control for time of the season and vegetation cover, $c$ determines the rate and direction of the ER in a temperature range, and $\mathrm{T}$ is temperature (Tuittila et al. 2004). Models were tested using SigmaPlot 11 (SYSTAT Software Inc., CA).

Water and temperature treatment effects on peak season $\mathrm{CH}_{4}$ net fluxes were compared using a nested two-way ANOVA, with water levels nested within years (factors: water table, 3 levels, and temperature, 2 levels, using SPSS 11 (SPSS Inc. 2002). Plots were classified based on the water table recorded the day of flux measurements. Some plots had a different classification between years, $67 \%$ of the T-CTL and $44 \%$ of the OTC plots changed from 2007 to 2008. 


\section{Results}

\section{Weather and hydrological manipulation}

The site experienced higher growing season air temperatures in 2007 (6.6 0.3 $\left.{ }^{\circ} \mathrm{C}\right)$ than in $2008\left(4.1 \pm 0.3{ }^{\circ} \mathrm{C}, \mathrm{p}<0.0001\right)$. Similarly, PAR was higher in $2007(420 \pm 16$

$\left.\mu \mathrm{mol} \mathrm{m} \mathrm{s}^{-1}\right)$ than in $2008\left(357 \pm 16 \mu \mathrm{mol} \mathrm{m}^{-2} \mathrm{~s}^{-1}, \mathrm{p}<0.006\right.$, Figure 2$)$. Growing season rainfall was lower in $2007(12.9 \mathrm{~mm})$ than in 2008 (43.7 mm, source National Climatic Data Center, and National Oceanic and Atmospheric Administration).

On average soil $(-2 \mathrm{~cm})$ temperatures in 2007 were higher than those in 2008 (Figure 3). OTC plots were warmer under every water table category and year combination, but the difference was significant only in the dry and intermediate water categories in 2007 (Figure 3). Different water table categories did not strongly affect surface soil temperatures in 2007, however, in 2008 the surface soil temperatures between dry and flooded water categories were significant $(\mathrm{p}<0.05)$. Water table differed significantly between water table categories during 2007 and 2008. Within water table categories, water table between T-CTL and OTC plots did not differ (Figure 3).

On average the thaw depth tended to be less deep in 2007 than in $2008(\mathrm{~F}=17.133$, $\mathrm{p}<0.0001)$. Water table categories had a significant effect on the thaw, with shallowest recorded under drier conditions in 2007. Temperature treatments (OTCs) increased thaw significantly, but the difference was significant only in the dry water table category $(p<0.05$, Figure 3$)$. The results revealed a trend where warmer and wetter conditions favored deeper thaws. 


\section{$\mathrm{CO}_{2}$ flux components}

We found that $\mathrm{CO}_{2}$ flux components responded differently to the main effects of temperature, year and water table category (Table 1). The interaction between temperature, water table category and year was significant only for ER, and temperature treatments appeared to magnify the effect of water table categories (Table 1, Figure 4).

Mean seasonal GPP within years did not respond to water table categories in the T-CTL plots. For the OTC plots however, GPP responded negatively to increased water table; the dry water table category showed the highest rates both years $(\mathrm{p}<0.05)$. Although OTC plots presented higher GPP rates, the differences in GPP between T-CTL and OTC plots were significant only in the dry water table category in 2007 (Figure 5).

Mean seasonal ER generally responded negatively to increased water table. On average ER was higher in the dry year, 2007, than in 2008. In 2007 the water table categories did not strongly affect ER in the T-CTL plots, but the ER rates in the OTC plots declined significantly in response to increased water level, with the highest rates found in the dry treatment $(\mathrm{p}<0.05)$. Warming only affected the dry treatment $(\mathrm{p}<0.05$, Figure 5). In 2008, ER rates in the T-CTL and OTC plots were negatively affected by increased water table and the flooded treatment had the lowest ER rates $(p<0.05)$. On average, warming resulted in higher ER rates than those of the T-CTL plots, however, the difference was not significant (Figure 5)

Unlike GPP and ER, NEE did not respond significantly to increased water table, although the response of NEE was similar both years with the rates slightly higher in 2008. In 2007, NEE of T-CTL plots did not differ between water table categories, while the NEE rates in the OTC plots were the lowest in the intermediate water category. The 
OTC plots presented higher rates in each water category, however, the differences were not significant. Similarly in 2008, the T-CTL presented lower rates of NEE than warmed plots, but the difference was not significant (Figure 5).

To test the sensitivity of $\mathrm{CO}_{2}$ fluxes to changes in water table using the GPP and ER models, we mathematically maintained PPFD $\left(600 \mu \mathrm{mol} \mathrm{m}^{-2} \mathrm{~s}^{-1}\right)$, NDVI (0.6), and temperature $\left(10^{\circ} \mathrm{C}\right)$ constant across a range of water levels (Figure 6). The models showed results consistent with those observed in the seasonal means, although the performance of the models differed with the temperature treatments and models had difficulty duplicating the variation in fluxes early in the season or at very low fluxes. Nevertheless, all independent testing with the data not used in the model construction yielded significant correlations (Table 3).

During both years modeled warmed plots showed higher $\mathrm{GPP}_{\max }$ at lower optimal water table, suggesting that an increase in temperature positively affected photosynthesis and sensitivity to water table. The increase in water availability in 2008 raised the GPP rates of both the T-CTL and warmed plots. However, the GPP max $_{\text {ox }}$ of the warmed plots in 2008 increased considerably compared to 2007 (Table 2, Figure 6) even though surface temperatures were lower in 2008 than 2007 (Figure 3). For $\mathrm{ER}_{\max }$, warmed plots presented higher $\mathrm{ER}_{\max }$ at lower water tables than that of the T-CTL plots in both years. In 2008 the $\mathrm{ER}_{\max }$ in the warmed plots was considerably higher than the T-CTL plots, indicating that higher water availability, such as that seen in 2008 compared to 2007, in addition to warming effect can affect the ER rates. 


\section{Methane}

Peak season $\mathrm{CH}_{4}$ measurements responded positively to increased water tables and warming within years (Figure 7). Although not significantly different, the $\mathrm{CH}_{4}$ fluxes were on average higher in 2007 than in 2008. Similar to the seasonal means, the water tables recorded at the time of the $\mathrm{CH}_{4}$ assessments showed significant differences between water table categories. Within water table categories, the water table between OTC and T-CTL plots did not differ (Figure 4). Although not significant, soil temperatures $(-10 \mathrm{~cm})$ presented a positive relationship with water table increase.

\section{Discussion}

Ecosystem biophysical responses to water table change and warming

Historically, ecosystems in the Arctic Coastal Plain of Alaska have been characterized by the presence of high soil moisture availability, with nearly $22 \%$ of the area covered by thaw lakes and $50 \%$ by vegetated drained lake basins (Hinkel et al. 2003). Because of the large expanse of relatively low relief tundra on the Arctic Coastal Plain, even a small change in water availability is likely to have a strong effect on ecosystem structure and function over short to long-term periods (Sturm et al. 2001, Oberbauer et al. 2007, Schuur et al. 2007). We found that while drying reduced thaw depth by reducing the thermal conductivity of the soil, flooding had the opposite effect, promoting a deepening of the active layer. Although there is considerable uncertainty about the predictions for summer precipitation from regional climate models in the Arctic Coastal Plain, one scenario predicts a $30 \%$ increase in summer precipitation and consequently higher water table and deeper thaw (IPCC 2007). The effect of raised water 
tables on thaw could be particularly strong if rain events increase between the middle and end of the growing season when seasonal thaw is approaching maximum depth, and the water retention capacity of the ground is at its highest. However, because warming can also increase evapotranspiration, the effect of increased temperatures on thawing is likely to be tightly coupled to changes in precipitation (Hinzman and Kane 1992).

Warming and water availability interacted to further increase thaw depth (Figure 3). Under every water table condition, warming significantly increased surface temperature and thaw depth. Even though we expected warming to increase evapotranspiration, reducing soil moisture and conduction of heat into the soil, we observed that thaw was deeper with OTC warming, yet only under the dry manipulation was the difference significant $(\mathrm{p}<0.05)$. These results suggest that even under dry conditions soil moisture was sufficiently high for conduction of surface thermal energy to deeper soil layers.

\section{$\mathrm{CO}_{2}$ flux responses to water table change and warming}

Overall we found that high water tables significantly reduced both GPP and ER. Net ecosystem exchange presented a bimodal response to water table change (OTC plots), with high water tables exerting control over oxygen availability in the soil, thus limiting soil microbial activity and favoring carbon accumulation, but at the same time lowering photosynthesis by reducing $\mathrm{CO}_{2}$ diffusion rates into the leaves, especially those of mosses (Williams and Flanagan 1996, Oechel et al. 1998, Riutta et al. 2007, Chivers et al. 2009). Warming magnified all $\mathrm{CO}_{2}$ flux components (Figure 5), particularly in the intermediate and dry conditions where GPP and ER rates increased considerably. 
Conversely, the presence of high water tables (flooded plots) dampened the effect of warming for all $\mathrm{CO}_{2}$ flux components. Two possible conclusions emerge from these results: 1) under high water tables, water table controls $\mathrm{CO}_{2}$ flux components more so than temperature as a result of a decrease in $\mathrm{CO}_{2}$ and $\mathrm{O}_{2}$ diffusion through water, or 2) OTC passive warming was not sufficient to warm the plots under the presence of standing water to significantly affect $\mathrm{CO}_{2}$ flux components.

Similar to the results of seasonal mean comparisons (Figure 6), the models revealed important interactions between water table and temperature treatments (Table 2 and Figure 6). We expected that as the water table drops and leaf area becomes available for gas exchange, GPP would increase rapidly to an asymptote where photosynthesis becomes light saturated at an optimal water table. Below this water table, photosynthesis should be restricted by reduction in soil moisture (Tuittila et al. 2004). During both years OTCs presented higher GPP $\mathrm{max}_{\max }$ at lower optimal water table, suggesting that an increase in temperature positively affected photosynthesis and that the negative effect of high water table on photosynthesis is magnified at higher temperatures. Combining the results from the seasonal means and models we postulate that: 1) GPP is negatively affected by high water tables as a result of leaf area submersion or the effect of reduced oxygen availability in the root system (sensu Gebauer et al. 1995), 2) GPP is positively affected by warming, especially under low water table depths, 3) GPP models (all water categories combined) suggest that the combined effect of warming and increased water availability ( $\sim 5 \mathrm{~cm}$ increase from 2007 to 2008 , but without submersion of the leaf area) strongly increases the $\mathrm{GPP}_{\max }$ potential. 
Similarly, the $\mathrm{ER}_{\max }$ models showed that warming had a positive effect on ER, however, differences were not as great as those measured for GPP. The ER response to water table variation had a sigmoid form, where water table defined the upper (high water table) and lower (low water table) asymptotes. On the basis of the control that water table exerts on ER rates (Oberbauer et al. 1991, Oechel et al. 1998, Sjogersten et al. 2006), we expected a reduction in ER as water table increased. All models showed a strong response of ER to water table changes, positive when low and negative when water table was near the surface (Figure 6). The effect of high water tables on the ER of T-CTL plots was not as clear, presumably as a result of few data points at the higher end of the water tables categories in 2007.

Similar to previous work (Oberbauer et al. 1992, Oechel et al. 1998, Riutta et al. 2007), our models show a strong increase in ER rates as water table deepens. Seasonal ER averages presented a linear response to water table, suggesting that the observed water tables were still sufficient to sustain microbial and plant physiological activity. Additionally, the ER models showed a decrease in ER rates as the water table dropped between -10 to $-20 \mathrm{~cm}$, possibly reflecting water limitation. Furthermore, the results from the ER models also suggest that if soil moisture is not limiting, the effect of temperature on the rate of change in ER is twice as great (parameter $c$ ) when the surface (mostly moss) dries out (Table 2, Figure 6). Similar to Chivers et al. (2009) and others (Oechel et al. 1998, Oberbauer et al. 2007), this result underlines the importance of the interaction between water table, soil temperature and ecosystem responses, where a change in temperature has stronger effect on ER in moist soils than in dry soils. 
The direction of the NEE response (sink/source) to changes in water table and warming is determined by the individual responses of GPP and ER (Oberbauer et al. 2007, Chivers et al. 2009). In the T-CTL plots, water table increase had a negative effect on both GPP and ER, however, the effect was greater on ER, thus NEE was larger as a result of lower losses rather than increased uptake (Figure 5). In the OTC plots, NEE presented a bimodal response to water table changes, with similar results under very different water table conditions: 1) similar to the T-CTL plots, NEE increased as a result of the reduction in respiratory losses (ER) in the flooded plots, 2) under dry conditions, NEE also increased but as a result of a large increase in GPP rather than a decrease in ER.

Our results suggest that in the short-term an increase in water availability will most likely reduce ER, but at the same time can increase NEE. The opposite responses of ER and NEE to changes in water table are in concordance with the natural history of Alaskan Coastal Plain where carbon accumulation has occurred as a result of small respiratory losses rather than high productivity (Tieszen 1978). Temperature exerts a strong control on both uptake and respiration, but the effect on GPP was stronger than on ER. Although we expected a decrease in GPP as a result of the desiccation observed in the moss layer in 2007 (dry T-CTL plots, Figure 5), the dry OTC plots showed the highest GPP rates both years, suggesting that the increase in GPP was mostly a result of vascular plant uptake and large enough to compensate for the decrease in moss productivity and increase in ER. 


\section{Peak season $\mathrm{CH}_{4}$ responses to water table and warming}

Methane measurements showed significant responses to increased water table and warming (Figure 7). Similar to previous research, we found that the increase in anoxic conditions within years as a result of raised water tables had a significant effect on $\mathrm{CH}_{4}$ emissions (Vourlitis et al. 1993, Verville et al. 1998, Turetsky et al. 2008). Warming in almost every water table condition had a positive effect on the $\mathrm{CH}_{4}$ flux, but the increased efflux was not always significant. A striking finding was the relative similarity of the average $\mathrm{CH}_{4}$ fluxes between 2007 and 2008, despite the considerable differences in water table depth and precipitation between years. Previous work by von Fischer and Hedin (2002) found production of $\mathrm{CH}_{4}$ even under dry and oxic soils. These results suggest that even under dry conditions, water and anoxic conditions could be present at the top of the frozen soil where $\mathrm{CH}_{4}$ can be produced and diffused into the vascular roots, bypassing the oxidation layer within the soil and reaching the atmosphere (Kelker and Chanton 1997, King et al. 1998, Verville et al. 1998).

Components of $\mathrm{CO}_{2}$ flux (GPP, NEE, ER) and $\mathrm{CH}_{4}$ efflux were not correlated, similar to prior studies suggesting that $\mathrm{CH}_{4}$ production might not be carbon limited (von Fischer and Hedin 2007, Zona et al. 2009).

Although our $\mathrm{CH}_{4}$ data represent only peak season, we found a strong consistency between years that shows a significant response to water table (Figure 7). Nevertheless, the warming effect on $\mathrm{CH}_{4}$ efflux and small differences in net fluxes between years regardless of contrasting water table conditions raises important questions: 1) can a significant amount of $\mathrm{CH}_{4}$ be produced at the top of the frozen soil and transported into the atmosphere even during "dry" conditions?, 2) accounting for tundra microtopography, 
what role does ecosystem structure play in controlling seasonal $\mathrm{CH}_{4}$ efflux under dry conditions?, 3) Would $\mathrm{CH}_{4}$ efflux decrease under warmer scenarios?

During the two seasons of hydrological and temperature manipulation, thaw depth, net $\mathrm{CO}_{2}$ uptake, and net $\mathrm{CH}_{4}$ flux, presented a positive response to increased water and warming. Within years drying and warming had the opposite effect on thaw and $\mathrm{CH}_{4}$ efflux, but not on $\mathrm{CO}_{2}$ net uptake. The complex responses of the ecosystem to changes in water and temperature revealed the high sensitivity of a dominant Arctic Coastal Plain land cover type to biophysical change.

\section{Conclusions}

From two seasons of hydrological and temperature manipulation in a vegetated thaw lake basin on the Arctic Coastal Plain we have learned that $\mathrm{CO}_{2}$ and $\mathrm{CH}_{4}$ fluxes and thaw depth have a linear response to change in water table and that the magnitude of the responses is affected by the complex interactions with other parameters such as temperature.

We conclude that: 1) drying increased ER and GPP, and decreased $\mathrm{CH}_{4}$ and thaw, 2) drying in combination with warming magnified the impact of drying on GPP and ER, but contrary to what we expected under dry conditions, warming continued to increase $\mathrm{CH}_{4}$ efflux and thaw depth, 3) flooding decreased both GPP and ER, and increased $\mathrm{CH}_{4}$ efflux and thaw depth, 4) flooding and warming also reduced GPP and ER, and increased $\mathrm{CH}_{4}$ efflux and thaw depth. Drying alone reduced seasonal NEE, but warming stimulated a bimodal response to water table fluctuation with highest uptake under drained and flooded conditions. 
Even though $\mathrm{CH}_{4}$ flux increased with water table within years, similar rates between years regardless of the very distinct weather conditions underscores the need for greater understanding of the mechanisms favoring $\mathrm{CH}_{4}$ production under dry conditions.

Our study demonstrates that snow-free ecosystem carbon balance is highly sensitive to short-term changes in water table and warming. Over longer time periods, hydrological and temperature changes will most likely alter soil biophysical properties, nutrient cycles, and other ecosystem structural and functional components. We have shown that following short-term warming and alteration of water table depth vascular productivity can compensate for increased in respiratory losses. Over longer time periods, however the shift from a carbon sink to source in some Arctic ecosystems will depend on the ability of the primary producers to offset the expected increase in microbial activity and availability of labile soil organic carbon as a result of permafrost degradation.

\section{Acknowledgments}

We thank the Ukpeagvik Inupiat Corporation (UIC) for providing support and access to the Barrow Environmental Observatory. We also thank the National Science Foundation Biocomplexity in the Environment-Coupled Biogeochemical Cycles program (award \# 0421588), and logistics funded by the Office of Polar Programs. We recognize that our field work was a success thanks to help of many people, especially the Barrow Scientific Consortium (BASC), Chico Perales and CPS, UIC, the North Slope Borough, Florida International University, ARCUS PolarTREC and Jose Luciani. We thank the National Climatic Data Center, and National Oceanic and Atmospheric Administration for the use of climate data. 


\section{Tables}

Table 1. Summary of a 3-way analysis of variance (ANOVA) with water table category nested within years for the seasonal means of the $\mathrm{CO}_{2}$ flux components across water and temperature manipulations. Significant $\mathrm{P}$ values are indicated in bold.

\begin{tabular}{|c|c|c|c|}
\hline Variable & $D f$ & $F$ & P-value \\
\hline \multicolumn{4}{|l|}{ Gross Primary Productivity (GPP) } \\
\hline Temperature treatment & 1 & 8.214 & 0.006 \\
\hline Year & 1 & 2.017 & 0.161 \\
\hline Water table category (year) & 4 & 2.795 & 0.035 \\
\hline Temperature treatment*year & 1 & 0.292 & 0.591 \\
\hline Temperature*Water table category (year) & 4 & 1.796 & 0.143 \\
\hline Error & 54 & & \\
\hline \multicolumn{4}{|l|}{ Net ecosystem exchange (NEE) } \\
\hline Temperature treatment & 1 & 3.164 & 0.081 \\
\hline Year & 1 & 4.755 & 0.034 \\
\hline Water table category (year) & 4 & 0.185 & 0.945 \\
\hline Temperature treatment*year & 1 & 0.110 & 0.742 \\
\hline Temperature*Water table category (year) & 4 & 0.314 & 0.868 \\
\hline Error & 54 & & \\
\hline \multicolumn{4}{|l|}{ Ecosystem Respiration (ER) } \\
\hline Temperature treatment & 1 & 7.735 & 0.007 \\
\hline Year & 1 & 31.894 & $<0.0001$ \\
\hline Water table category (year) & 4 & 12.817 & $<0.0001$ \\
\hline Temperature treatment*year & 1 & 2.155 & 0.148 \\
\hline Temperature*Water table category (year) & 4 & 3.341 & 0.016 \\
\hline Error & 54 & & \\
\hline
\end{tabular}


Table 2. Nonlinear regression parameters for gross primary productivity (GPP), and ecosystem respiration (ER) during 2007 and 2008 using Eq. 1 and 2 respectively with $80 \%$ of the data. Temperature control plots, T-CTL, and warmed plots, OTC.

\begin{tabular}{|c|c|c|c|c|}
\hline \multirow{3}{*}{$\begin{array}{l}\text { Gross primary productivity (GPP) } \\
\text { Parameters }\end{array}$} & \multicolumn{4}{|c|}{ Estimates } \\
\hline & \multicolumn{2}{|c|}{2007} & \multicolumn{2}{|c|}{2008} \\
\hline & $T-C T L$ & OTC & $T-C T L$ & OTC \\
\hline $\operatorname{Pmax}\left(\mu \mathrm{mol} \mathrm{m} \mathrm{m}^{-2} \mathrm{~s}^{-1}\right)$ & 8.1 & 11.3 & 10.9 & 18.4 \\
\hline$k\left(\mu \mathrm{mol} \mathrm{m} \mathrm{m}^{-2} \mathrm{~s}^{-1}\right)$ & 453.3 & 478.9 & 714.0 & 752.7 \\
\hline up $(\mathrm{cm})$ & -13.4 & -23.5 & -16.6 & -24.1 \\
\hline tp $(\mathrm{cm})$ & 13.9 & 22.7 & 25.0 & 20.6 \\
\hline$R^{2}$ adj. (\%) & 74 & 77 & 71 & 78 \\
\hline$N$ & 524 & 389 & 792 & 662 \\
\hline$d f r e g, d f r e s$ & 4,520 & 4,385 & 4,788 & 4,658 \\
\hline Ecosystem respiration (ER) & \multicolumn{4}{|c|}{ Estimates } \\
\hline \multirow[t]{2}{*}{ Parameters } & \multicolumn{2}{|c|}{2007} & \multicolumn{2}{|c|}{2008} \\
\hline & $T-C T L$ & OTC & $T-C T L$ & OTC \\
\hline$R \max \left(\mu \operatorname{mol~} m^{-2} s^{-1}\right)$ & -1.4 & -1.7 & -1.1 & -1.3 \\
\hline$u R(\mathrm{~cm})$ & -16.2 & -20.3 & -13.7 & -17.7 \\
\hline$t R(\mathrm{~cm})$ & 32.0 & 23.7 & 18.0 & 16.2 \\
\hline$c$ & 0.05 & 0.05 & 0.10 & 0.11 \\
\hline$R^{2} \operatorname{adj} .(\%)$ & 63 & 63 & 40 & 53 \\
\hline$N$ & 524 & 389 & 792 & 662 \\
\hline$d f r e g, d f r e s$ & 4,520 & 4,385 & 4,788 & 4,658 \\
\hline
\end{tabular}


Table 3. Independent testing of the models. Linear correlations between measured and expected GPP and ER using $20 \%$ of the flux values randomly selected from the original data set. These data were not used in model construction. Temperature control plots, TCTL, and warmed plots, OTC.

\begin{tabular}{|c|c|c|c|c|}
\hline \multicolumn{5}{|c|}{ Gross primary productivity (GPP) } \\
\hline Year & Temperature Treatment & $R^{2} \operatorname{adj.~(\% )~}$ & $\mathbf{N}$ & $P$-value \\
\hline \multirow[t]{2}{*}{2007} & T-CTL & 73 & 130 & $<0.0001$ \\
\hline & OTC & 84 & 97 & $<0.0001$ \\
\hline \multirow[t]{2}{*}{2008} & T-CTL & 63 & 198 & $<0.0001$ \\
\hline & OTC & 74 & 166 & $<0.0001$ \\
\hline \multicolumn{5}{|c|}{ Ecosystem respiration (ER) } \\
\hline Year & Temperature Treatment & $R^{2}$ adj. (\%) & $\mathbf{N}$ & $P$-value \\
\hline \multirow[t]{2}{*}{2007} & T-CTL & 56 & 130 & $<0.0001$ \\
\hline & OTC & 73 & 97 & $<0.0001$ \\
\hline \multirow{2}{*}{2008} & $\mathrm{~T}-\mathrm{CTL}$ & 40 & 198 & $<0.0001$ \\
\hline & OTC & 58 & 166 & $<0.0001$ \\
\hline
\end{tabular}




\section{Figures}

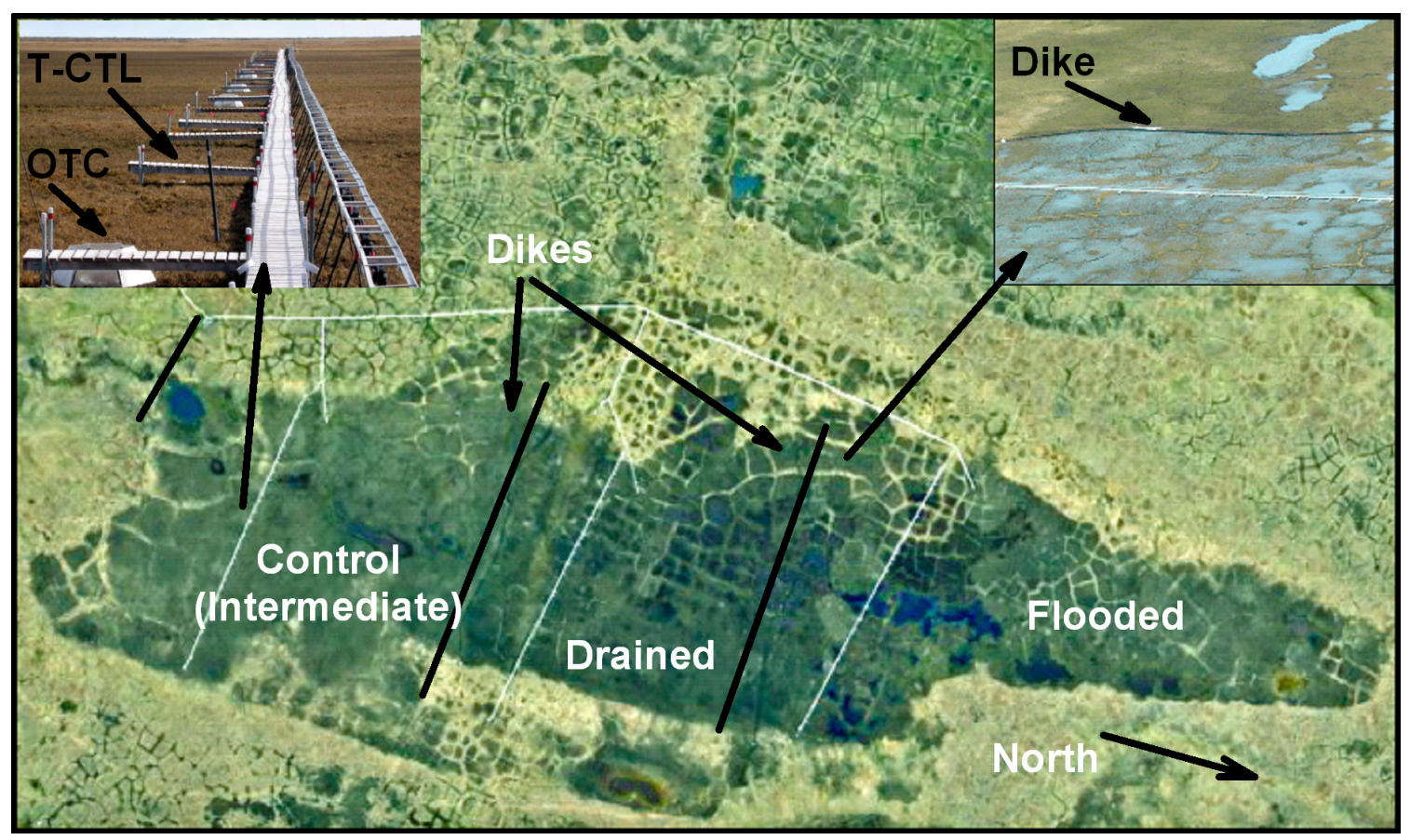

Figure 1. Study site, lake sections and plot layout (insert). 


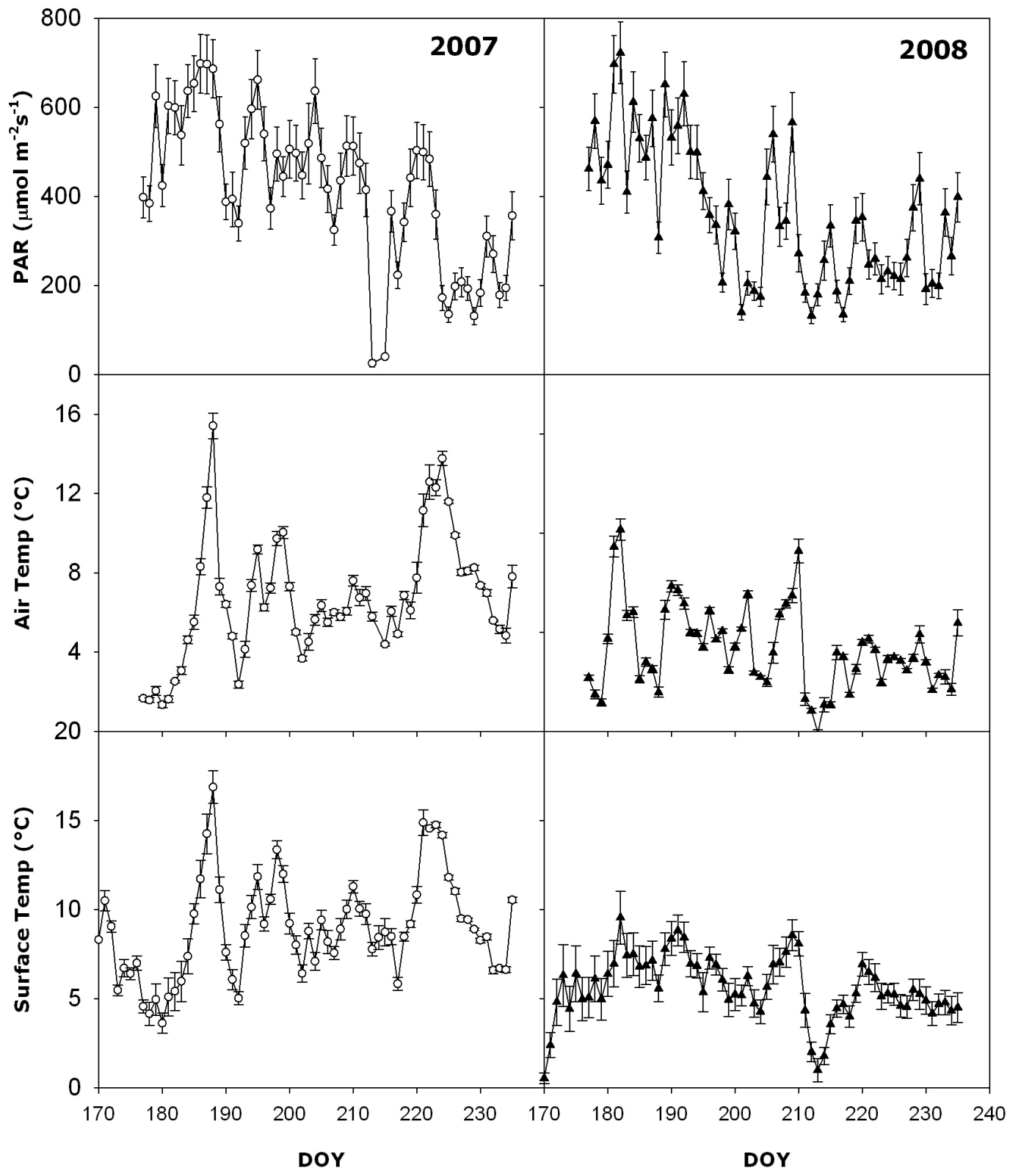

Figure 2. Photosynthetically active radiation (PAR), air temperature, and surface temperature $(-2 \mathrm{~cm})$ for the study site for 2007 and 2008. Errors bars represent \pm one standard error of the mean. 


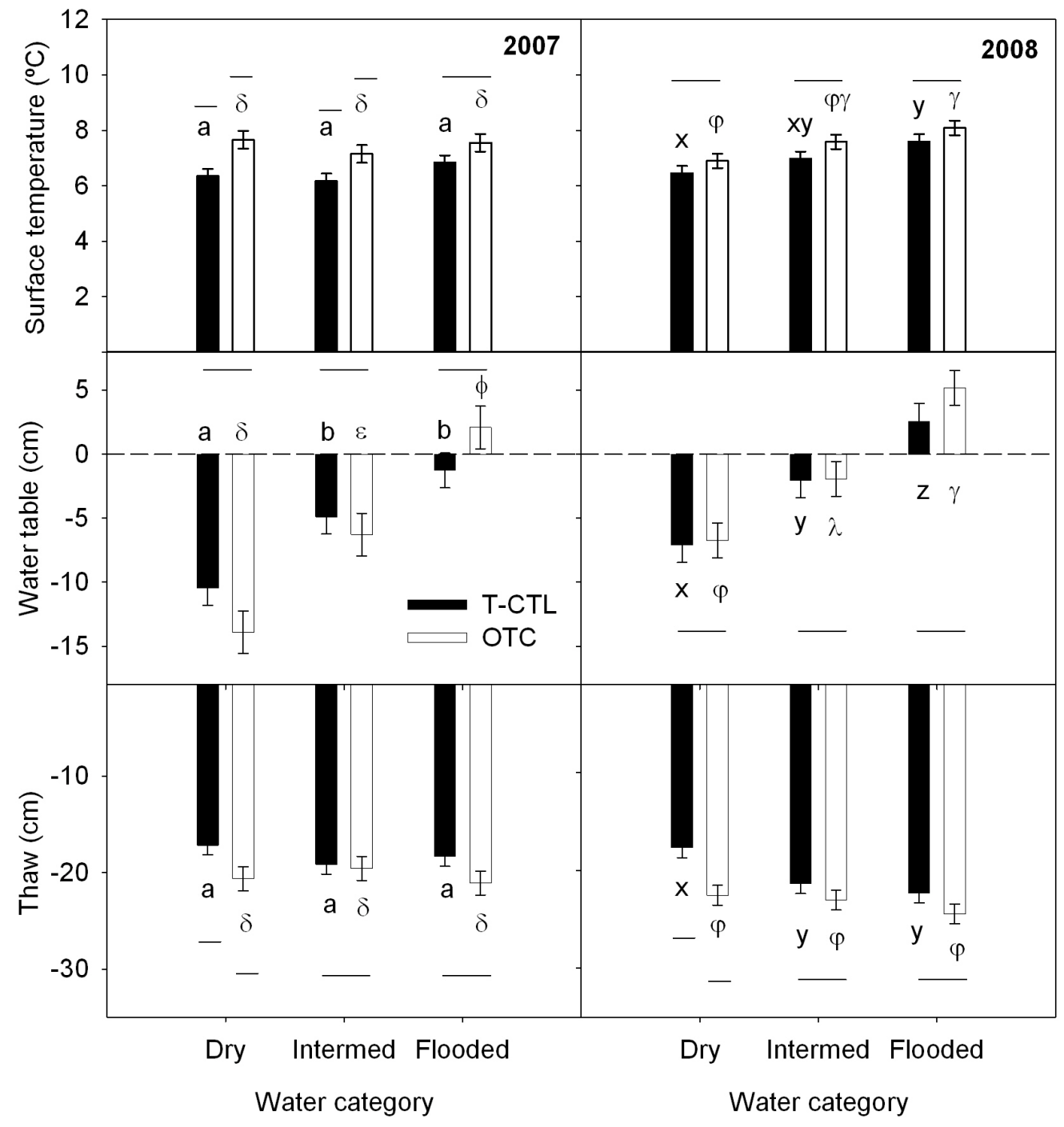

Figure 3. Mean surface temperatures $(-2 \mathrm{~cm})$, water table category and thaw by temperature and water categories and year. Shaded bars represent temperature control plots (T-CTL), unshaded bars represent warmed plots (open top chambers, OTC). Errors bars represent \pm one standard error of the mean. Between water categories, different letters represent significant differences at $p<0.05$. Within water categories, bar under different line present a significant difference at $\mathrm{p}<0.05$ between temperature treatments. 


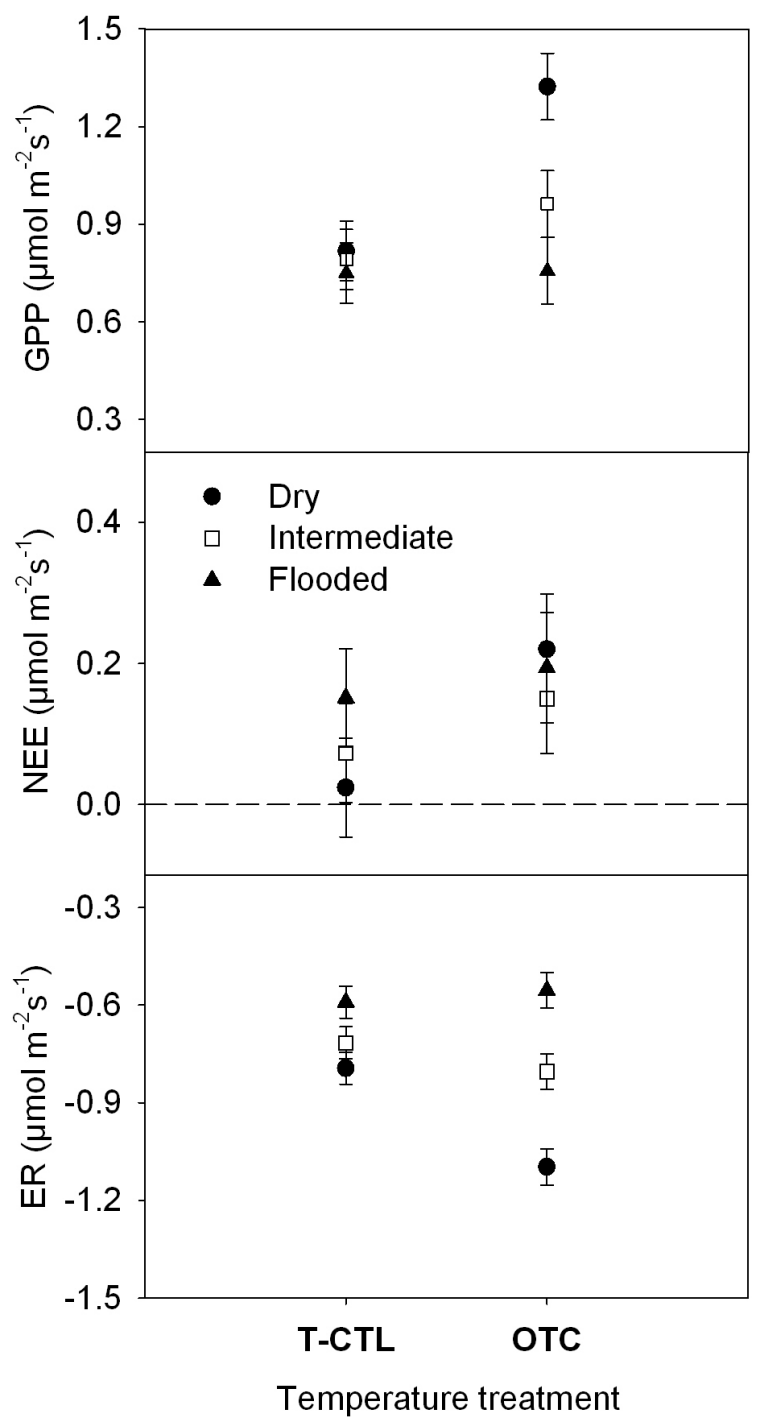

Figure 4. Main effect of temperature on $\mathrm{CO}_{2}$ flux components. Seasonal mean $\mathrm{CO}_{2}$ flux for both season separated by temperature and water table categories. GPP, gross primary productivity. NEE, net ecosystem exchange. ER, ecosystem respiration. Temperature control plots, T-CTL. Open top chambers, OTC. Positive numbers represent $\mathrm{CO}_{2}$ uptake. Errors bars represent \pm one standard error of the mean, temperature treatment effect: GPP, $\mathrm{F}=8.214, \mathrm{p}=0.006, \mathrm{NEE}, \mathrm{F}=3.164, \mathrm{p}=0.081$ and $\mathrm{ER}, \mathrm{F}=7.735, \mathrm{p}=0.007$. 


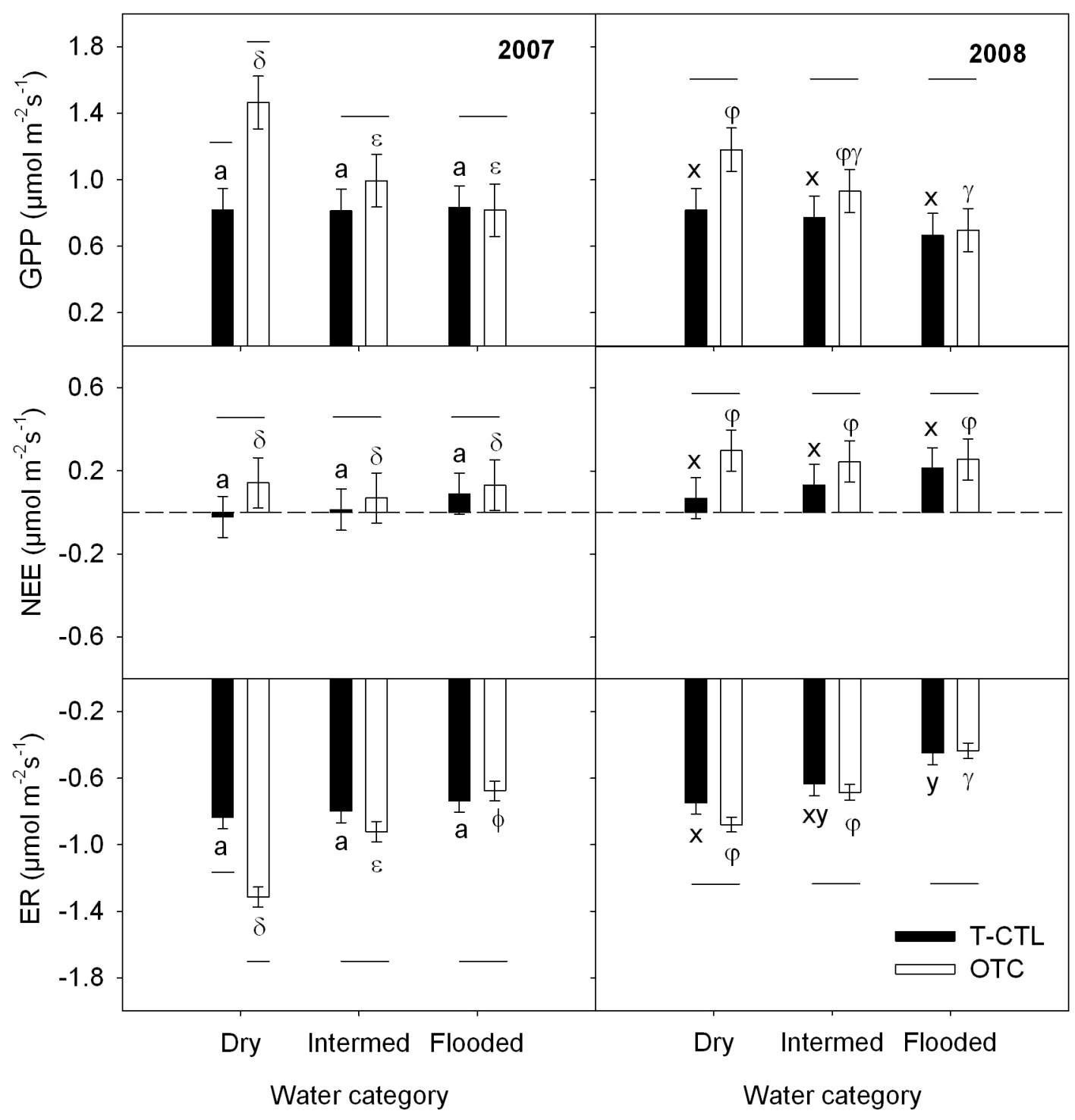

Figure 5. Seasonal mean $\mathrm{CO}_{2}$ flux separated by temperature and water category and year. GPP, gross primary productivity standardized by PAR (photosynthetically active radiation). NEE, net ecosystem exchange. ER, ecosystem respiration. Positive numbers represent $\mathrm{CO}_{2}$ uptake. Shaded bars represent temperature control plots (T-CTL), unshaded bars represent warmed plots (open top chambers, OTC). Errors bars represent \pm one standard error of the mean. Between water table categories, different letters 
represent significant differences at $\mathrm{p}<0.05$. Within water categories, bars under different line present a significant difference at $\mathrm{p}<0.05$ between temperature treatments. 


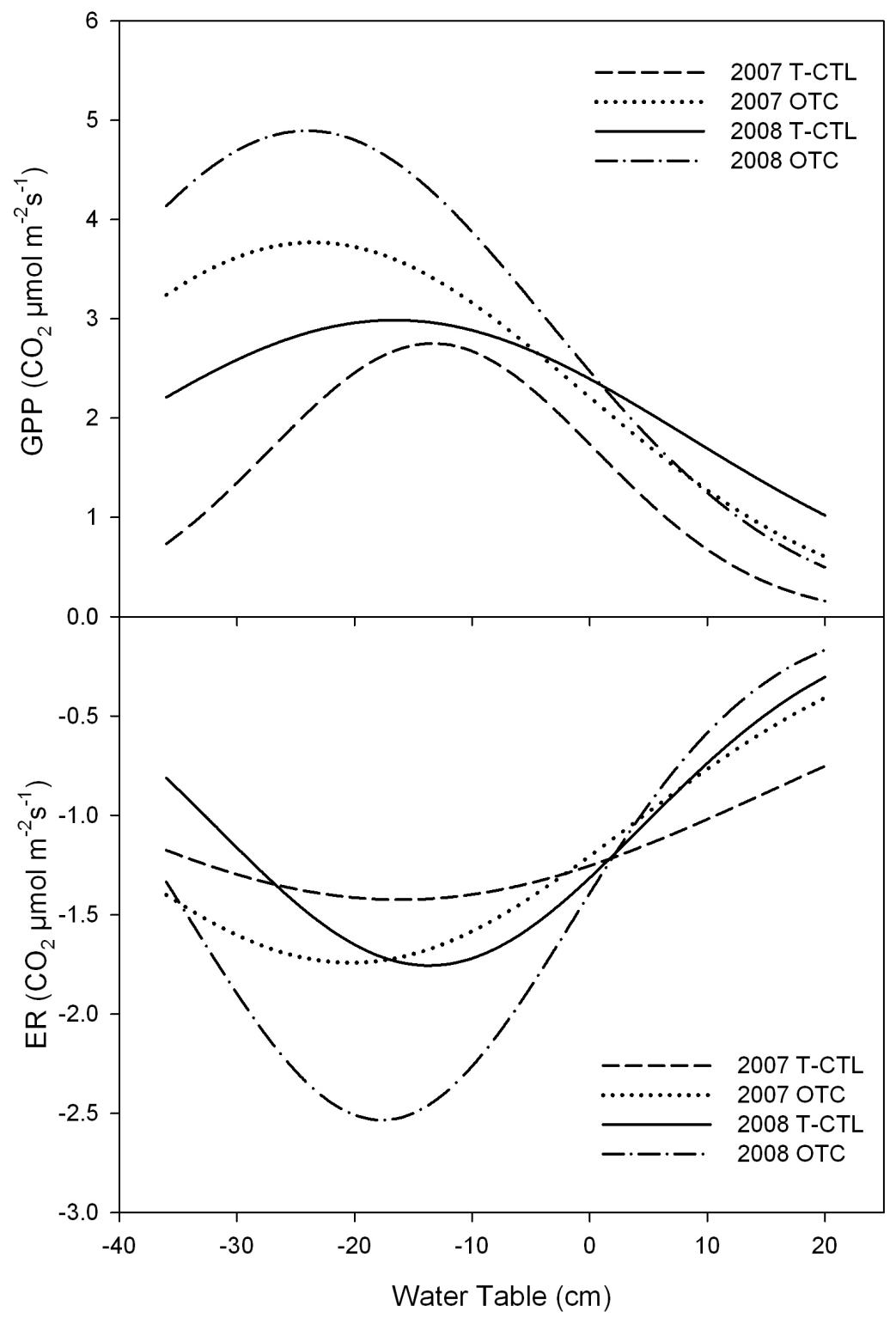

Figure 6. Gross primary productivity (GPP, upper panel) response to water table change and PPFD; and ecosystem respiration (ER) response to water table and temperature (lower panel). Models based on equations 1 and 2, where PPFD (600 $\left.\mu \mathrm{mol} / \mathrm{m}^{2} \mathrm{~s}\right), \mathrm{NDVI}$ (0.6), and temperature $\left(10^{\circ} \mathrm{C}\right)$ were kept constant. Temperature control plots, T-CTL, and open top chamber, OTC. 




Figure 7. Peak season $\mathrm{CH}_{4}$ efflux, water table, and soil temperature at $10 \mathrm{~cm}$ separated by warming treatment, water table category and year. Positive numbers represent $\mathrm{CH}_{4}$ release. Water table is referenced to top of the moss layer. Shaded bars represent temperature control plots (T-CTL), unshaded bars represent warmed plots (open top chambers, OTC). Errors bars represent \pm one standard error of the mean. Within years, 
water table categories with different letters and symbols represent significant differences at $\mathrm{p}<0.05$. Temperature treatments under a different horizontal line present a significant difference at $\mathrm{p}<0.05$. 


\section{LITERATURE CITED}

Berestovskaya, Y. Y., Rusanov, II, L. V. Vasil'eva, and N. V. Pimenov. 2005. The processes of methane production and oxidation in the soils of the Russian Arctic tundra. Microbiology 74:221-229.

Beringer, J., A. H. Lynch, F. S. Chapin, M. Mack, and G. B. Bonan. 2001. The representation of arctic soils in the land surface model: The importance of mosses. Journal of Climate 14:3324-3335.

Billings, W. D., K. M. Peterson, G. R. Shaver, and A. W. Trent. 1977. Root-growth, respiration, and carbon-dioxide evolution in an arctic tundra soil. Arctic And Alpine Research 9:129-137.

Bockheim, J. G., L. R. Everett, K. M. Hinkel, F. E. Nelson, and J. Brown. 1999. Soil organic carbon storage and distribution in Arctic Tundra, Barrow, Alaska. Soil Science Society of America Journal 63:934-940.

Boike, J., C. Wille, and A. Abnizova. 2008. Climatology and summer energy and water balance of polygonal tundra in the Lena River Delta, Siberia. Journal of Geophysical Research-Biogeosciences 113:G03025.

Bubier, J. L. 1995. The Relationship of Vegetation to Methane Emission and Hydrochemical Gradients in Northern Peatlands. Journal of Ecology 83:403-420.

Chapin, F. S., G. R. Shaver, A. E. Giblin, K. J. Nadelhoffer, and J. A. Laundre. 1995. Responses of arctic tundra to experimental and observed changes in climate. Ecology 76:694-711.

Chivers, M. R., M. R. Turetsky, J. M. Waddington, J. W. Harden, and A. D. McGuire. 2009. Effects of Experimental Water Table and Temperature Manipulations on Ecosystem $\mathrm{CO}_{2}$ Fluxes in an Alaskan Rich Fen. Ecosystems 12:1329-1342.

Christensen, T. R., T. Friborg, M. Sommerkorn, J. Kaplan, L. Illeris, H. Soegaard, C. Nordstroem, and S. Jonasson. 2000. Trace gas exchange in a high-arctic valley 1. Variations in $\mathrm{CO}_{2}$ and $\mathrm{CH}_{4}$ flux between tundra vegetation types. Global Biogeochemical Cycles 14:701-713.

Christensen, T. R., N. Panikov, M. Mastepanov, A. Joabsson, A. Stewart, M. Oquist, M. Sommerkorn, S. Reynaud, and B. Svensson. 2003. Biotic controls on $\mathrm{CO}_{2}$ and $\mathrm{CH}_{4}$ exchange in wetlands - a closed environment study. Biogeochemistry 64:337-354. 
Curtis, J., G. Wendler, R. Stone, and E. Dutton. 1998. Precipitation decrease in the western arctic, with special emphasis on Barrow and Barter Island, Alaska. International Journal of Climatology 18:1687-1707.

Elberling, B., C. Nordstrom, L. Grondahl, H. Sogaard, T. Friborg, T. R. Christensen, L. Strom, F. Marchand, and I. Nijs. 2008. High-arctic soil $\mathrm{CO}_{2}$ and $\mathrm{CH}_{4}$ production controlled by temperature, water, freezing and snow. Advances in Ecological Research 40:441-472.

Engstrom, R., A. Hope, H. Kwon, D. Stow, and D. Zamolodchikov. 2005. Spatial distribution of near surface soil moisture and its relationship to microtopography in the Alaskan Arctic coastal plain. Nordic Hydrology 36:219-234.

Friedlingstein, P., P. Cox, R. Betts, L. Bopp, W. Von Bloh, V. Brovkin, P. Cadule, S. Doney, M. Eby, I. Fung, G. Bala, J. John, C. Jones, F. Joos, T. Kato, M. Kawamiya, W. Knorr, K. Lindsay, H. D. Matthews, T. Raddatz, P. Rayner, C. Reick, E. Roeckner, K. G. Schnitzler, R. Schnur, K. Strassmann, A. J. Weaver, C. Yoshikawa, and N. Zeng. 2006. Climate-carbon cycle feedback analysis: Results from the (CMIP)-M-4 model intercomparison. Journal of Climate 19:3337-3353.

Funk, D. W., E. R. Pullman, K. M. Peterson, P. M. Crill, and W. D. Billings. 1994. Influence of water-table on carbon-dioxide, carbon-monoxide, and methane fluxes from taiga bog microcosms. Global Biogeochemical Cycles 8:271-278.

Gebauer, R. L. E., J. F. Reynolds, and J. D. Tenhunen. 1995. Growth and Allocation of the Arctic Sedges Eriophorum angustifolium and Eriophorum vaginatum - Effects of Variable Soil Oxygen and Nutrient Availability. Oecologia 104:330-339.

Gorham, E. 1991. Northern peatlands - role in the carbon-cycle and probable responses to climatic warming. Ecological Applications 1:182-195.

Gornall, J. L., I. S. Jonsdottir, S. J. Woodin, and R. Van der Wal. 2007. Arctic mosses govern below-ground environment and ecosystem processes. Oecologia 153:931941.

Hinkel, K. M., W. R. Eisner, J. G. Bockheim, F. E. Nelson, K. M. Peterson, and X. Y. Dai. 2003. Spatial extent, age, and carbon stocks in drained thaw lake basins on the Barrow Peninsula, Alaska. Arctic Antarctic and Alpine Research 35:291-300.

Hinzman, L. D., N. D. Bettez, W. R. Bolton, F. S. Chapin, M. B. Dyurgerov, C. L. Fastie, B. Griffith, R. D. Hollister, A. Hope, H. P. Huntington, A. M. Jensen, G. J. Jia, T. Jorgenson, D. L. Kane, D. R. Klein, G. Kofinas, A. H. Lynch, A. H. Lloyd, A. D. McGuire, F. E. Nelson, W. C. Oechel, T. E. Osterkamp, C. H. Racine, V. E. Romanovsky, R. S. Stone, D. A. Stow, M. Sturm, C. E. Tweedie, G. L. Vourlitis, M. D. Walker, D. A. Walker, P. J. Webber, J. M. Welker, K. Winker, and K. 
Yoshikawa. 2005. Evidence and implications of recent climate change in northern Alaska and other arctic regions. Climatic Change 72:251-298.

Hinzman, L. D. and D. L. Kane. 1992. Potential response of an arctic watershed during a period of global warming. Journal of Geophysical Research-Atmospheres 97:2811-2820.

Hobbie, S. E. and F. S. Chapin. 1998. Response of tundra plant biomass, aboveground production, nitrogen, and $\mathrm{CO}_{2}$ flux to experimental warming. Ecology 79:15261544.

Hollister, R. D. and P. J. Webber. 2000. Biotic validation of small open-top chambers in a tundra ecosystem. Global Change Biology 6:835-842.

Hollister, R. D., P. J. Webber, and C. E. Tweedie. 2005. The response of Alaskan arctic tundra to experimental warming: differences between short- and long-term responses. Global Change Biology 11:525-536.

Huemmrich, K. F., G. Kinoshita, J. A. Gamon, S. Houston, H. Kwon, and W. C. Oechel. 2010. Tundra carbon balance under varying temperature and moisture regimes. Journal of Geophysical Research-Biogeosciences 115:G00102.

Intergovernmental Panel on Climate Change (IPCC). 2007. Climate Change 2007: The Physical Science Basis. Contribution of Working Group I to the Fourth Assessment Report (AR4) of the Intergovernmental Panel on Climate Change, edited by S. Solomon et al., 996 pp., Cambridge Univ. Press, Cambridge, U. K.

Kaufman, D. S., D. P. Schneider, N. P. McKay, C. M. Ammann, R. S. Bradley, K. R. Briffa, G. H. Miller, B. L. Otto-Bliesner, J. T. Overpeck, and B. M. Vinther. 2009. Recent Warming Reverses Long-Term Arctic Cooling. Science 325:1236-1239.

Kelker, D. and J. Chanton. 1997. The effect of clipping on methane emissions from Carex. Biogeochemistry 39:37-44.

King, J. Y., W. S. Reeburgh, and S. K. Regli. 1998. Methane emission and transport by arctic sedges in Alaska: Results of a vegetation removal experiment. Journal of Geophysical Research-Atmospheres 103:29083-29092.

Le Mer, J. and P. Roger. 2001. Production, oxidation, emission and consumption of methane by soils: A review. European Journal of Soil Biology 37:25-50.

Marion, G. M., G. H. R. Henry, D. W. Freckman, J. Johnstone, G. Jones, M. H. Jones, E. Levesque, U. Molau, P. Molgaard, A. N. Parsons, J. Svoboda, and R. A. Virginia. 1997. Open-top designs for manipulating field temperature in high-latitude ecosystems. Global Change Biology 3:20-32. 
Merbold, L., W. L. Kutsch, C. Corradi, O. Kolle, C. Rebmann, P. C. Stoy, S. A. Zimov, and E. D. Schulze. 2009. Artificial drainage and associated carbon fluxes $\left(\mathrm{CO}_{2} / \mathrm{CH}_{4}\right)$ in a tundra ecosystem. Global Change Biology 15:2599-2614.

Oberbauer, S. F., C. T. Gillespie, W. Cheng, R. Gebauer, A. S. Serra, and J. D. Tenhunen. 1992. Environmental-effects on $\mathrm{CO}_{2}$ efflux from riparian tundra in the northern foothills of the Brooks Range, Alaska, USA. Oecologia 92:568-577.

Oberbauer, S. F., J. D. Tenhunen, and J. F. Reynolds. 1991. Environmental-effects on $\mathrm{CO}_{2}$ efflux from water track and tussock tundra in arctic Alaska, USA. Arctic and Alpine Research 23:162-169.

Oberbauer, S. F., C. E. Tweedie, J. M. Welker, J. T. Fahnestock, G. H. R. Henry, P. J. Webber, R. D. Hollister, M. D. Walker, A. Kuchy, E. Elmore, and G. Starr. 2007. Tundra $\mathrm{CO}_{2}$ fluxes in response to experimental warming across latitudinal and moisture gradients. Ecological Monographs 77:221-238.

Oechel, W. C., S. J. Hastings, G. Vourlitis, M. Jenkins, G. Riechers, and N. Grulke. 1993. Recent change of Arctic tundra ecosystems from a net carbon-dioxide sink to a source. Nature 361:520-523.

Oechel, W. C., G. L. Vourlitis, S. J. Hastings, R. P. Ault, and P. Bryant. 1998. The effects of water table manipulation and elevated temperature on the net $\mathrm{CO}_{2}$ flux of wet sedge tundra ecosystems. Global Change Biology 4:77-90.

Post, W. M., W. R. Emanuel, P. J. Zinke, and A. G. Stangenberger. 1982. Soil carbon pools and world life zones. Nature 298:156-159.

Riutta, T., J. Laine, and E. S. Tuittila. 2007. Sensitivity of $\mathrm{CO}_{2}$ exchange of fen ecosystem components to water level variation. Ecosystems 10:718-733.

Schreader, C. P., W. R. Rouse, T. J. Griffis, L. D. Boudreau, and P. D. Blanken. 1998. Carbon dioxide fluxes in a northern fen during a hot, dry summer. Global Biogeochemical Cycles 12:729-740.

Schuur, E. A. G., J. Bockheim, J. G. Canadell, E. Euskirchen, C. B. Field, S. V. Goryachkin, S. Hagemann, P. Kuhry, P. M. Lafleur, H. Lee, G. Mazhitova, F. E. Nelson, A. Rinke, V. E. Romanovsky, N. Shiklomanov, C. Tarnocai, S. Venevsky, J. G. Vogel, and S. A. Zimov. 2008. Vulnerability of permafrost carbon to climate change: Implications for the global carbon cycle. Bioscience 58:701-714.

Schuur, E. A. G., K. G. Crummer, J. G. Vogel, and M. C. Mack. 2007. Plant species composition and productivity following permafrost thaw and thermokarst in alaskan tundra. Ecosystems 10:280-292. 
Sjogersten, S., R. van der Wal, and S. J. Woodin. 2006. Small-scale hydrological variation determines landscape $\mathrm{CO}_{2}$ fluxes in the high Arctic. Biogeochemistry 80:205-216.

Solomon, S., G.-K. Plattner, R. Knutti, and P. Friedlingstein. 2009. Irreversible climate change due to carbon dioxide emissions. Proceedings of the National Academy of Sciences 106:1704-1709.

Strack, M., J. M. Waddington, M. C. Lucchese, and J. P. Cagampan. 2009. Moisture controls on $\mathrm{CO}_{2}$ exchange in a Sphagnum-dominated peatland: results from an extreme drought field experiment. Ecohydrology 2:454-461.

Sturm, M., C. Racine, and K. Tape. 2001. Climate change - Increasing shrub abundance in the Arctic. Nature 411:546-547.

Sullivan, P. F., S. J. T. Arens, R. A. Chimner, and J. M. Welker. 2008. Temperature and microtopography interact to control carbon cycling in a high arctic fen. Ecosystems 11:61-76.

Tarnocai, C., J. G. Canadell, E. A. G. Schuur, P. Kuhry, G. Mazhitova, and S. Zimov. 2009. Soil organic carbon pools in the northern circumpolar permafrost region. Global Biogeochemical Cycles 23:GB2023.

Tieszen, L. L. 1978. Introduction. Pages 3-18 in L. L. Tieszen, editor. Vegetation and production ecology of an Alaskan arctic tundra. Springer-Verlag, New York.

Tuittila, E. S., H. Vasander, and J. Laine. 2004. Sensitivity of C sequestration in reintroduced Sphagnum to water-level variation in a cutaway peatland. Restoration Ecology 12:483-493.

Turetsky, M. R., C. C. Treat, M. P. Waldrop, J. M. Waddington, J. W. Harden, and A. D. McGuire. 2008. Short-term response of fluxes and methanogen activity to water table and soil warming manipulations in an Alaskan peatland. Journal of Geophysical Research-Biogeosciences 113: G00A10.

Verville, J. H., S. E. Hobbie, F. S. Chapin, and D. U. Hooper. 1998. Response of tundra $\mathrm{CH}_{4}$ and $\mathrm{CO}_{2}$ flux to manipulation of temperature and vegetation. Biogeochemistry 41:215-235.

von Fischer, J. C. and L. O. Hedin. 2002. Separating methane production and consumption with a field-based isotope pool dilution technique. Global Biogeochemical Cycles 16(3):1034. 
von Fischer, J. C. and L. O. Hedin. 2007. Controls on soil methane fluxes: Tests of biophysical mechanisms using stable isotope tracers. Global Biogeochemical Cycles 21: GB2007.

Vourlitis, G. L., W. C. Oechel, S. J. Hastings, and M. A. Jenkins. 1993. The effect of soil moisture and thaw depth on $\mathrm{CH}_{4}$ flux from wet coastal tundra ecosystems on the North Slope of Alaska. Chemosphere 26:329-337.

Walker, D. A., G. J. Jia, H. E. Epstein, M. K. Raynolds, F. S. Chapin, C. Copass, L. D. Hinzman, J. A. Knudson, H. A. Maier, G. J. Michaelson, F. Nelson, C. L. Ping, V. E. Romanovsky, and N. Shiklomanov. 2003. Vegetation-soil-thaw-depth relationships along a Low-Arctic bioclimate gradient, Alaska: Synthesis of information from the ATLAS studies. Permafrost and Periglacial Processes 14:103-123.

Walter, K. M., J. P. Chanton, F. S. Chapin, E. A. G. Schuur, and S. A. Zimov. 2008. Methane production and bubble emissions from arctic lakes: Isotopic implications for source pathways and ages. Journal of Geophysical Research-Biogeosciences 113:G00A08.

Whalen, S. C. 2005. Biogeochemistry of methane exchange between natural wetlands and the atmosphere. Environmental Engineering Science 22:73-94.

Williams, T. G. and L. B. Flanagan. 1996. Effect of changes in water content on photosynthesis, transpiration and discrimination against ${ }^{13} \mathrm{CO}_{2}$ and $\mathrm{C}^{18} \mathrm{O}^{16} \mathrm{O}$ in Pleurozium and Sphagnum. Oecologia 108:38-46.

Zona, D., W. C. Oechel, J. Kochendorfer, K. T. P. U, A. N. Salyuk, P. C. Olivas, S. F. Oberbauer, and D. A. Lipson. 2009. Methane fluxes during the initiation of a large-scale water table manipulation experiment in the Alaskan Arctic tundra. Global Biogeochemical Cycles 23:GB2013 


\title{
4. Chapter 3: Effects of Long-Term Warming on the Peak Season $\mathrm{CO}_{2}$ Flux Components of Arctic Tundra at a Continental and Coastal Location in Northern
}

Alaska

Paulo C. Olivas ${ }^{1}$, Steven F. Oberbauer ${ }^{1}$, Craig E. Tweedie ${ }^{2}$, Robert Hollister ${ }^{3}$

${ }^{1}$ Dept. of Biological Sciences, Florida International University, 11200 S.W. $8^{\text {th }}$ St, Miami, FL 33199, USA

${ }^{2}$ Dept. of Biological Sciences, University of Texas at El Paso, 500 West University Avenue, El Paso, TX 79968, USA

${ }^{3}$ Dept. of Biology, Grand Valley State University, Campus Drive, Allendale, Michigan 49401-9403, USA

\begin{abstract}
Low temperatures and waterlogged soils have contributed to maintain low ecosystem respiration (ER) rates and decomposition in the Arctic. As a result, Arctic ecosystems hold large amounts of soil organic carbon under cold and conditions. Recent models predict a significant increase of global temperatures, with the largest increases in the polar regions. An increase of the ER rates in the Arctic could represent a positive feedback to the atmospheric $\mathrm{CO}_{2}$ concentration and further increase the global temperature. Warming also will likely increase gross primary productivity (GPP), counteracting the increase in ER. To evaluate the long-term effect of warming on tundra
\end{abstract}


$\mathrm{CO}_{2}$ exchange processes of sites with different temperature and moisture regimes, we measured ecosystem $\mathrm{CO}_{2}$ fluxes on experimentally warmed plots in dry and wet sites from two locations in northern Alaska. The study sites were established in the mid 90's as part of the International Tundra Experiment (ITEX) network. We used passive warming for the temperature manipulation and static chamber techniques to measure $\mathrm{CO}_{2}$ exchange. After several years of manipulation, warming still has a significant effect on $\mathrm{CO}_{2}$ exchange, however, the response was not the same at each site and location. The coastal location presented stronger responses of the $\mathrm{CO}_{2}$ flux components to warming than the inland location. The dry site in the coastal location was a $\mathrm{CO}_{2}$ source as result of warming. The ER presented a positive significant response to temperature across years, but the relationship with year was not significant. Our results suggest that the coastal location responded differently to warming than the inland location. Dry areas, especially near the arctic coast, can be sources of $\mathrm{CO}_{2}$ even after more than a decade of warming. Conversely, after a period of aboveground biomass increase, wet sites presented no significant response to warming after several years of warming. Arctic ecosystems can readily respond to warming, however over time nutrient reallocation, self-shading, and soil insulation may down-regulate gross primary productivity (GPP) and ER in wet areas. In dry areas where absorption and reallocation of nutrients by the vegetation is slow, the ecosystem could sustain high ER rates for long periods in response to warming.

\section{Introduction}

Arctic regions hold nearly 1672 Gt of the world's soil organic carbon (Tarnocai et al. 2009). Close to $190 \mathrm{Gt}$ of that soil carbon is stored within the seasonal active layer 
and the uppermost permafrost (Post et al. 1982, Tarnocai et al. 2009). Unique conditions such as litter quality (woody and moss tissue), low temperatures and waterlogged soils in the Arctic have favored the slow decomposition of organic matter and the accumulation of substantial amounts of soil organic carbon (Hobbie et al. 2000, Callaghan et al. 2004), despite the fact that arctic ecosystems present low productivity (Callaghan et al. 2004).

Recent climate models have shown that the global mean temperature is very likely to increase, particularly affecting the arctic regions (Solomon et al. 2009). Changes in temperature are likely to alter both the thermal and hydrological regimes of some arctic ecosystems, increasing respiratory losses and thus potentially shifting the tundra from a carbon sink to a source (Oechel et al. 1993, Schuur et al. 2008). However, a change in the thermal and hydrological regimes could also increase productivity of some plant groups, such as the graminoids and deciduous shrubs, offsetting the increase of respiratory losses (Chapin et al. 1995, Sturm et al. 2001). The effects of changes in thermal and hydrological regimes on the short-term responses of productivity and respiration have been widely studied (Oechel et al. 1998, Sommerkorn 2008, Sullivan et al. 2008, Chivers et al. 2009, Olivas et al. 2010). In contrast, longer-term responses such as decadal time spans have seldom been explored (Chapin et al. 1995, Shaver et al. 1998, Johnson et al. 2000, Hollister et al. 2005b, Oberbauer et al. 2007). Ecosystem responses to changes in thermal regimens can have different effects on the net carbon balance depending on the timescale, for instance the effect of increased temperature is likely to be faster for photosynthesis and heterotrophic respiration than for soil organic matter accumulation (Chapin and Shaver 1996, Shaver et al. 2000). 
The effects of increased temperature on ecosystem processes, such as gross primary productivity (GPP) and ecosystem respiration (ER), are tightly linked to different hydrological regimes. In areas with predominantly dry conditions the ecosystem response to warming is expected to be different than that of waterlogged areas. In dry areas warming could decrease net ecosystem exchange (NEE) by increasing ER and reducing GPP; the magnitude and extent of the response would be a function of the soil carbon, moisture, and ecosystem structure. High soil oxygen availability could favor microbial activity under warmer conditions, but warming could also increase evapotranspiration reducing soil moisture and eventually produce a decline in microbial activity and ER (Allison and Treseder 2008). In waterlogged areas, warming is likely to have a positive effect on both ER and GPP as a result of the positive effect of increased temperature on metabolic processes of plants and microbes (Oberbauer et al. 1998, Sommerkorn et al. 1999, Brooker and van der Wal 2003, Boddy et al. 2008).

Additionally, similar to dry areas, warming in the waterlogged areas can increase evapotranspiration, potentially lowering the water table. A reduction in water table will increase soil oxygen availability positively affecting both ER and GPP (Oberbauer et al. 1991, Olivas et al. 2010). Therefore, the direction of NEE ( $\mathrm{CO}_{2}$ source or sink) would be tightly related to the photosynthetic capacity and microbial activity of the ecosystem (Oberbauer et al. 1991, Olivas et al. 2010).

The long-term effect of warming on the sink/source capacity of some arctic ecosystems is tightly linked to the quantity and quality of the soil organic matter and, therefore, the ecosystem structure (Thormann et al. 2004). For instance, mosses and deciduous shrubs supply low quality litter (e.g., high C:N ratios and complex carbon 
chains in moss litter that make them very recalcitrant) that have lower turnover rates than graminoids, promoting carbon storage (Hobbie 1996, Thormann et al. 2004). In addition to litter quality, high water tables can also affect substrate availability for microbial and fungal decomposition as a result of the reduction in soil oxygen availability (Dowding and Widden 1974, Hodkinson et al. 1999). Therefore, parameters that influence hydrology, such as topography and permafrost would play an important role in soil organic matter accumulation. Areas with historically high water tables hold larger amounts of soil organic carbon than drier areas in part as a result of anoxic conditions (Giblin et al. 1991, Michaelson et al. 1996, Bockheim et al. 1999). However, areas with high productivity, such as tussock tundra, can also present high soil organic matter under high oxygen availability because the rate of litter addition (high productivity) is greater than decomposition rates (Gebauer et al. 1996). As a result of the differences in the soil carbon available (quantity and quality), the effect of warming on dry and wet areas is expected to be different. For instance, in moist areas, warming could increase GPP of graminoids and mosses that, in turn, would increase the litter deposition and insulation of the soil reducing temperature and ER. Moist areas also represent a larger potential carbon source under warmer conditions than dry sites because lowering of the water table could expose the organic matter to microbial decomposition. However, the effect of warming on ER could be much faster in dry sites than in the moist/wet areas as result of the buffering effect of waterlogged conditions. Nevertheless, once the carbon has been decomposed in the dry sites, the direction of NEE might switch from the site being a source to being neutral or a sink (Shaver et al. 2000), while the response to warming in 
the wet/moist sites may last much longer as result of the large amount of carbon in the soil (Chapin and Shaver 1996, Shaver et al. 2000).

Geographical position is another important factor that could determine the effect of warming on ER, GPP and NEE. Areas located near the coast can have a different response to warming than areas located more in the continental interior where summer conditions can be warmer. For instance, changes in the sea ice extent and decrease of albedo are likely to have a more immediate effect on coastal areas than on continental sites (Bhatt et al. 2010).

Short-term (1-3 years) effects of warming on ecosystem processes, such as changes in ER, GPP, and NEE, have been assessed by previous research (Oberbauer et al. 1998, Sullivan et al. 2008, Chivers et al. 2009), although, understanding of the long-term ( $>5$ years) effects of warming on ecosystem processes is still limited (Oechel et al. 2000, Shaver et al. 2006, Oberbauer et al. 2007). Instantaneous photosynthetic and heterotrophic respiration rates can respond very quickly to changes in temperature, but maximum photosynthetic capacity $\left(\mathrm{GPP}_{\max }\right)$ is likely to be affected by long-term changes in ecosystem structure. For instance, a shift in species composition could increase ecosystem light use efficiency and decrease the light compensation point (LCP), increasing the sink capacity of the ecosystem. LCP (measured in quantum units) is the point in a light response curve at which GPP and ER are equal, thus NEE is zero. A long-term increase of the LCP can indicate that the abiotic and biotic processes favoring an increase in ER are functioning at a faster rate than the changes in the photosynthetic capacity of the ecosystem (e.g., change in ecosystem structure). 
The main goal of this study was to determine the long-term (decadal) effect of passive warming on ecosystem processes, such as ER, GPP, and NEE, at the two ends of a hydrological gradient and at a coastal and a continental location. We also explored the long-term (decadal) trend of the sink capacity of the tundra. We specifically asked: 1) has there been change in the long-term trend of the sink capacity of the tundra; 2) does warming increase $\mathrm{CO}_{2}$ losses by increasing ER in both wet and dry sites; 3 ) is the warming effect on the sink capacity of the ecosystem stronger on the wet sites than on the dry sites; and 4) does warming have a stronger effect on the coastal location (Barrow) than on the continental location (Atqasuk)? We hypothesized that: 1) as result of the increase of the global temperature the long-term trend of the sink capacity of some arctic ecosystems has decreased; 2) warming will decrease the sink potential of the ecosystem by increasing ER; 3) since the labile carbon stocks are larger in wet/moist areas, warming would have a stronger negative effect on the $\mathrm{CO}_{2}$ sink capacity of the ecosystem in these areas; and 4) since the coastal site presents lower summer mean air temperatures, warming should have a stronger effect in the coastal location than in the continental location.

\section{Methods}

Study site

The study sites were located in the northern Coastal Plain of Alaska. The coastal sites were located near Barrow $\left(71^{\circ} 18^{\prime} \mathrm{N}, 156^{\circ} 40^{\prime} \mathrm{W}\right)$, while the inland sites were located near the village of Atqasuk $\left(70^{\circ} 29^{\prime} \mathrm{N}, 157^{\circ} 25^{\prime} \mathrm{W}\right), 100 \mathrm{~km}$ south of Barrow. The mean 
July air temperatures are $3.7^{\circ} \mathrm{C}$ for Barrow and $9{ }^{\circ} \mathrm{C}$ for Atqasuk (Haugen and Brown 1980). At each location two sites were established, one in a dry heath and one in a wet meadow. The sites were selected based on similarities between Barrow and Atqasuk. The dry heath (Dry) in Barrow was located on an old beach ridge with well-drained soils (xeric pergelic cryaquepts), while the wet meadow (Wet) was located at the edge of a thawed lake basin with poorly-drained soils (histic pergelic cryaquepts). The dry site in Atqasuk was located on a rim of a semi-drained basin with well-drained soils (pergelic cryosamments), while the wet site was located near a lake edge with poorly-drained histic pergelic cryaquepts (Webber 1978, Komarkova and Webber 1980, Hollister et al. 2005b).

\section{Experimental design}

At each location (Barrow and Atqasuk), twenty temperature-control plots (TCTL) and twenty temperature-treated plots fitted with open top chambers (OTC) were established in each site (Dry and Wet). Open top chambers used for passive warming followed the specifications of Molau and Mølgaard (1996). The OTCs had a conical, hexagonal shape, were $35 \mathrm{~cm}$ high and had $60 \mathrm{~cm}$ and $103 \mathrm{~cm}$ of opening at the top and bottom, respectively. The warming treatment was done only during the growing season, and the OTCs were placed soon after the snowmelt and removed at the end of the growing season. OTCs have been extensively used by the International Tundra Experiment network (ITEX, http://www.geog.ubc.ca/itex/, Henry and Molau 1997) to simulate climate change conditions. The effectiveness of the OTC for warming has been assessed previously by Marion et al. (1997) and Hollister and Webber (2000). 
$\mathrm{CO}_{2}$ flux sampling

We measured three components of the $\mathrm{CO}_{2}$ flux, the net ecosystem exchange (NEE), gross primary productivity (GPP), and ecosystem respiration (ER) using similar techniques to those described by Oberbauer et al. (2007). Measurements were made over a single $24 \mathrm{~h}$ period at peak growing season (July 25-Aug 5) across an 11 year period from 2000 to 2010. Measurement years were: 2000, 2001, 2002, 2005, 2006, 2007, 2008, 2009, and 2010. Equipment malfunction and lack of access prevented completion of measurements at Atqasuk in 2006 and 2009, respectively. To measure $\mathrm{CO}_{2}$ exchange, we used a LI-6200 portable photosynthesis system (LI-COR, Lincoln, Nebraska, USA) fitted with a transparent acrylic chamber coupled to a base ( $46 \mathrm{~cm}$ diameter PVC) permanently installed in the soil on five plots of each treatment (T-CTL and OTC) at each site (Wet and Dry. The $\mathrm{CO}_{2}$ exchange rates (NEE) were measured by determining the change in carbon dioxide concentration three times after an incubation time of 30-s changes at each plot. Before initiating each recording, an equilibration time was allowed between the machine and chamber. The measurements were repeated until a steady trend was obtained. To avoid the build up of excessive $\mathrm{CO}_{2}$ concentrations and humidity inside of the chamber, which could alter the natural conditions, the chamber was not kept on the plot for long periods. Plots were measured every four hours during a period of 24 hours.

Ecosystem respiration (dark respiration) was measured by covering the chamber with a dark cloth and allowing enough time for photosynthesis to stop before taking respiration measurements. As a result of the large number of plots, measurements of NEE and ER in all plots were done only during one sample period (04:00 hours). During the other sampling periods, NEE was measured in all plots, but ER was measured only on 
one reference plot. To estimate the ER of the other plots for each sampling period, the ER of the reference plot at each sampling period was multiplied by the ratio of ER of the reference plot to ER of each of the other plots at the sampling time 04:00 hours. In other words, the diurnal response of the ER of the reference plot was used to calculate the diurnal response of ER of each of the other plots by applying the diurnal response of the ER of the reference plot to the ER measured at 4:00 am in the other plots. In 2005 two reference plots were measured, and in 2009 and 2010 ER was measured on all plots at all sampling periods but using a $20 \mathrm{~s}$ incubation period. The GPP was calculated as the difference between NEE and ER. Similar to what Oberbauer et al. (2007) observed in some of the dry site plots at Barrow, some plots occasionally had unusually large NEE rates compared to ER rates, producing negative GPP rates. Under these circumstances the measurements were repeated or the GPP discarded. The data of the $\mathrm{CO}_{2}$ flux components are presented following the ecosystem notation, where $\mathrm{CO}_{2}$ loss from the system (ER) is treated as a negative flux, and photosynthetic uptake (GPP) is treated as a positive flux.

\section{Data analysis}

The long-term effects of temperature were analyzed using a linear mixed model. Location (Atqasuk and Barrow), site (Dry and Wet), and treatment (T-CTL and OTC) were fixed effects while year was used as a repeated measures. We used type III tests of fixed effects and first-order autoregressive structure with heterogeneous variances for the residuals. For the multiple comparisons, we used the least significant difference. As a result of a potential effect of variable light conditions between peak season $\mathrm{CO}_{2}$ 
assessments among years, we used ER as a proxy to evaluate the long-term relationships between year (change in time) and temperature on ecosystem processes because ER is more likely to reflect the conditions of the seasonal growing. The relationship between peak season ER and temperature and year were analyzed using a linear regression.

To further understand the warming effects on some ecosystem processes, we determined the light compensation point (LCP) and apparent quantum yield ( $\phi)$ for each treatment at each site and location. The LCP and $\phi$ were derived from the light response curve model described by a nonrectangular hyperbola (Leverenz and Jarvis 1979, Marshall and Biscoe 1980, Terashima and Saeki 1985, Ogren 1993). The equation presents a linear relationship between photosynthesis and light under low irradiance conditions, and an asymptotic response to light at high levels of irradiance:

$$
\Theta * \mathrm{P}^{2}-\left(\phi * \mathrm{I}+\mathrm{P}_{\max }\right) * \mathrm{P}+\phi^{*} \mathrm{I}^{*} \mathrm{P}_{\max }=0
$$

where $P\left(\mu \mathrm{mol} \mathrm{m} \mathrm{m}^{-2} \mathrm{~s}^{-1}\right)$ is the rate of photosynthesis, $I\left(\mu \mathrm{mol} \mathrm{m} \mathrm{s}^{-2}\right)$ is the irradiance, $\phi$ is the maximum quantum yield $(\mathrm{mol} / \mathrm{mol})$ or slope of the curve at low irradiance levels, $\Theta$ is the convexity of the curve, and $P_{\max }\left(\mu \mathrm{mol} \mathrm{m} \mathrm{m}^{-2} \mathrm{~s}^{-1}\right)$ is the lightsaturated rate of photosynthesis.

The nonrectangular hyperbola model was modified to determine the LCP $(\mu \mathrm{mol}$ $\mathrm{m}^{-2} \mathrm{~s}^{-1}$ ) at the ecosystem level using NEE and ER as the net assimilation and respiration parameters:

$$
\mathrm{LCP}=\left(\Theta * \mathrm{ER}^{2}-\mathrm{ER}^{*} \mathrm{NEE} \mathrm{E}_{\max }\right) /\left(\mathrm{ER}^{*} \phi-\mathrm{NEE}_{\max } * \phi\right)
$$

As a result of the variable light conditions observed during the years, in some instances the light available was not enough for light saturation measurements $(\Theta$ near 
$0.01,35 \%$ in Barrow and 29\% in Atqasuk), however, since LCP and $\phi$ are parameters that can be determined at non light saturated conditions since by definition the LCP is the point at which GPP $+\mathrm{ER}=0$ and the light available was sufficient to determine this parameters. Smith et al. (1976) found no significant change in the LCP with increasing light intensities.

We also calculated the thaw degree days (TDD) as the sum of degrees above the zero degrees estimated from the mean daily temperature from May 15 to the day of the $\mathrm{CO}_{2}$ measurement. We used the methodology suggested by Molau and Mølgaard (1996). We determined the change of TDD over time using a linear regression between TDD and year. The statistical analysis was performed using PASW Statistics GradPack 18 (SPSS Inc., 2009).

\section{Results}

Interannual variability in the $\mathrm{CO}_{2}$ flux components and warming effects

The $\mathrm{CO}_{2}$ flux components presented considerable variation across years for the two locations (Figure 1). However, in general GPP was greater at the Barrow location $(2.16 \pm 0.059)$ than at Atqasuk $(1.59 \pm 0.063, F=24.05, \mathrm{p}<0.0001)$. Wet sites $(2.4 \pm 0.06)$ presented higher GPP rates than Dry sites $(1.32 \pm 0.06, F=166.39, \mathrm{p}<0.0001)$. OTC treatment $(1.98 \pm 0.06)$ presented higher GPP rates than the T-CTL treatment $(1.76 \pm 0.06$, $\mathrm{F}=6.34, \mathrm{p}=0.014)$. The NEE rates did not differ between Atqasuk and Barrow $(\mathrm{F}=2.215$, $\mathrm{p}=0.145)$. The NEE rates of the Dry sites $(-0.163 \pm 0.05)$ were significantly lower than those of the Wet sites $(0.66 \pm 0.05, F=141.4, p<0.0001)$. Warming significantly reduced 
the NEE rates; the OTC plots $(0.144 \pm 0.05)$ presented lower rates than the T-CTL plots $(0.352 \pm 0.05, \mathrm{~F}=9.04, \mathrm{p}=0.003)$. The interactions revealed that warming was significant only for NEE at the Barrow Dry site (three-way interaction, Table 1, F=18.0, p<0.0001). The ER rates were higher in Barrow $(-1.91 \pm 0.06)$ than in Atqasuk $(-1.27 \pm 0.07, \mathrm{~F}=53.4$, $\mathrm{p}<0.0001)$. On average, the Wet sites $(-1.74 \pm 0.06)$ presented larger ER rates than the Dry sites $(-1.45 \pm 0.06, \mathrm{~F}=11.32, \mathrm{p}=0.001)$. The warming treatment significantly increased the carbon losses and the ER rates of the OTC plots $(-1.80 \pm 0.06)$ were higher than those of the T-CTL plots $(-1.38 \pm 0.06, F=23.53, \mathrm{p}<0.0001)$. The significant twoway interactions revealed that the warming treatment effect on ER was affected by the location and site (Table 1). The multiple comparison revealed that the ER rates of the OTC plots were higher than those of the T-CTL in the Dry sites at Atqasuk $(\mathrm{F}=3.996$, $\mathrm{p}=0.047)$ and Barrow $(\mathrm{F}=45.07, \mathrm{p}<0.0001)$.

Year and temperature relationships with ER

The regressions between year and ER were not significant for any of the treatments at any of the sites and locations, except for OTC at the wet site in Barrow $(p=0.002$, Table 2 and Figure 2). In the case of temperature, we found that the ER was significantly correlated with peak season air temperature in all conditions, except for OTC plots in the Dry site at Barrow (Table 2), but the correlations were not very strong (maximum $\mathrm{R}^{2}$ adj.=0.56). 
Measurements of thaw degree-days (TDD) and the relation with year revealed an increase in temperature for Atqasuk $\left(\mathrm{R}^{2} \mathrm{adj} .=0.41\right)$, and Barrow $\left(\mathrm{R}^{2} \mathrm{adj} .=0.60\right)$; however, the relationship was only significant for the latter $(\mathrm{F}=11.69, \mathrm{p}=0.0142)$.

\section{Change in ecosystem flux properties}

We observed that the ratio GPP to ER was different for T-CTL and OTC at each site and location; a ratio higher than 1 indicated that a site was a $\mathrm{CO}_{2} \operatorname{sink}$ (Figure 3). In Atqasuk the plots (T-CTL and OTC) at the Wet site presented higher GPP/ER ratios than the plots at the Dry site, indicating higher sink capacity. The plots in the Dry site presented GPP/ER ratios that represented net balance or a small $\mathrm{CO}_{2}$ source. In Barrow, the results were similar, except for the OTC plots in the Dry site. These plots presented low GPP/ER ratios resulting in net $\mathrm{CO}_{2}$ sources during all years but 1 (Figure 3). In general, the ratio GPP/ER of the Dry sites at the two locations was close to net balance. In Barrow the warming treatment in the Dry site had an important effect on both GPP and ER; these sites presented the largest variation with coefficients of variation of $53 \%$ and $56 \%$, respectively.

The change in LCP was variable and not significantly correlated with year, although of an upward trend was observed in the last years (Figure 4). On average the LCP was lower in Atqasuk (146.2 \pm 22.8$)$ than in Barrow (213.5 $\pm 21.7, \mathrm{~F}=4.575, \mathrm{p}=0.037)$. Similarly, on average the plots in the Wet sites $(127.9 \pm 22.1)$ presented lower LCP than the plots in the Dry sites $(231.8 \pm 22.4, \mathrm{~F}=10.889, \mathrm{p}=0.002)$. Although on average the OTC plots presented higher LCP than the T-CTL, the difference was not significant ( $\mathrm{F}=3.247, \mathrm{p}=0.077)$. At both locations LCP was positively related to air temperature, but 
the relationship was significant only for the $\mathrm{T}-\mathrm{CTL}\left(\mathrm{R}^{2}\right.$ ajd. $\left.=0.42, \mathrm{~F}=6.78, \mathrm{p}=0.047\right)$, and OTC plots $\left(\mathrm{R}^{2}\right.$ ajd. $\left.=0.54, \mathrm{~F}=9.54, \mathrm{p}=0.021\right)$ at the Wet site in Barrow.

The apparent quantum yield ( $\phi$, Eq. 1$)$ did not vary significantly $(F=0.866$, $\mathrm{p}=0.363$ ). Similarly, warming had a slightly positive effect on $\phi$, but the large variation in the ecosystem response resulted in a non-significant effect of warming $(\mathrm{F}=1.032$, $\mathrm{p}=0.321$ ). The comparison of the Dry and Wet sites revealed a significant difference in $\phi$ : on average the plots in the Wet sites $(0.013 \pm 0.001)$ presented higher $\phi$ than the plots in the Dry sites $(0.007 \pm 0.001, \mathrm{~F}=28.88, \mathrm{p}<0.0001$, Figure 5). In Atqasuk, $\phi$ did not present a significant trend with time. In Barrow $\phi$ of both the T-CTL and OTC plots in the Dry site presented an increase with time, while the opposite was observed for the OTC plots in the Wet site. However, these relationships were not significant (Figure 5).

\section{Discussion}

We determined the long-term (decadal) effect of passive warming at the two ends of a hydrological gradient in two locations (coastal and inland) in northern Alaska. The significant warming effects on some ecosystem processes along with the changes in the control areas revealed a potential for shift from a $\mathrm{CO}_{2}$ sink to a source, particularly in the Dry areas (Figure 1\&3). Although our study represents a snapshot of the growing season during each sampling year, the peak season measurements can serve as valid proxies to evaluate the long-term changes in some ecosystem processes, especially changes in the photosynthetic capacity and microbial activity (Stow et al. 1993, Boelman et al. 2003, Epstein et al. 2004). 
The relationship between TDD and year showed that the Barrow location has experienced a significant increase in temperature in the past decade. In Atqasuk, although the temperature presented an upward trend, the increase was not significant. Similar to our findings, there is recent evidence that showed a significant increase of the summer temperature along the coast of the Chukchi and Bering Seas (Bhatt et al. 2010). Bhatt et al. (2010) suggests that the warming trend along the arctic coast is associated with the decrease in sea ice near the coast. Current models predict a continued increase in temperatures in some areas of the Arctic (IPCC 2007, Solomon et al. 2009), which most likely would negatively affect sea ice extent and as a consequence present a positive feedback to warming of the areas near the arctic coast. Increased temperatures can potentially reduce water availability via evapotranspiration or thickening of the active layer (IPCC 2007). However, a decrease in albedo in the ocean would likely increase water temperature and evaporation (Swann et al. 2010), and as a result the potential for rain events could increase (IPCC 2007).

A temperature increase can trigger a change in the source/sink potential of the systems, particularly in Barrow. Our ER data did not show a significant trend with year for any of the locations, sites and treatments except for the OTC plots in the Wet site in Barrow; however, the relationship of ER with temperature, although weak in some plots was significant in almost all locations, sites and treatments (Table 2 and 3). The significant relationship between ER and temperature suggests that the systems respond to temperature, but other local conditions (such as hydrology, soil temperature, vegetation, soil organic matter, among others) might strengthen or dampen the effect of an increase in regional temperatures. 
Gross primary productivity was greater in Barrow than in Atqasuk, at both the Dry and Wet sites (Figure 1), and the Wet sites presented higher rates than the Dry sites. Although on average the OTC plots presented higher GPP rates than the T-CTL, at each location the differences were not significant for any of the sites. The small effect of the warming treatment on the GPP suggests that: 1) the increase in temperature was not sufficiently large; 2) that these ecosystems are less responsive to warming in the longterm; or 3) that a significant response to warming occurred early in the treatment but had diminished by the time flux measurements began. The $\mathrm{CO}_{2}$ flux measurements were initiated several years after the establishment of the warming experiment, however, biomass and canopy measurement recorded by Hollister et al. (2005b) showed a positive response to warming in both sites and locations. Warming increased productivity and above ground biomass, and eventually the amount of standing dead biomass (Hollister et al. 2005b). An increase in the standing biomass can bring about self-shading and soil insulation reducing light penetration, negatively affecting photosynthesis, especially of understory species such as mosses, and reducing soil temperatures (Hollister et al. 2005b, Street et al. 2007). If so, an initial positive response to warming could have been followed by a down regulation in the GPP of the ecosystem as it reached a new steady state that did not differ significantly from the temperature control conditions. Initial temperature stimulation could have promoted an increase in the organic matter decomposition, increasing nutrient availability and uptake causing the reallocation of nutrients into stems and leaf area. As a result of the slow decomposition rates of some plant material (Hobbie 1996), reallocation of nutrients into woody stems and mosses can cause these nutrients to be locked up for a long period reducing the overall nutrient 
availability of the ecosystem. Therefore, factors such as self-shading, reallocation and decrease in nutrient availability can play an important role in ameliorating the long-term effects of increased temperature. During previous research at the same study sites, Hollister et al. (2005b) hypothesized that the long-term responses to warming of the sites at Atqasuk will eventually be larger than those of the Barrow. However, we did not observe large differences in the response between sites during the period of our study, though the Barrow plots continue to respond more readily to warming.

Similar to GPP, ER presented a positive response to warming, and the effect was larger in the sites at the Barrow location. Contrary to what Hollister et al. (2005) expected, the long-term response of the Atqasuk location has not been strong. In the Dry site warming slightly increased ER, but very dry conditions present at this site might over time be limiting microbial activity (Allison and Treseder 2008). In the Wet site the large amount of standing biomass in the OTC plots, previously documented by Hollister et al (2005), reduced the warming effect of the OTCs on the soil. Similarly, the OTC plots in the Barrow Wet site showed a considerable presence of dead standing biomass. In this site the difference between T-CTL and OTC plots was also not significant. The lack of a significant response of ER to warming in the Wet sites at the two locations suggests: 1) that the dead standing biomass has created an effective insulating layer that reduces the effect of warming; or 2) that after an initial response to warming that promoted the increase in biomass, these sites might have reach a steady state adapted to the warming treatment. Conversely, the OTC plots located at the Dry site presented significantly higher ER rates than those of the T-CTL plots. This result suggests that in contrast to the plots located at the Wet sites in both places, warming still had an effect on the $\mathrm{CO}_{2}$ flux 
components of the plots in the Dry sites. Barrow sites presented a stronger warming effect than Atqasuk; a potential explanation is that as a result of the low summer temperatures and cloudy conditions that characterized the weather in Barrow (Brown et al. 1980), the ecosystem was more temperature limited. However, the lack of significant correlation of the OTC plots in the Dry site with air temperature (Table 3) indicates that other factors such as precipitation might be affecting the ER rates of this site across years. Oberbauer et al (2007) reported unexplained out-gassing events in the OTC plots in the Dry site of Barrow, suggesting that these sporadic events could have reduced the relationship between ER and temperature. The GPP of the OTC plots of the Dry site in Barrow was higher as compared to the GPP of the OTC plots in the Dry site in Atqasuk, but regardless of higher photosynthesis, the system was still not capable of shifting from a source to a sink. Alternative to some level of acclimatization by the vegetation and processes, the availability and depletion of below ground organic matter could also affect the responses of ER to warming (Hartley et al. 2008).

\section{Location and site effects on changes of ecosystem flux characteristics}

In response to changes in temperature, some physiological characteristics of the ecosystem might acclimatize to new thermal regimes (Oechel et al. 2000). In temperature-limited system such as the Arctic (Sutton 1969, Anderson and McNaughton 1973), warming is likely to increase the light compensation point as a result of the disproportional effect on respiration (Rawat and Purohit 1991). Although GPP and ER readily respond to temperature, ER in the short-term can react more quickly than GPP, therefore increasing the amount of light required to keep the system in balance or 
functioning as a sink (Smith et al. 1976). The GPP response to temperature might be limited in the short-term as a result of the built-in system lags in nutrient reallocation and leaf area production and development. In the Dry sites at both locations, the LCP of the OTC plots was higher than that of the T-CTL plots, while in the Wet sites at both locations the LCP did not differ. We expected that as a result of the large supply of soil organic carbon, an increase in temperature should positively affect microbial activity and therefore increase the LCP, but the relationship was not significant. In the Wet sites the LCP was lower than that in the Dry sites, with no difference between the OTC and TCTL plots, suggesting that the warming effect on the soil processes was reduced by the insulating effect of the increase in standing dead or by the presence of waterlogged soils. Water-saturated soils would negatively affect ER, decreasing the LCP. Alternatively, an increase in the photosynthetic capacity of the system can also explain low LCP.

The apparent quantum yield $(\phi)$ is a physiological parameter importantly affected by the seasonal development of leaf area (Ogren 1993, Street et al. 2007). However it is also affected by temperature and total leaf area (Ehleringer and Bjorkman 1977, Street et al. 2007). Therefore, a shift in $\phi$ at peak season across years could be associated with a change in the photosynthetic efficiency of the system as result of a change in temperature or a shift in leaf area. Additionally, the ecosystem structure, and physical parameters such as moisture can also affect $\phi$. In Atqasuk the plots at the Wet site presented on average higher $\phi$ than the plots at the Dry site with no significant trend with year. In Barrow, $\phi$ was also higher in the plots in the Wet site than in plots of the Dry site, but with an apparent downward trend in the Wet plots and an upward trend in the Dry plots. Although these trends are not significant, they suggest a potential change in the 
photosynthetic capacity of the system associated with a shift in species composition or an increase in shading as a result of higher dead standing biomass (Hollister et al. 2005b).

\section{Previous findings}

Long-term effects of warming on arctic ecosystem processes have been addressed previously (Hobbie and Chapin 1998, Shaver et al. 1998, Hollister et al. 2005b, Hollister et al. 2006, Shaver et al. 2006, Oberbauer et al. 2007); however, the results obtained from these experiments were mixed, with results ranging from strong responses to warming to small or non-significant responses. Similarly, our results showed a significant warming effect in some sites and not in others. For instance, warming experiments done in a wet sedge tundra near Prudhoe Bay, Alaska, showed little response of the gross ecosystem photosynthesis (GEP) to warming (Oechel et al. 1998). Contrary to what Hollister et al. (2005a) found in our study sites, where the ecosystem quickly responded to warming by increasing canopy height and standing dead, Oechel et al. (1998) suggested that the lack of an initial ecosystem response to warming in their sites was a result of a lag in the effectiveness of the warming treatment. Similar to ecosystem response in our sites (Hollister et al. 2005a), Shaver et al. (1998) found a positive trend to the increase in above ground biomass in response to warming in a wet sedge tundra near Toolik Lake, Alaska. Shaver et al. (1998) also found a significant positive response of GEP, ER, and NEE to warming. At the same study sites, Johnson et al. (2000) found that after eight years of chronic warming, the increased temperatures had a small effect on the $\mathrm{CO}_{2}$ flux components. Oechel et al. (2000) reported acclimatization of the ecosystem to a decadal longer warming. They found that the ecosystem was capable of returning to summer sink 
activity after a period of substantial $\mathrm{CO}_{2}$ losses. These three studies present similar results to trends observed in our study and by Hollister et al. (2005a), where warming had a positive initial effect on canopy structure and biomass production, but showed a decrease in the long-term effect of warming on the $\mathrm{CO}_{2}$ components, especially at the Wet sites. The $\mathrm{CO}_{2}$ flux measurements at our sites started several years after the establishment of the warming manipulation. Consequently, we did not measure the initial response of the $\mathrm{CO}_{2}$ components to warming, but the positive responses observed in the ecosystem structure by Hollister et al. (2005a) should serve as a good proxy for a positive initial response of ecosystem GPP to warming.

The warming effects on Dry sites found in previous studies are in accord with the results seen in our study. Christensen et al. (1997) and Jones et al. (1998) found that warming had positive effect on both GEP and ER, with the effect on the latter being larger, causing in most cases a shift of the ecosystem from a $\mathrm{CO}_{2}$ sink to a $\mathrm{CO}_{2}$ source. Conversely, Illeris et al. (2004) found that after 11 years of experimental warming in a subarctic dry heath, the effects on the $\mathrm{CO}_{2}$ flux components were not significant. These mixed results suggest that spatial heterogeneity and temporal scales play an important role in the effect of warming on the tundra and that ecosystems can respond and acclimatize at different rates to changes in temperature.

\section{Long-term ecosystem response to warming}

Responses of ecosystems to warming operate at different time scales depending on physiological and physical constraints (Shaver et al. 2000). In arctic ecosystems, as a result of the temperature limitation (Sutton 1969, Anderson and McNaughton 1973), an 
initial response to warming can be an increase in GPP and ER with time scales of hours to days to two years. The initial increase in ER is likely to promote organic matter breakdown that would, in turn, result in an increase of the soil nutrient availability (Hobbie 1996, Thormann et al. 2004). Higher nutrient availability can promote an increase in the microbial community and ER (Shaver et al. 1998). As a result of the short life cycles of the microbial community (Edwards et al. 2006, Cleveland et al. 2007), nutrients in the microbial biomass will eventually be released into the soil for plant uptake and reallocation. Because of the slow decomposition rates of plant matter in the arctic ecosystems and the intrinsic importance of the litter quality in the decomposition process (Aber et al. 1990, Hobbie 1996), nutrient reallocation into recalcitrant plant tissue (woody and moss tissue) can represent a temporary loss of nutrients from the system (Rastetter et al. 1991). Therefore, the process of nutrient reallocation can over a relatively short period down-regulate both GPP and ER, causing the system to converge into a potential NEE balance after a period of increased biomass (Shaver et al. 2000).

Over time, changes in species composition, quantity and quality of the organic matter, and microbial community, among others, play a role in the time for reintegration of nutrients into the system (Zak and Kling 2006, Clemmensen et al. 2008). For instance, a microbial community dominated by fungus can more readily breakdown woody material than can bacteria (Thormann et al. 2004), however, waterlogged soil can negatively affect fungal and microbial activity, and thus slow down the decomposition process.

Factorial experiments that have incorporated temperature and nutrient manipulations in the Arctic have shown that after an initial positive effect of warming, 
the temperature effect decreases (Shaver et al. 1998), while the nutrient additions continue to have a positive effect on the growth, and decomposition, promoting a change in species composition (Hobbie and Chapin 1998, Shaver et al. 1998). Thus, in the shortterm an increase in temperature can have a positive effect on the ecosystem metabolic activities, but in the long-term (if moisture is not limited) a decrease in nutrient availability and plant acclimatization can reduce the effect of temperature. Therefore, predictions about the long-term effects of increased temperature on the ecosystem processes become difficult because the Dry areas continue to respond to temperature by losing $\mathrm{CO}_{2}$ while Wet areas respond by increasing biomass.

\section{Conclusions and future implications}

As result of the small ratios of GPP/ER, small changes in the photosynthetic capacity, resulting from a change in species composition or stress and an increase in the microbial activity, could turn some dry areas of the Arctic into $\mathrm{CO}_{2}$ sources. The OTC plots in the Barrow Dry sites are examples of the effect of warming on the reduction of the ecosystem $\mathrm{CO}_{2}$ sink capacity. Although these plots presented an increase in GPP, the increase in ER was larger resulting in a net carbon loss.

Some arctic ecosystems might be able to acclimatize at the decadal scale to changes in temperature, and then reach a new steady state after increasing above ground biomass. Other areas, where the existing plant community cannot take advantage of an increase in nutrient availability, might continue to exhibit $\mathrm{CO}_{2}$ losses for longer period.

We conclude that: 1) even though we found a significant correlation between ER and temperature, the data do not show evidence of a decrease in the sink capacity of the 
T-CTL plots of the study sites; 2) warming decreased the sink potential of the Dry sites, especially at Barrow; 3) although we observed an increase of the standing dead biomass at the Wet sites, we did not observe an increase in the ER, and on average the Wet sites were $\mathrm{CO}_{2}$ sinks; 4) warming had an stronger effect on the coastal site of Barrow than inland site of Atqasuk, with a particularly strong effect on the Dry site.

This study revealed that coastal locations can respond differently to warming and that topography affects the magnitude of ecosystem response to warming. Also, the relatively quick nutrient reallocation (into standing dead biomass) at some sites suggests that arctic ecosystems can readily respond to warming, but nutrient reallocation and nutrients locked up in new organic matter can down-regulate GPP and ER. Therefore, nutrient reallocation could function as a process to ameliorate the effect of increased temperatures. Processes such as decomposition rates, change in species composition, herbivory, and dead standing biomass quality need to be accounted for to further understand the long-term responses of arctic ecosystems to warming.

\section{Acknowledgments}

This research was conducted on the Barrow Environmental Observatory, a private reserve owned by the Ukpeagvik Inupiat Corporation (UIC). We are grateful to the Barrow Scientific Consortium (BASC), UIC, the North Slope Borough, Florida International University, Jose Luciani, Andrea Kuchy, Jason Shone, Robert Wilder, and Elizabeth Eubanks for their great contribution. 


\section{Tables}

Table 1. Summary table of the mixed model effect analysis. Location, site, and treatment where fixed effects, year was the repeated measures effect. Gross primary productivity (GPP), net ecosystem exchange (NEE), ecosystem respiration (ER). We used type III tests of fixed effects and first-order autoregressive structure with heterogeneous variances for the residuals.

\begin{tabular}{|c|c|c|c|c|c|}
\hline Variable & Source & $\begin{array}{c}\text { Numerator } \\
d f\end{array}$ & $\begin{array}{c}\text { Denominator } \\
d f^{*}\end{array}$ & $\boldsymbol{F}$ & Sig. \\
\hline \multirow[t]{7}{*}{ GPP } & Location & 1 & 89.8 & 45.1 & $<0.0001$ \\
\hline & Site & 1 & 89.8 & 166.4 & $<0.0001$ \\
\hline & Treatment & 1 & 89.8 & 6.3 & 0.014 \\
\hline & Location $*$ Site & 1 & 89.8 & 1.0 & 0.310 \\
\hline & Location $*$ Treatment & 1 & 89.8 & 0.2 & 0.637 \\
\hline & Site ${ }^{*}$ Treatment & 1 & 89.8 & 0.3 & 0.581 \\
\hline & Location*Site*Treatment & 1 & 89.8 & 0.4 & 0.509 \\
\hline \multirow[t]{7}{*}{$N E E$} & Location & 1 & 135.2 & 2.1 & 0.146 \\
\hline & Site & 1 & 135.2 & 141.4 & $<0.0001$ \\
\hline & Treatment & 1 & 135.2 & 9.0 & 0.003 \\
\hline & Location $*$ Site & 1 & 135.2 & 0.8 & 0.383 \\
\hline & Location $*$ Treatment & 1 & 135.2 & 9.2 & 0.003 \\
\hline & Site ${ }^{*}$ Treatment & 1 & 135.2 & 18.0 & $<\mathbf{0 . 0 0 0 1}$ \\
\hline & Location*Site*Treatment & 1 & 135.2 & 7.9 & 0.006 \\
\hline \multirow[t]{7}{*}{$E R$} & Location & 1 & 118.5 & 53.4 & $<0.0001$ \\
\hline & Site & 1 & 118.5 & 11.3 & 0.001 \\
\hline & Treatment & 1 & 118.5 & 23.5 & $<0.0001$ \\
\hline & Location * Site & 1 & 118.5 & 2.4 & 0.127 \\
\hline & Location $*$ Treatment & 1 & 118.5 & 8.8 & 0.004 \\
\hline & Site ${ }^{*}$ Treatment & 1 & 118.5 & 13.0 & $<0.0001$ \\
\hline & Location*Site*Treatment & 1 & 118.5 & 1.7 & 0.198 \\
\hline
\end{tabular}

* The denominator degrees of freedom were adjusted for unequal variances for each variable 
Table 2. Linear relationship between year and ecosystem respiration (ER) for Atqasuk and Barrow for the Dry and Wet sites. Treatments: temperature control plots (T-CTL), and warmed plots (open top chambers, OTC).

\begin{tabular}{lllrrr}
\hline \multicolumn{1}{c}{ Location } & Site & Treatment & $R^{2}$ Adj. & Fvalue & P-value \\
\hline Atqasuk & Dry & T-CTL & 0.07 & 3.06 & 0.064 \\
$\mathrm{~N}=35$ & Dry & OTC & 0.012 & 1.427 & 0.241 \\
& Wet & T-CTL & -0.03 & 0.123 & 0.728 \\
& Wet & OTC & 0.007 & 3.524 & 0.069 \\
\cline { 2 - 6 } Barrow & Dry & T-CTL & 0.05 & 3.4638 & 0.069 \\
$\mathrm{~N}=45$ & Dry & OTC & -0.01 & 0.303 & 0.585 \\
& Wet & T-CTL & 0.06 & 3.953 & 0.053 \\
& Wet & OTC & $\mathbf{0 . 1 8}$ & $\mathbf{1 0 . 8 2 3}$ & $\mathbf{0 . 0 0 2}$ \\
\hline
\end{tabular}

Table 3. Linear relationship between peak season air temperature and ecosystem respiration (ER) for Atqasuk and Barrow for the Dry and Wet sites. Treatments: temperature control plots (T-CTL), and warmed plots (open top chambers, OTC).

\begin{tabular}{lllrrr}
\hline \multicolumn{1}{c}{ Location } & Site & Treatment & $R^{2}$ Adj. & F value & \multicolumn{1}{c}{ P-value } \\
\hline Atqasuk & Dry & T-CTL & 0.46 & 29.75 & $<\mathbf{0 . 0 0 0 1}$ \\
N=35 & Dry & OTC & 0.56 & 44.88 & $<\mathbf{0 . 0 0 0 1}$ \\
& Wet & T-CTL & 0.37 & 20.64 & $<\mathbf{0 . 0 0 0 1}$ \\
& Wet & OTC & 0.24 & 11.49 & $\mathbf{0 . 0 0 1 8}$ \\
\cline { 2 - 6 } Barrow & Dry & T-CTL & 0.21 & 13.29 & $\mathbf{0 . 0 0 0 7}$ \\
N=45 & Dry & OTC & -0.01 & 0.7 & 0.41 \\
& Wet & T-CTL & 0.27 & 17.48 & $\mathbf{0 . 0 0 0 1}$ \\
& Wet & OTC & 0.37 & 26.46 & $<\mathbf{0 . 0 0 0 1}$ \\
\hline
\end{tabular}


Figures

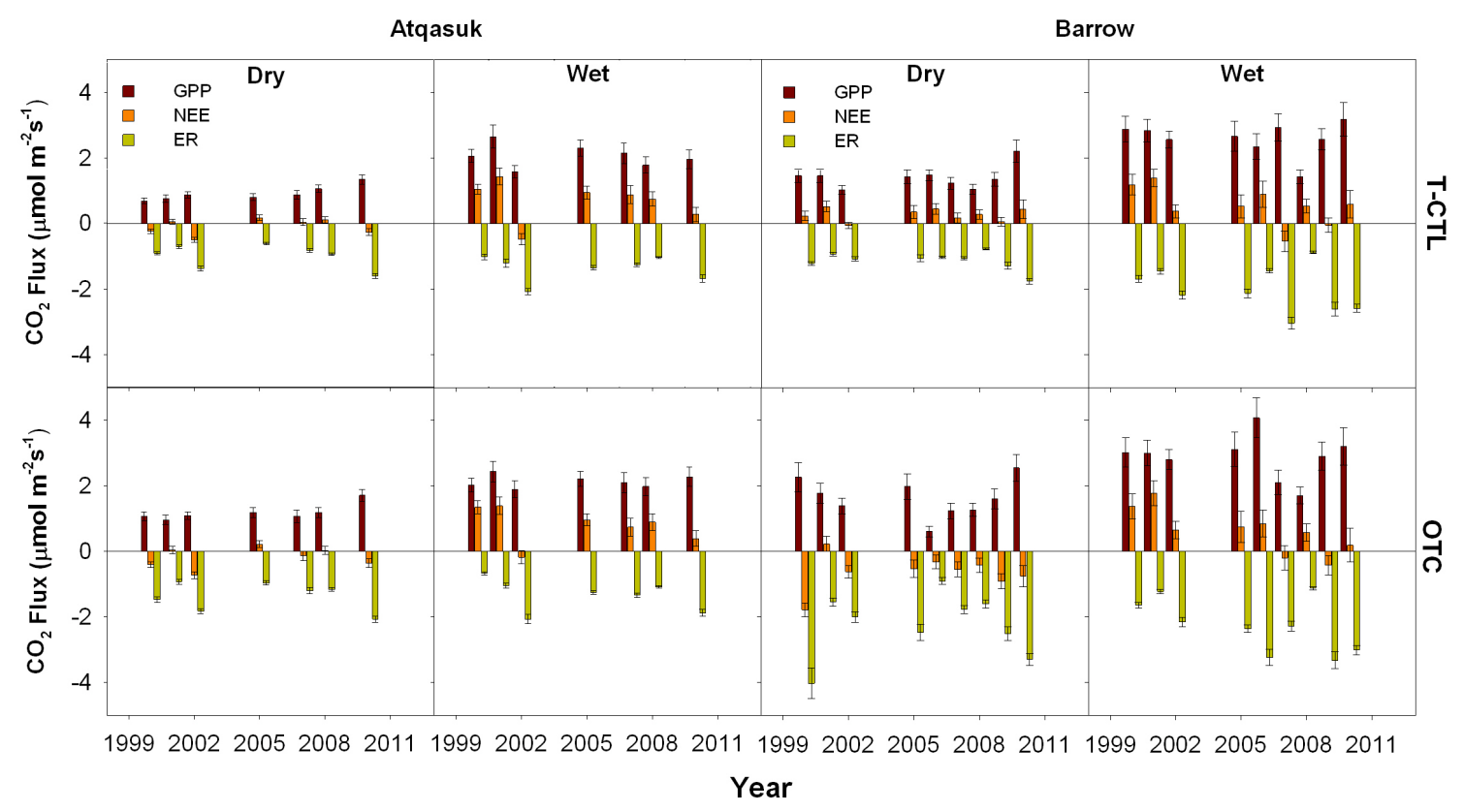

Figure 1. Peak season gross primary productivity (GPP), net ecosystem exchange (NEE), and ecosystem respiration (ER) for temperature control plots (T-CTL), and warmed plots (open top chambers, OTC) in Dry and Wet sites at Atqasuk and Barrow. Bars represent peak season daily means, and error bars one standard error of the mean. 


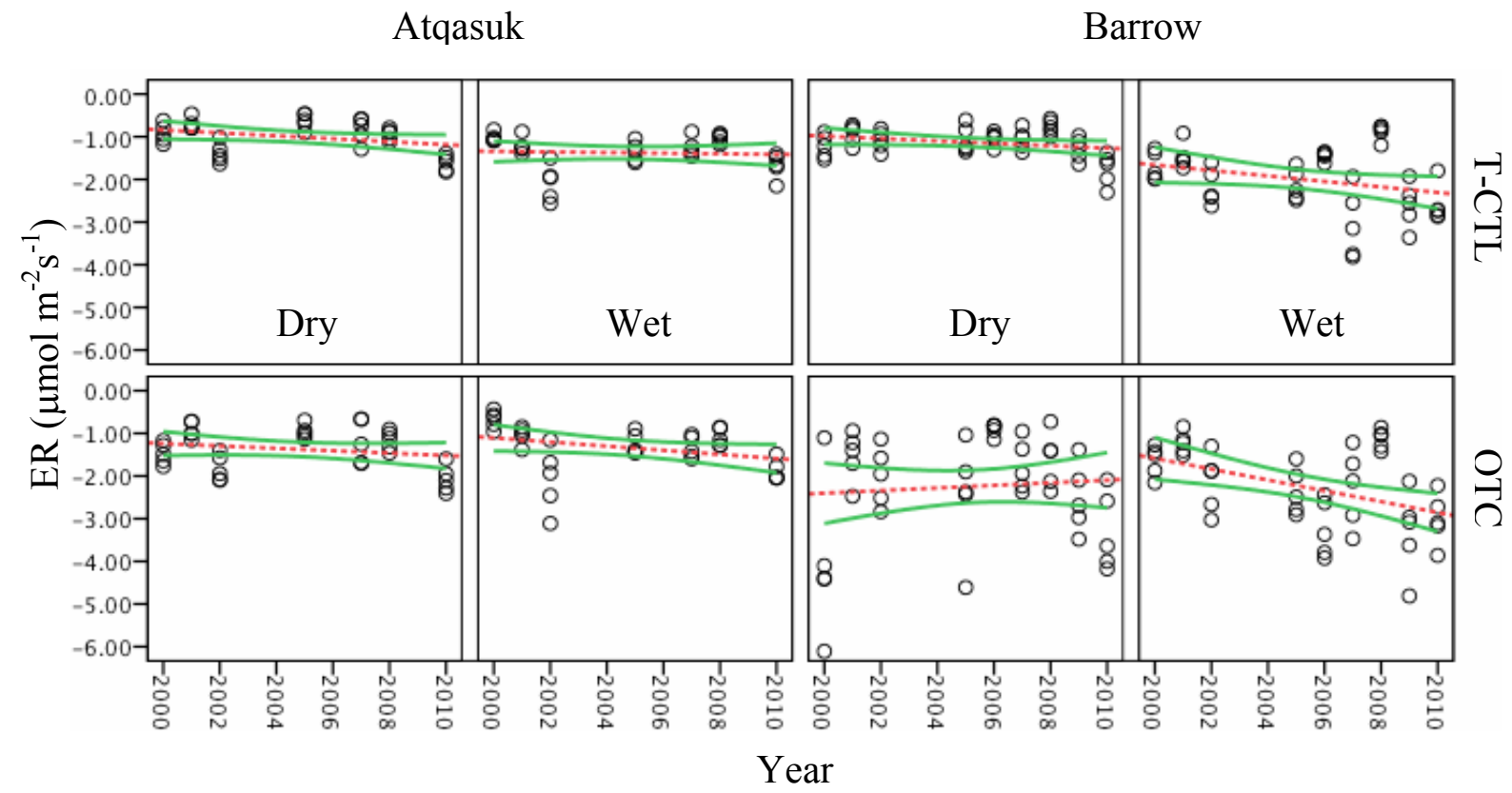

Figure 2. Linear relationship between ecosystem respiration (ER) and year at peak season for temperature control plots (T-CTL), and warmed plots (open top chambers, OTC) in Dry and Wet sites at Atqasuk and Barrow. 


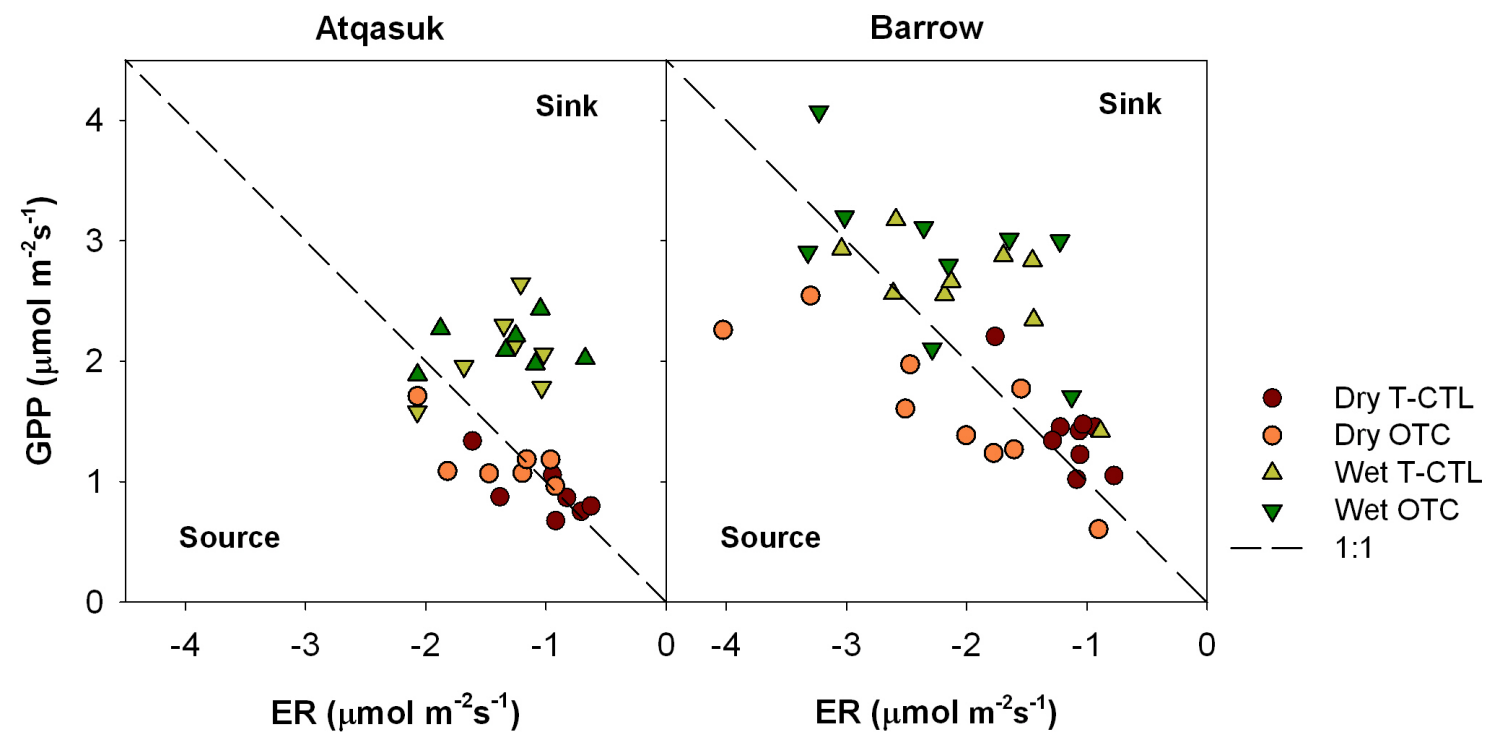

Figure 3. Ratios of gross primary productivity (GPP) to ecosystem respiration (ER) for temperature control plots (T-CTL), and warmed plots (open top chambers, OTC) in Dry and Wet sites at Atqasuk and Barrow. Dashed line (1:1) represents the $\mathrm{CO}_{2}$ balance line at which net ecosystem exchange is zero. GPP/ER ratios less than one represent $\mathrm{CO}_{2}$ sources. 


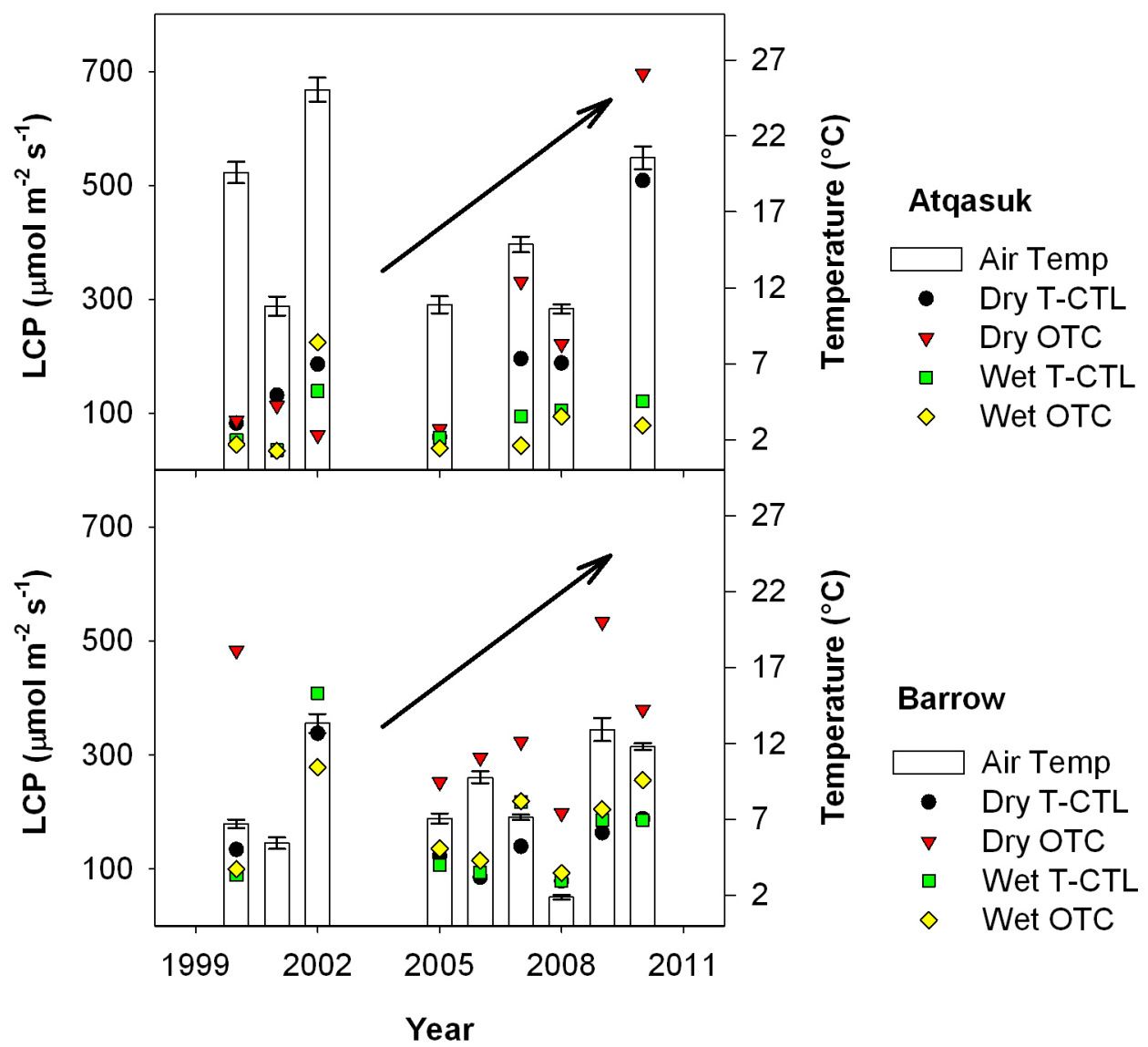

Figure 4. Light compensation point (LCP) for the warmed plots (open top chambers, OTC) and temperature control plots (T-CTL) in the Dry and Wet site at Atqasuk and Barrow. LCP was calculated using Eq. 2. Bars represent air temperature and error bars the standard error of the mean. 


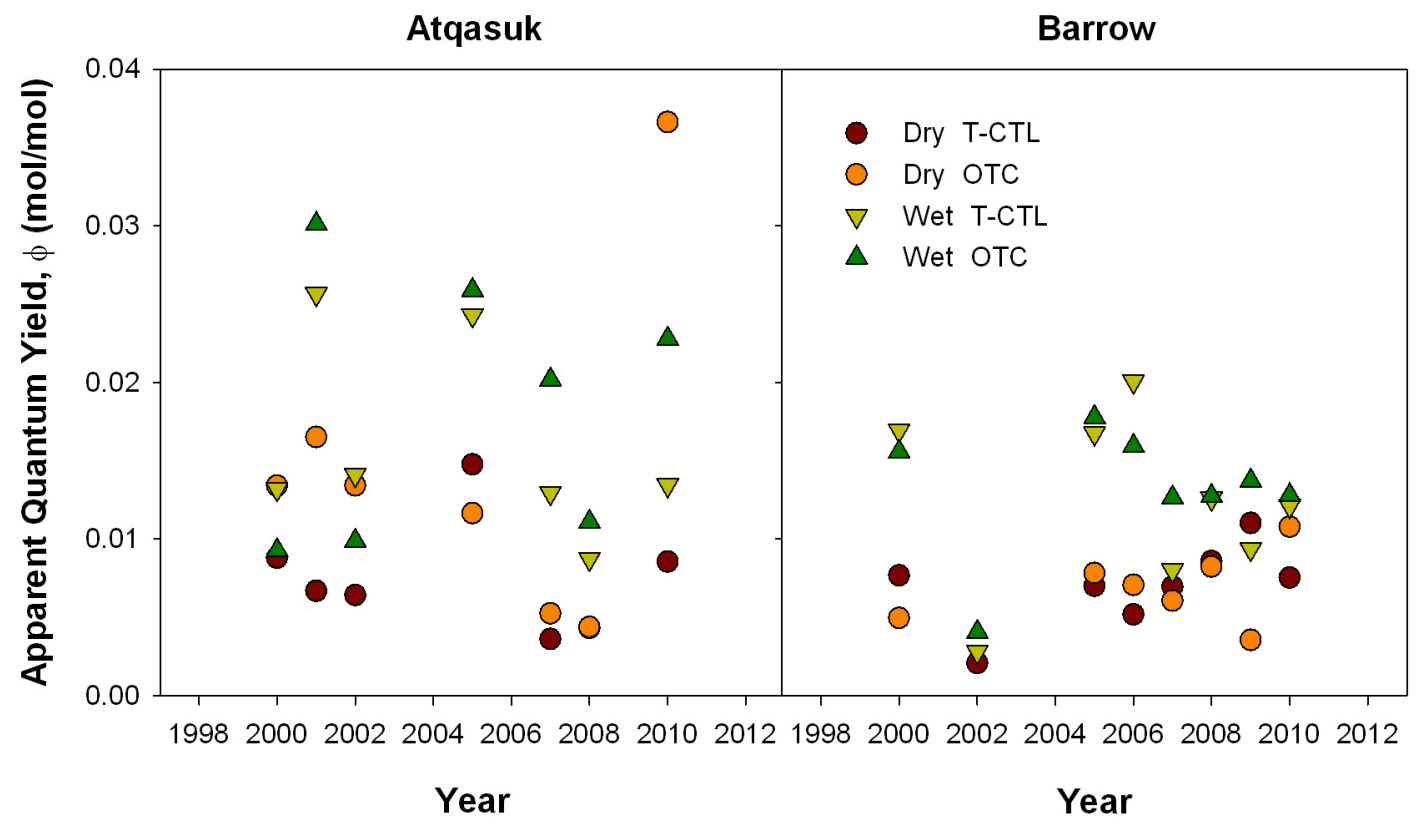

Figure 5. Apparent quantum yield $(\phi)$ for the warmed (open top chambers, OTC) and temperature control plots (T-CTL) in the Dry and Wet site at Atqasuk and Barrow. $\phi$ was calculated using Eq. 2. $\phi$ describes the moles of $\mathrm{CO}_{2}$ fixed by moles of light absorbed. 


\section{LITERATURE CITED}

Aber, J. D., J. M. Melillo, and C. A. McClaugherty. 1990. Predicting long-term patterns of mass-loss, nitrogen dynamics, and soil organic-matter formation from initial fine litter chemistry in temperate forest ecosystems. Canadian Journal of BotanyRevue Canadienne De Botanique 68:2201-2208.

Allison, S. D. and K. K. Treseder. 2008. Warming and drying suppress microbial activity and carbon cycling in boreal forest soils. Global Change Biology 14:2898-2909.

Anderson, J. E. and S. J. McNaughton. 1973. Effects of Low Soil Temperature on Transpiration, Photosynthesis, Leaf Relative Water Content, and Growth Among Elevationally Diverse Plant Populations. Ecology 54:1220-1233.

Bhatt, U. S., D. A. Walker, M. K. Raynolds, J. C. Comiso, H. E. Epstein, G. S. Jia, R. Gens, J. E. Pinzon, C. J. Tucker, C. E. Tweedie, and P. J. Webber. 2010. Circumpolar Arctic Tundra Vegetation Change Is Linked to Sea Ice Decline. Earth Interactions 14:8.

Bockheim, J. G., L. R. Everett, K. M. Hinkel, F. E. Nelson, and J. Brown. 1999. Soil organic carbon storage and distribution in Arctic Tundra, Barrow, Alaska. Soil Science Society of America Journal 63:934-940.

Boddy, E., P. Roberts, P. W. Hill, J. Farrar, and D. L. Jones. 2008. Turnover of low molecular weight dissolved organic C (DOC) and microbial C exhibit different temperature sensitivities in Arctic tundra soils. Soil Biology \& Biochemistry 40:1557-1566.

Boelman, N. T., M. Stieglitz, H. M. Rueth, M. Sommerkorn, K. L. Griffin, G. R. Shaver, and J. A. Gamon. 2003. Response of NDVI, biomass, and ecosystem gas exchange to long-term warming and fertilization in wet sedge tundra. Oecologia 135:414-421.

Brooker, R. and R. van der Wal. 2003. Can soil temperature direct the composition of high arctic plant communities? Journal of Vegetation Science 14:535-542.

Brown, J., K. R. Everett, P. J. Webber, S. F. M. Jr., and D. F. Murray. 1980. The coastal tundra at Barrow. Pages 1-29 in J. Brown, P. C. Miller, L. L. Tieszen, and F. L. Bunnell, editors. An arctic ecosystem: the coastal tundra at Barrow, Alaska. Dowden, Hutchinson, and Ross, Stroudsburg, Pennsylvania, USA.

Callaghan, T. V., L. O. Bjorn, Y. Chernov, T. Chapin, T. R. Christensen, B. Huntley, R. A. Ims, M. Johansson, D. Jolly, S. Jonasson, N. Matveyeva, N. Panikov, W. Oechel, and G. Shaver. 2004. Effects on the function of arctic ecosystems in the short- and long-term perspectives. Ambio 33:448-458. 
Chapin, F. S. and G. R. Shaver. 1996. Physiological and growth responses of arctic plants to a field experiment simulating climatic change. Ecology 77:822-840.

Chapin, F. S., G. R. Shaver, A. E. Giblin, K. J. Nadelhoffer, and J. A. Laundre. 1995. Responses of Arctic Tundra to Experimental and Observed Changes in Climate. Ecology 76:694-711.

Chivers, M. R., M. R. Turetsky, J. M. Waddington, J. W. Harden, and A. D. McGuire. 2009. Effects of Experimental Water Table and Temperature Manipulations on Ecosystem $\mathrm{CO}_{2}$ Fluxes in an Alaskan Rich Fen. Ecosystems 12:1329-1342.

Christensen, T. R., A. Michelsen, S. Jonasson, and I. K. Schmidt. 1997. Carbon dioxide and methane exchange of a subarctic heath in response to climate change related environmental manipulations. Oikos 79:34-44.

Clemmensen, K. E., P. L. Sorensen, A. Michelsen, S. Jonasson, and L. Strom. 2008. Sitedependent $\mathrm{N}$ uptake from $\mathrm{N}$-form mixtures by arctic plants, soil microbes and ectomycorrhizal fungi. Oecologia 155:771-783.

Cleveland, C. C., D. R. Nemergut, S. K. Schmidt, and A. R. Townsend. 2007. Increases in soil respiration following labile carbon additions linked to rapid shifts in soil microbial community composition. Biogeochemistry 82:229-240.

Dowding, P. and P. Widden. 1974. Some relationships between fungi and their environment in tundra regions. Pages 123-150 in A. J. Holding, O. W. Heal, S. F. MacLean, and P. W. Flanagan, editors. Soli Organisms and decomposition in Tundra. Swedish IBP, Stockholm, Sweden.

Edwards, K. A., J. McCulloch, G. P. Kershaw, and R. L. Jefferies. 2006. Soil microbial and nutrient dynamics in a wet Arctic sedge meadow in late winter and early spring. Soil Biology \& Biochemistry 38:2843-2851.

Ehleringer, J. and O. Bjorkman. 1977. Quantum yields for $\mathrm{CO}_{2}$ uptake in $\mathrm{C}_{3}$ and $\mathrm{C}_{4}$ plants - dependence on temperature, $\mathrm{CO}_{2}$, and $\mathrm{O}_{2}$ concentration. Plant Physiology 59:86-90.

Epstein, H. E., M. P. Calef, M. D. Walker, F. S. Chapin, and A. M. Starfield. 2004. Detecting changes in arctic tundra plant communities in response to warming over decadal time scales. Global Change Biology 10:1325-1334.

Gebauer, R. L. E., J. D. Tenhunen, and J. F. Reynolds. 1996. Soil aeration in relation to soil physical properties, nitrogen availability, and root characteristics within an arctic watershed. Plant and Soil 178:37-48. 
Giblin, A. E., K. J. Nadelhoffer, G. R. Shaver, J. A. Laundre, and A. J. McKerrow. 1991. Biogeochemical diversity along a riverside toposequence in arctic Alaska. Ecological Monographs 61:415-435.

Hartley, I. P., D. W. Hopkins, M. H. Garnett, M. Sommerkorn, and P. A. Wookey. 2008. Soil microbial respiration in arctic soil does not acclimate to temperature. Ecology Letters 11:1092-1100.

Haugen, R. K. and J. Brown. 1980. Coastal-inland distributions of summer airtemperature and precipitation in northern Alaska. Arctic and Alpine Research 12:403-412.

Henry, G. H. R. and U. Molau. 1997. Tundra plants and climate change: the International Tundra Experiment (ITEX). Global Change Biology 3:1-9.

Hobbie, S. E. 1996. Temperature and plant species control over litter decomposition in Alaskan tundra. Ecological Monographs 66:503-522.

Hobbie, S. E. and F. S. Chapin. 1998. Response of tundra plant biomass, aboveground production, nitrogen, and $\mathrm{CO}_{2}$ flux to experimental warming. Ecology 79:15261544.

Hobbie, S. E., J. P. Schimel, S. E. Trumbore, and J. R. Randerson. 2000. Controls over carbon storage and turnover in high-latitude soils. Global Change Biology 6:196210.

Hodkinson, I. D., N. R. Webb, J. S. Bale, and W. Block. 1999. Hydrology, water availability and tundra ecosystem function in a changing climate: the need for a closer integration of ideas? Global Change Biology 5:359-369.

Hollister, R. D. and P. J. Webber. 2000. Biotic validation of small open-top chambers in a tundra ecosystem. Global Change Biology 6:835-842.

Hollister, R. D., P. J. Webber, and C. Bay. 2005a. Plant response to temperature in Northern Alaska: Implications for predicting vegetation change. Ecology 86:1562-1570.

Hollister, R. D., P. J. Webber, and C. E. Tweedie. 2005b. The response of Alaskan arctic tundra to experimental warming: differences between short- and long-term responses. Global Change Biology 11:525-536.

Hollister, R. D., P. J. Webber, F. E. Nelson, and C. E. Tweedie. 2006. Soil thaw and temperature response to air warming varies by plant community: Results from an open-top chamber experiment in northern Alaska. Arctic Antarctic and Alpine Research 38:206-215. 
Illeris, L., S. M. Konig, P. Grogan, S. Jonasson, A. Michelsen, and H. Ro-Poulsen. 2004. Growing-season carbon dioxide flux in a dry subarctic heath: Responses to longterm manipulations. Arctic Antarctic and Alpine Research 36:456-463.

Intergovernmental Panel on Climate Change (IPCC). 2007. Climate Change 2007: The Physical Science Basis. Contribution of Working Group I to the Fourth Assessment Report (AR4) of the Intergovernmental Panel on Climate Change, edited by S. Solomon et al., 996 pp., Cambridge Univ. Press, Cambridge, U. K.

Johnson, L. C., G. R. Shaver, D. H. Cades, E. Rastetter, K. Nadelhoffer, A. Giblin, J. Laundre, and A. Stanley. 2000. Plant carbon-nutrient interactions control $\mathrm{CO}_{2}$ exchange in Alaskan wet sedge tundra ecosystems. Ecology 81:453-469.

Jones, M. H., J. T. Fahnestock, D. A. Walker, M. D. Walker, and J. M. Welker. 1998. Carbon dioxide fluxes in moist and dry arctic tundra during season: Responses to increases in summer temperature and winter snow accumulation. Arctic and Alpine Research 30:373-380.

Komarkova, V. and P. J. Webber. 1980. Two low Arctic vegetation maps near Atkasook, Alaska. Arctic and Alpine Research 4:447-472.

Leverenz, J. W. and P. G. Jarvis. 1979. Photosynthesis in sitka spruce .VIII. Effects of light-flux density and direction on the rate of net photosynthesis and the stomatal conductance of needles. Journal of Applied Ecology 16:919-932.

Marion, G. M., G. H. R. Henry, D. W. Freckman, J. Johnstone, G. Jones, M. H. Jones, E. Levesque, U. Molau, P. Molgaard, A. N. Parsons, J. Svoboda, and R. A. Virginia. 1997. Open-top designs for manipulating field temperature in high-latitude ecosystems. Global Change Biology 3:20-32.

Marshall, B. and P. V. Biscoe. 1980. A model for $\mathrm{C}_{3}$ leaves describing the dependence of net photosynthesis on irradiance. Journal of Experimental Botany 31:29-39.

Michaelson, G. J., C. L. Ping, and J. M. Kimble. 1996. Carbon storage and distribution in tundra soils of Arctic Alaska, USA. Arctic and Alpine Research 28:414-424.

Molau, U. and P. Mølgaard. 1996. International Tundra Experiment (ITEX) manual.in D. P. Center, editor., Copenhagen, Denmark.

Oberbauer, S. F., G. Starr, and E. W. Pop. 1998. Effects of extended growing season and soil warming on carbon dioxide and methane exchange of tussock tundra in Alaska. Journal of Geophysical Research-Atmospheres 103:29075-29082. 
Oberbauer, S. F., J. D. Tenhunen, and J. F. Reynolds. 1991. Environmental-effects on $\mathrm{CO}_{2}$ efflux from water track and tussock tundra in arctic Alaska, USA. Arctic and Alpine Research 23:162-169.

Oberbauer, S. F., C. E. Tweedie, J. M. Welker, J. T. Fahnestock, G. H. R. Henry, P. J. Webber, R. D. Hollister, M. D. Walker, A. Kuchy, E. Elmore, and G. Starr. 2007. Tundra $\mathrm{CO}_{2}$ fluxes in response to experimental warming across latitudinal and moisture gradients. Ecological Monographs 77:221-238.

Oechel, W. C., S. J. Hastings, G. Vourlitis, M. Jenkins, G. Riechers, and N. Grulke. 1993. Recent Change of Arctic Tundra Ecosystems from a Net Carbon-Dioxide Sink to a Source. Nature 361:520-523.

Oechel, W. C., G. L. Vourlitis, S. J. Hastings, R. P. Ault, and P. Bryant. 1998. The effects of water table manipulation and elevated temperature on the net $\mathrm{CO}_{2}$ flux of wet sedge tundra ecosystems. Global Change Biology 4:77-90.

Oechel, W. C., G. L. Vourlitis, S. J. Hastings, R. C. Zulueta, L. Hinzman, and D. Kane. 2000. Acclimation of ecosystem $\mathrm{CO}_{2}$ exchange in the Alaskan Arctic in response to decadal climate warming. Nature 406:978-981.

Ogren, E. 1993. Convexity of the photosynthetic light-response curve in relation to intensity and direction of light during growth. Plant Physiology 101:1013-1019.

Olivas, P. C., S. F. Oberbauer, C. E. Tweedie, W. C. Oechel, and A. Kuchy. 2010. Responses of $\mathrm{CO}_{2}$ flux components of Alaskan coastal plain tundra to shifts in water table. JGR Biosciences. in press

Post, W. M., W. R. Emanuel, P. J. Zinke, and A. G. Stangenberger. 1982. Soil carbon pools and world life zones. Nature 298:156-159.

Rastetter, E. B., M. G. Ryan, G. R. Shaver, J. M. Melillo, K. J. Nadelhoffer, J. E. Hobbie, and J. D. Aber. 1991. A general biogeochemical model describing the responses of the $\mathrm{C}$-cycle and $\mathrm{N}$-cycle in terrestrial ecosystems to changes in $\mathrm{CO}_{2}$, climate, and n-deposition. Tree Physiology 9:101-126.

Rawat, A. S. and A. N. Purohit. 1991. $\mathrm{CO}_{2}$ and water-vapor exchange in 4 alpine herbs at 2 altitudes and under varying light and temperature conditions. Photosynthesis Research 28:99-108. 
Schuur, E. A. G., J. Bockheim, J. G. Canadell, E. Euskirchen, C. B. Field, S. V. Goryachkin, S. Hagemann, P. Kuhry, P. M. Lafleur, H. Lee, G. Mazhitova, F. E. Nelson, A. Rinke, V. E. Romanovsky, N. Shiklomanov, C. Tarnocai, S. Venevsky, J. G. Vogel, and S. A. Zimov. 2008. Vulnerability of permafrost carbon to climate change: Implications for the global carbon cycle. Bioscience 58:701-714.

Shaver, G. R., J. Canadell, F. S. Chapin, J. Gurevitch, J. Harte, G. Henry, P. Ineson, S. Jonasson, J. Melillo, L. Pitelka, and L. Rustad. 2000. Global warming and terrestrial ecosystems: A conceptual framework for analysis. Bioscience 50:871882.

Shaver, G. R., A. E. Giblin, K. J. Nadelhoffer, K. K. Thieler, M. R. Downs, J. A. Laundre, and E. B. Rastetter. 2006. Carbon turnover in Alaskan tundra soils: effects of organic matter quality, temperature, moisture and fertilizer. Journal of Ecology 94:740-753.

Shaver, G. R., L. C. Johnson, D. H. Cades, G. Murray, J. A. Laundre, E. B. Rastetter, K. J. Nadelhoffer, and A. E. Giblin. 1998. Biomass and $\mathrm{CO}_{2}$ flux in wet sedge tundras: Responses to nutrients, temperature, and light. Ecological Monographs 68:75-97.

Smith, E. W., N. E. Tolbert, and H. S. Ku. 1976. Variables Affecting the $\mathrm{CO}_{2}$ Compensation Point. Plant Physiology 58:143-146.

Solomon, S., G.-K. Plattner, R. Knutti, and P. Friedlingstein. 2009. Irreversible climate change due to carbon dioxide emissions. Proceedings of the National Academy of Sciences 106:1704-1709.

Sommerkorn, M. 2008. Micro-topographic patterns unravel controls of soil water and temperature on soil respiration in three Siberian tundra systems. Soil Biology \& Biochemistry 40:1792-1802.

Sommerkorn, M., M. Bolter, and L. Kappen. 1999. Carbon dioxide fluxes of soils and mosses in wet tundra of Taimyr Peninsula, Siberia: controlling factors and contribution to net system fluxes. Polar Research 18:253-260.

Stow, D. A., B. H. Burns, and A. S. Hope. 1993. Spectral, Spatial and Temporal Characteristics of Arctic Tundra Reflectance. International Journal of Remote Sensing 14:2445-2462.

Street, L. E., G. R. Shaver, M. Williams, and M. T. Van Wijk. 2007. What is the relationship between changes in canopy leaf area and changes in photosynthetic $\mathrm{CO}_{2}$ flux in arctic ecosystems? Journal of Ecology 95:139-150. 
Sturm, M., C. Racine, and K. Tape. 2001. Climate change - Increasing shrub abundance in the Arctic. Nature 411:546-547.

Sullivan, P. F., S. J. T. Arens, R. A. Chimner, and J. M. Welker. 2008. Temperature and microtopography interact to control carbon cycling in a high arctic fen. Ecosystems 11:61-76.

Sutton, C. D. 1969. Effect of low soil temperature on phosphate nutrition of plants-A review. Journal of the Science of Food and Agriculture 20:1-3.

Swann, A. L., I. Y. Fung, S. Levis, G. B. Bonan, and S. C. Doney. 2010. Changes in Arctic vegetation amplify high-latitude warming through the greenhouse effect. Proceedings of the National Academy of Sciences of the United States of America 107:1295-1300.

Tarnocai, C., J. G. Canadell, E. A. G. Schuur, P. Kuhry, G. Mazhitova, and S. Zimov. 2009. Soil organic carbon pools in the northern circumpolar permafrost region. Global Biogeochemical Cycles 23:GB2023.

Terashima, I. and T. Saeki. 1985. A new model for leaf photosynthesis incorporating the gradients of light environment and of photosynthetic properties of chloroplasts within a leaf. Annals of Botany 56:489-499.

Thormann, M. N., S. E. Bayley, and R. S. Currah. 2004. Microcosm tests of the effects of temperature and microbial species number on the decomposition of Carex aquatilis and Sphagnum fuscum litter from southern boreal peatlands. Canadian Journal of Microbiology 50:793-802.

Webber, P. J. 1978. Spatial and temporal variation of the vegetation and its production, Barrow, Alaska. Pages 37-112 in L. L. Tieszen, editor. Vegetation and Production Ecology of an Alaskan Arctic Tundra. Springer-Verlag, New York, NY, USA.

Zak, D. R. and G. W. Kling. 2006. Microbial community composition and function across an arctic tundra landscape. Ecology 87:1659-1670. 


\section{Conclusions}

Our work shows that snow-free ecosystem carbon balance is highly sensitive to short-term changes in water table and warming. However, over longer time periods, hydrological and temperature changed soil biophysical properties, nutrient cycles, and other ecosystem structural and functional components that down regulated GPP and ER especially in wet areas. We have shown that following short-term warming and alteration of water table depth, vascular productivity can compensate for increased respiratory losses. Yet, the shift from a carbon sink to source in some arctic ecosystems will depend on: 1) the ability of the primary producers to offset the expected increase in microbial activity and, 2) the availability of labile soil organic carbon as a result of permafrost degradation. Even though methane flux increased with water table within years, similar rates between years regardless of the very distinct weather conditions underscores the need for greater understanding of the mechanisms favoring methane production under dry conditions.

Additionally, our study revealed that coastal locations can respond differently than inland locations to warming and that topography importantly affects the magnitude of ecosystems response to warming. Also, the relatively quick nutrient reallocation (into standing dead biomass) in some sites, suggests that arctic ecosystems can readily respond to warming, but nutrient reallocation and nutrients locked up in new organic matter can down-regulate GPP and ER. Processes such as decomposition rates, change in species composition, herbivore, standing dead biomass quality need to be accounted for to further understand the long-term responses of arctic ecosystems to warming. 
We determined that water table interacts differently with GPP, NEE and ER, and that: 1) low water tables increased GPP but also ER, negatively affecting NEE because the response of ER was larger than that of GPP, 2) high water tables reduced GPP and ER, but the effect on the ER was larger, therefore increasing the seasonal uptake, and 3) microtopography had a significant effect on ER, but not on GPP. However, the difference in strength of the correlations between water table and GPP among the different microsites suggests that microtopography position affects the response of GPP to water table, especially in the wet sedge areas.

For the combined effect of water table manipulation and temperature, we determined that: 1) drying increased ER and GPP, and decreased methane and thaw, 2) drying in combination with warming magnified the impact of drying on GPP and ER, but contrary to what we expected under dry conditions, warming continued to increase methane efflux and thaw depth, 3) flooding decreased both GPP and ER, and increased methane efflux and thaw depth, 4) flooding and warming also reduced GPP and ER, and increased methane efflux and thaw depth. Drying alone reduced seasonal NEE, but warming stimulated a bimodal response to water table fluctuation with highest uptake under drained and flooded conditions.

For the response of the long-term effects of warming on $\mathrm{CO}_{2}$ exchange, we conclude that: 1) even though we found a significant correlation between ER and temperature, the data do not show evidence of a decrease in the sink capacity of the temperature control plots of the study sites; 2) warming decreased the sink potential of the dry sites, especially at Barrow; 3) although we observed an increase of the standing dead biomass at the Wet sites, we did not observe an increase in the ER, and on average 
the wet sites were $\mathrm{CO}_{2}$ sinks; 4) warming had an stronger effect on the coastal site of Barrow than the inland site of Atqasuk, with a particularly strong effect on the dry site.

The prohibitive cost of large hydrological manipulations limited our study to a single lake, restricting our ability to scale up our results to the whole Coastal Plain. Additionally, the high cost of maintaining long-term manipulations such as the ITEX experiment represents an important constraint in the understanding of the effects of temperature and water table changes on some ecosystem processes. One big challenge is to understand not only how the ecosystem function and structure respond to long-term changes in water availability and warming, but also how changes in these parameters can affect the biophysical properties of the ecosystems. Another challenge would be to build up the capacity to scale up ecosystem processes to the landscape at different time scales to better quantify key physiological processes, such as productivity, and the potential effects of changes in biophysical parameters can have on it. 


\section{Significance}

Arctic soils store close to $14 \%$ of the global soil carbon and are susceptible to changes in water availability and increased temperature. Recent estimates have determined that the Arctic holds close to 1672 Gt of carbon, including the deep permafrost deposits. Therefore, the expected increase in temperature is very likely to accelerate changes in the hydrologic and thermal regimes, potentially promoting permafrost degradation. In the past, most experiments have been mostly focused on warming, and not on the combined effects of warming and water table manipulation on the carbon cycle. This study is one of the first studies to incorporate large-scale hydrological manipulation with warming. Additionally, the number of long-term assessments of the ecosystem response to warming is low. Although, there is still uncertainty not only about hidden thresholds in the effects of temperature and soil moisture on the ecosystem function and structure, but also in the magnitude of the ecosystem responses to changes in these variables at the landscape level. My work has increased the understanding of the short-term effects of water and temperature manipulations on the ecosystem $\mathrm{CO}_{2}$ and $\mathrm{CH}_{4}$ exchange and the long-term effects of warming on the $\mathrm{CO}_{2}$ flux components. 
VITA

PAULO C. OLIVAS

1995-2000

B.S., Forest Engineering Instituto Tecnológico de Costa Rica.

2001-2002

Field Technician

Organization for Tropical Studies

University of Turku, Finland

2002

Laboratory Technician

University of Turku, Finland

2003-2005

Forest Technician and Project Manager

Organization for Tropical Studies

Sarapiquí, Costa Rica

2005-2007

M.S. in Biological Sciences

Florida International University

2007- 2010

Doctoral Candidate in Biology

Florida International University

\section{PUBLICATIONS}

Clark, DB; Olivas, PC; Oberbauer, SF; Clark, DA; Ryan, MG. 2008. First direct landscape-scale measurement of tropical rain forest Leaf Area Index, a key driver of global primary productivity. Ecology Letters 11 (2): 163-172.

Jones, MM; Olivas, P; Tuomisto, H; Clark, DB. 2007. Environmental and neighborhood effects on tree fern distributions in a neotropical lowland rain forest. Journal of Vegetation Science 18 (1): 13-24.

Jones, MM; Tuomisto, H; Borcard, D; Legendre, P; Clark, DB; Olivas, PC. 2008. Explaining variation in tropical plant community composition: influence of environmental and spatial data quality. Oecologia 155 (3): 593-604.

Jones, MM; Tuomisto, H; Clark, DB; Olivas, P. 2006. Effects of mesoscale environmental heterogeneity and dispersal limitation on floristic variation in rain forest ferns. Journal of Ecology 94 (1): 181-195. 
Jones, MM; Tuomisto, H; Olivas, PC. 2008. Differences in the degree of environmental control on large and small tropical plants: just a sampling effect?. Journal of Ecology 96 (2): 367-377.

Olivas, P. C., S. F. Oberbauer, C. E. Tweedie, W. C. Oechel, and A. Kuchy. 2010. Responses of $\mathrm{CO}_{2}$ flux components of Alaskan coastal plain tundra to shifts in water table. JGR Biosciences. In press

Zona, D., W. C. Oechel, J. Kochendorfer, K. T. P. U, A. N. Salyuk, P. C. Olivas, S. F. Oberbauer, and D. A. Lipson. 2009. Methane fluxes during the initiation of a large-scale water table manipulation experiment in the Alaskan Arctic tundra. Global Biogeochemical Cycles 23:GB2013

\section{HONORS}

Dissertation Year Fellowship from University Graduate School at Florida International University, 2010.

First place for best poster presentation at the 11th Annual Biology Symposium, Department of Biology, Florida International University, 2009.

International Polar Year - Research Educational Opportunities in Antarctica for Minorities. Participation award for the field trip to Antarctic Peninsula, Winter 2007-2008. 